\title{
Teaching an old dog new tricks: Identifying policy and regulatory barriers in microgrid adoption
}

\author{
by
}

Amandeep Chahal

A thesis submitted to the Faculty of Graduate and Postdoctoral Affairs in partial fulfillment of the requirements for the degree of

\author{
Master of Arts \\ in \\ Sustainable Energy Public Policy
}

Carleton University

Ottawa, Ontario

C 2017 Amandeep Chahal 


\begin{abstract}
The electricity sector is poised to be a powerful enabler towards creating a low carbon economy. The Ontario government began instituting policies to achieve emissions reductions through programs like the Feed in Tariff. The initial policy framework advocated for a specific tool (renewable generation) to achieve its inferred mandate of reducing carbon emissions and codified these programs in legislation. As more technologies evolved additional policy prescriptions were created to integrate them; these include smart grid integration and energy storage procurement. The fundamental environmental objectives of reducing emissions were not mentioned in the creation of these policies. Ontario is now faced with a patchwork of policy tools that cannot value disruptive technologies like microgrids because the current electricity markets that could leverage them were designed to be compartmentalized and do not value emissions reductions. This thesis uses two examples of integrating microgrids in Ontario to highlight the challenges created by the current policy framework. This thesis argues that while the Ontario government has invested in creating tools to deploy some new technologies like renewable generation, without thoughtful reform it will be unable to effectively realize an environmental return on its investments.
\end{abstract}




\section{Acknowledgements}

I would like to thank my supervisor Professor Alexandra Mallett for helping guide me through this process and for always being just a phone call away. I would also like to thank all the industry experts who generously helped with this research.

Finally thank you to my family for encouraging me to seek out new ideas, and to Will and Naveli- for helping me find the words to share what I learned. 


\section{Table of Contents}

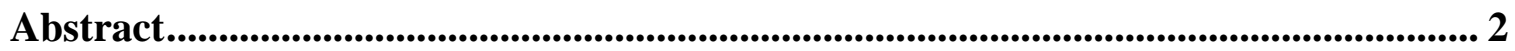

Acknowledgements .................................................................................................................................... 3

Table of Contents ........................................................................................................................................ 4

List of Tables .............................................................................................................................. 6

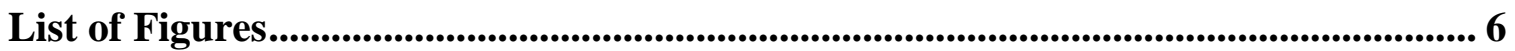

Glossary: ................................................................................................................................................. 8

1 Chapter: Introduction: Tea tea latte anyone?................................................................... 9

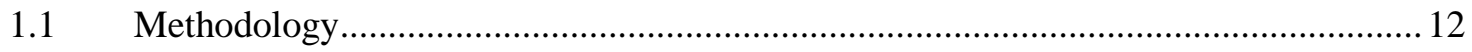

$1.2 \quad$ Influencing priorities, climate change …………………………………………...2

$1.3 \quad$ Unintended consequences ............................................................................22

$1.4 \quad$ Masala - the spices that make the study ……………............................................2

2 Chapter: Framework; guests at a tea party ................................................................. 34

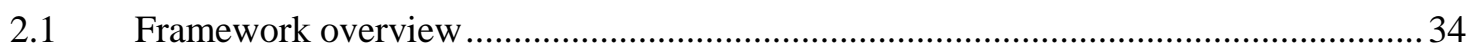

2.2 Motivating Mazzucato ………………………………………………………... 40

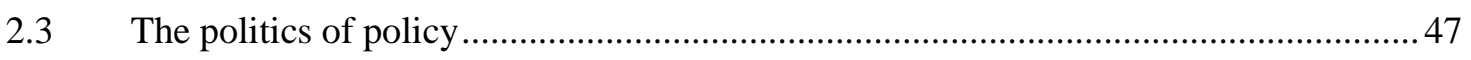

2.3.1 What matters to policy makers............................................................................... 49

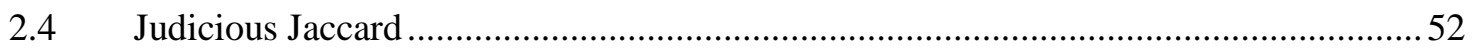

2.4.1 Political feasibility, a policy window opens...........................................................56

2.4.2 Implementing policy: walking the walk ……………………………………….....58

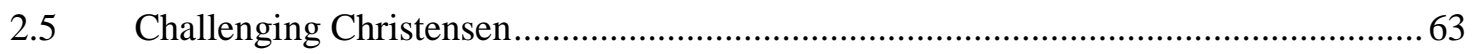

2.6 The final word: recipe for masala chai ...................................................................

3 Chapter: Context the market and technology ............................................................ 78

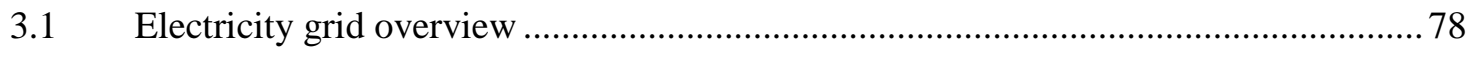




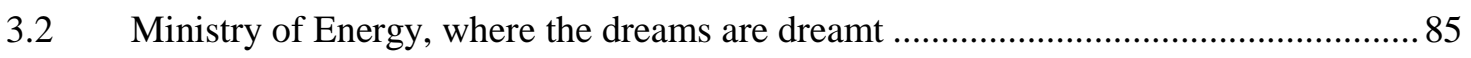

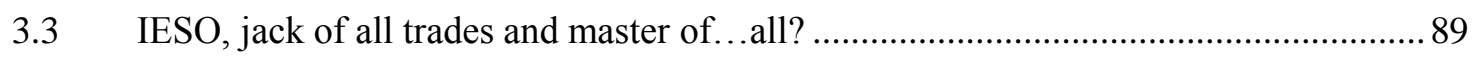

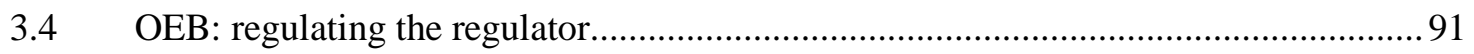

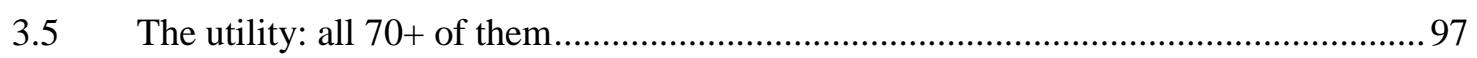

3.6 The IESO market, an electrifying game ........................................................... 99

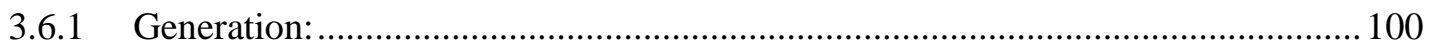

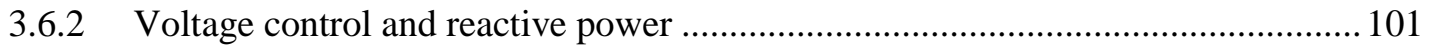

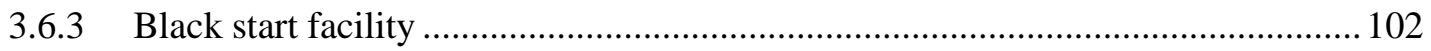

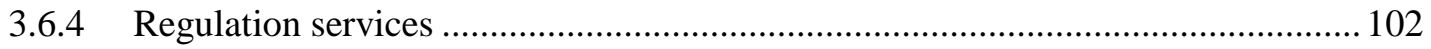

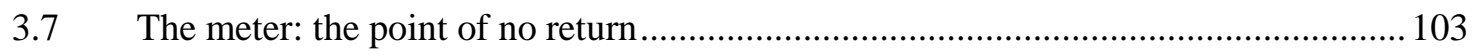

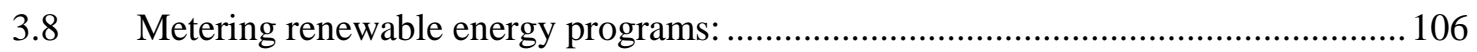

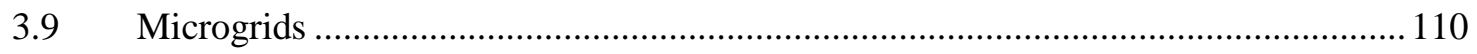

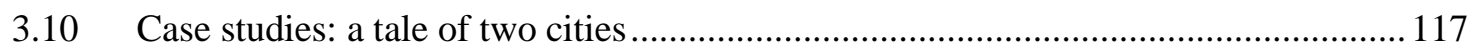

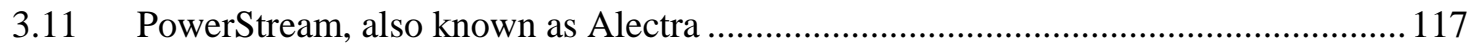

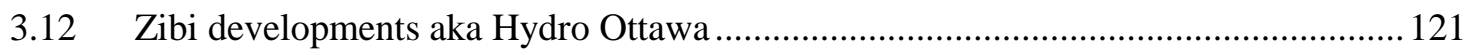

4 Chapter: Analysis, the entrepreneur's fate ................................................. 124

4.1 Hydro Ottawa: The sum of its parts................................................................. 125

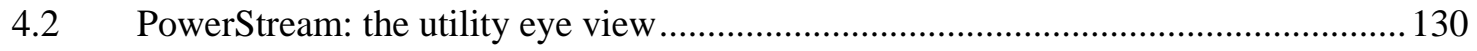

5 Chapter: Discussion; adjusting to industry change ................................................ 134

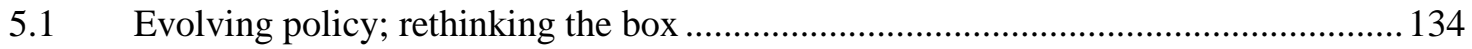

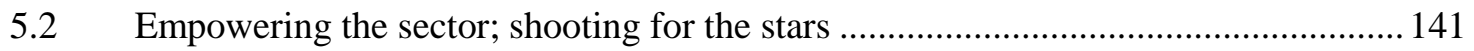

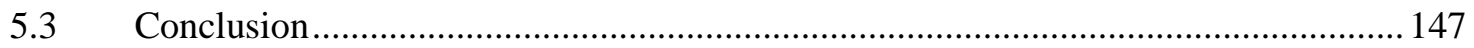

Bibliography or References...................................................................................... 151 


\section{List of Tables}

Table 1: PowerStream Microgrid Components .............................................................. 120

Table 2: Key business differences in microgrid design ............................................ 125

Table 3: Comparison of objective and definitions between the two Electricity Acts..... 139

\section{List of Figures}

Figure 1: Author's methodology for research

Figure 2: Ontario emissions summary illustrated from Environment and Climate Change Canada, NIR, Table A10-2 and Table 12-2 (May 14, 2017) .......................................... 28

Figure 3: Author's summary of the framework used for analysis ..................................... 36

Figure 4: iPod platform technology development contributions, Figure 13 from Mazzucato, M. (2015, p. 116), The Entrepreneurial State: debunking public vs. private sector myths, Anthem Press: London, UK, ISBN 9780857282521, US edition (Public Affairs)

Figure 5: Federally supported programs for science innovation taken from the Fundamental Science Review (“Canada’s Fundamental Science Review” 2017) ........... 44 Figure 6: Author's illustration of technology-policy interface ………............................. 54 Figure 7: Flow of electricity Image adapted from "How Electricity Is Delivered To Consumers - Energy Explained, Your Guide To Understanding Energy - Energy Information Administration," n.d. 80

Figure 8: Author illustration of Ontario electricity sector 81

Figure 9: Author's representation of the meter in the case studies 83 
Figure 10: Author's illustration of the IESO and distribution grid.............................. 100

Figure 11: Author summary of the key IESO markets ........................................... 103

Figure 12: Author's illustration of difference between utility meter and sub-meter..... 105

Figure 13: Author illustration of three IESO programs in relation to the meter............. 106

Figure 14: Illustration of a nanogrid relative to a microgrid .................................... 114

Figure 15: Schematic of PowerStream Microgrid .................................................. 119

Figure 16: Author's illustration of the impact of policy constraints on Zibi design....... 128

Figure 17: Zibi microgrid technology-policy interface ....................................... 129

Figure 18: Author's illustration of the PowerStream microgrid ................................ 131

Figure 19: Author's illustration of changes in operation between IESO and utility grid 143

Figure 20: Author's illustration of proposed DSO/IESO grids ................................. 145 


\section{Glossary:}

\begin{tabular}{|c|c|c|}
\hline 1 & Black start facility & $\begin{array}{l}\text { A black start facility is a generation facility that can start without } \\
\text { requiring any external electrical supply }\end{array}$ \\
\hline 2 & Energy storage & $\begin{array}{l}\text { A device that could store electricity. Including batteries, hydro } \\
\text { storage, flywheel storage. }\end{array}$ \\
\hline 3 & MicroFIT & $\begin{array}{l}\text { A program through which residential consumers can produce } \\
\text { upto } 1 \mathrm{~kW} \text { of electricity from renewable sources and sell it to the } \\
\text { electricity grid }\end{array}$ \\
\hline 4 & Net metering & $\begin{array}{l}\text { A program through which residential consumers can produce } \\
\text { upto } 1 \mathrm{~kW} \text { of renewable electricity and would receive a rebate } \\
\text { for their generaiton on their electricity bills. }\end{array}$ \\
\hline 5 & Microgrids & $\begin{array}{l}\text { A reorganization of existing electricity technologies that may } \\
\text { include generation, storage and an end consumer. }\end{array}$ \\
\hline 6 & Residential campus & $\begin{array}{l}\text { A residential development or campus that would have one main } \\
\text { meter with the utility but could be sub-metered for individual } \\
\text { electricity soncumers }\end{array}$ \\
\hline 7 & $\begin{array}{l}\text { Renewable } \\
\text { generation }\end{array}$ & $\begin{array}{l}\text { an energy source that is renewed by natural processes and } \\
\text { includes wind, water, biomass, biogas, biofuel, solar energy, } \\
\text { geothermal energy, tidal forces and such other energy sources }\end{array}$ \\
\hline 8 & FIT & $\begin{array}{l}\text { Feed in Tarrif, a program through which generators can produce } \\
\text { upto } 1 \mathrm{MW} \text { of electricity from renewable sources and sell it to } \\
\text { the electricity grid }\end{array}$ \\
\hline 9 & Transmission grid & $\begin{array}{l}\text { High voltage grid where high capacity electricity is generated } \\
\text { from large power plants like large hydro dams, nuclear plants } \\
\text { and natural gas plants to name a few. }\end{array}$ \\
\hline 10 & IESO & Independent Electricity System Operator \\
\hline 11 & Distribution grid & $\begin{array}{l}\text { Low voltage grid where electricity is moved from the } \\
\text { transmission grid to the end consumer. }\end{array}$ \\
\hline 12 & OEB & Ontario Energy Board \\
\hline 13 & Generation & Production of electricity \\
\hline 14 & $\begin{array}{l}\text { Utility/ } \\
\text { Distribution } \\
\text { company }\end{array}$ & $\begin{array}{l}\text { Regulated companies responsible for distributing electricity from } \\
\text { the transmission grid to the end consumer. }\end{array}$ \\
\hline 15 & Regulation services & $\begin{array}{l}\text { Regulations services help to maintain balance between load } \\
\text { (electricity consumption) and electricity generation in the grid }\end{array}$ \\
\hline 16 & $\begin{array}{l}\text { Disruptive } \\
\text { technologies }\end{array}$ & $\begin{array}{l}\text { straightforward innovations that consist of off-the-shelf } \\
\text { components that were put together in a simple architecture }\end{array}$ \\
\hline 17 & $\begin{array}{l}\text { Cleantech/ Clean } \\
\text { technologies }\end{array}$ & $\begin{array}{l}\text { technologies that produce less pollution as compared to current } \\
\text { alternatives or no pollution at all }\end{array}$ \\
\hline 18 & Meter & The point of transication in electricity markets \\
\hline 19 & $\begin{array}{l}\text { Voltage control } \\
\text { and reactive power }\end{array}$ & $\begin{array}{l}\text { Voltage control and reactive power are ancillary services that are } \\
\text { traditionally provided by generators }\end{array}$ \\
\hline
\end{tabular}




\section{Chapter: Introduction: Tea tea latte anyone?}

Language evolves over time with new words being created while old words change meaning. Take for instance the word 'google'-google, a word that was a novel spelling on the word googol which means 10 to the $100^{\text {th }}$ power, culturally signified an unfathomably large number. Today it has become synonymous with the idea of searching for information online. As David A. Vise and Mark Malseed chronicle the story of Google's founding, the term was not intended to have a meaning but rather to be an inside joke between the quirky founders Larry and Sergey (Vise and Malseed 2005). At the time, neither struggling grad student would realize that they had coined a new word. Today every meal finds itself interrupted when there is a disagreement of fact and arguments are won or lost with conviction, "I googled it"- the new punctuation of victory.

Where once an apple was a fruit, today one must clarify if the discussion is about a fruit or a company. Words and definitions are peculiar; sometimes the same word can mean different things depending on the location or context. Take for instance the word 'chai'. The word 'chai' evokes a familiar bouquet of smells, cardamom, ginger, cinnamon - the smells of India. The word 'chai' or 'cha', is, in fact, a word that exists in several languages in India as well as China and it means tea. The tea of choice being black tea; thus asking for chai would simply mean one desires a cup of black milk tea in India and black tea in China. The addition of any spice or 'masala' would be qualified in India as a 'masala chai' in Hindi or 'masala cha' in Punjabi- 20 more Indian languages to go! Those 
familiar with the term would find it amusing to order the redundant 'chai tea latte'effectively a 'tea tea latte'. However, it is not advisable to educate the barista on this nuance while ordering your 'tea tea latte' during a busy morning at one's favorite café; a polite suggestion to google it on their break should suffice.

Industries, like words, go through evolutions - their meanings are dynamic. As new technologies are developed the industries within which they operate are reshaped. Electricity generation, for instance, is technically merely an industry that is responsible for the generation of electricity. The technology to generate and consume electricity economically in large scale was once restricted to large power plants, like, hydro and thermal. The output from these power plants could easily be controlled by adjusting production to consumer demands. Thus, when electricity was spoken of in capacity, 1 MW of electricity was intrinsically linked to the association that $1 \mathrm{MW}$ was produced consistently and its time of production could be controlled as needed. The policy frameworks developed to govern the electricity sector were created with this idea of electricity generation in mind.

Innovation has given rise to new technologies like wind and solar that can be aggregated to large scale production but can also be distributed throughout the grid. Innovation has resulted in a change in how economical electricity generation is possible. The growth of technologies that can generate electricity from renewable sources like wind and solar has shifted how generation is thought of. Utilities now boast of the amount of renewable generation that is part of the electricity supply. However, there is a critical distinction in 
how solar and wind resources work that has not been fully addressed with this comparison. Wind and solar generation technically produce electricity. However, they remove the ability to control the production of electricity as needed. One MW of electricity produced by the wind is not the same as $1 \mathrm{MW}$ produced by a coal power plant. Coal plants produce a consistent $1 \mathrm{MW}$ of electricity, while wind produces $1 \mathrm{MW}$ only when the wind is blowing. In this context, electricity generated from wind is not the same as electricity generated from coal. Without accounting for this change in the nature of the technology a false equivalency exists that has given rise to much debate about the effectiveness of renewable energy generation. An intermittent source of renewable energy production can be used to replace $1 \mathrm{MW}$ of coal electricity, with the addition of energy storage. The technology solution to this shift in the concept of electricity generation exists; to account for the lack of control in generation one must store a reserve. From the technology perspective, the de-coupling of electricity generation from the idea of controllable electricity generation creates the value for a new technology like energy storage. Technology adapts to this shift by adding more 'masala' to the mix. A new innovation can help overcome a technological hurdle.

This thesis is a study of how regulated industries adapt to disruptive technologies as new policy objectives emerge in technology-driven sectors. The electricity sector in Ontario is closely studied in this thesis. The Ontario electricity sector was chosen because while the Ontario government has had programs to incorporate clean technologies like renewable generation, other technologies that can help facilitate a low carbon economy do not have well developed market mechanisms through which to be integrated. Technologies like 
energy storage and microgrids have the potential to help reduce emissions. These technologies are not experimental, they are developed and proven but within Ontario, the current market and industry design did not account for the unique value that they could provide in reducing emissions. Microgrids have the potential to help reduce emissions by integrating renewables, facilitating transportation electrification and increasing grid resilience. These technology attributes are discussed in detail in chapter 3.

While microgrids and energy storage can facilitate emissions reductions, the current industry design does not value those technologies for their unique attributes. Microgrids were chosen as a technology for analysis because they can provide value in many of the existing electricity markets while also being uniquely able to change and adapt to grid conditions. However, the current markets are not structured in a way to effectively utilize this feature of the technology, nor are they able to provide a clear mechanism for its integration. This thesis does not advocate for a specific technology to be adopted; rather it uses microgrids to reveal the policy constraints that impede the diffusion of technologies that can facilitate emissions reduction in Ontario. The following section highlights the key methodology used to analyze the electricity system and study its constraints.

\subsection{Methodology}

To understand how to integrate disruptive technologies in the electricity sector, two key areas were researched. The first of these areas being the design and operation of the electricity industry in Ontario and the second being the challenges faced by stakeholders 
trying to integrate new technologies in that sector. Understanding the electricity sector in Ontario required engagement with industry experts while understanding the experiences of technology integrators required a private sector view. Industry experts included those involved in managing and operating the Ontario electricity market, along with individuals who were thought leaders, or had worked extensively in the field. Similarly, entrepreneurs, established technology companies and non-government organizations were interviewed to understand the challenges that were being encountered by stakeholders trying to integrate new technologies in the electricity sector in Ontario. A total of 27 individuals were willing to participate through formal and informal interviews. Formal interviews (10 in total) include those stakeholders who were willing to formalize their contribution to the study by going through the ethics process. Informal interviews consisted of those individuals who were willing to help guide the research, provide continued support and analysis but either chose not to go through the ethics process or where a less formal approach was assessed to be more valuable to the study. Informal interviews with a total of 22 individuals were carried out for a total of 29 interviews (a few participants were interviewed more than once).

A key consideration in determining if an interviewee would be asked to do a formal or informal interview was the political sensitivity of the electricity sector in Ontario. In several cases the candid conversation with individuals close to the sector was considered to be more valuable than formalizing their involvement in the study. In certain circumstances I determined that a formal interview would have resulted in more guarded answers which would not have allowed for a deeper understanding of the sector. While 
all formal interviews are cited, the informal interviews were leveraged to guide the research and were complemented with extensive desk-based research.

Desk-based research consisted of reviewing existing research done in the sector from a policy and technology perspective. Additionally, to complement and reinforce the information learned from the informal interviews, it was considered vital to study and develop an understanding of the legislation, codes and market rules that govern the electricity sector in Ontario. For this research, the following vital documents were studied:

1. The Electricity Act, 1998 (2004 revision and 2016 revision)

2. The Ontario Electricity Board Act (2016 revision)

3. The IESO Market Rules (Chapters 1,4,5,6,7 and 11 out of 11 Chapters)

4. The Transmission Code

5. The Distribution Code

6. The Unit-Sub Metering Code

7. Ontario Climate Change Action Plan

Additional research was carried out which included extensive literature on the topic and is referenced throughout the paper. However, the documents listed above were used to both validate and speak to the findings made through the formal and informal interviews. These documents were studied in two phases: the first being independent research while the second round included additional interviews to confirm the documents were interpreted accurately. The second phase of study included formal and informal 
interviews. The second round of interviews to validate the interpretation of the documents was critical as the information presented within the codes, policy documents, etc., was a mix of legislative information, engineering information and market information. To ensure the integrity of the analysis presented in this thesis it was considered vital to validate that the information was interpreted accurately from a technical, legislative and market perspective from experts actively involved in these topics within the Ontario context.

The timeline of the research was divided into two stages: the first being exploratory and the second being detailed analysis; these are illustrated in Figure 1. Interviews were carried out in both stages. During the exploration stage, it was noted that two distinct divisions existed in the research. The policy research did not account for the technology integration or industry design issues while the technology research did not account for policy design or how the industry is operated. These two gaps informed the second stage of the research and the direction taken in this thesis. A large amount of policy research, including results presented at conferences would specify regulatory barriers as a main hurdle for technology adoption but would not articulate what those regulations were. A similar constraint was noted in the technology research that mentioned policy barriers towards microgrid adoption but did not articulate what those barriers were.

Thus, the second stage of this thesis was aimed at identifying specific policies that impede the adoption of disruptive technologies. The second stage is divided into four steps as illustrated in Figure 1Figure 3. The first of these steps was to understand how the 
industry was / is designed. It was during this stage that desk research was conducted to study and map the electricity sector through the literature mentioned above in this section. Following this step interviews were carried out to ensure that the documents were interpreted correctly. Prior interviews had revealed a nuance between the legislation as it was written and some industry best practices. These were flushed out in the second stage of the study and have been highlighted throughout the thesis. The third step involved an understanding of how the technology worked and the fourth step included a study of the current industry environment to determine what recommendations could be effectively integrated in Ontario.

Due to the complexity of the industry, the stakeholders and the technologies, it was considered that using a technology to highlight the policy challenges would simplify the study while also revealing critical issues. During the first stage of the study, energy storage and microgrids were being considered as examples of new technologies that were facing policy challenges within the Ontario electricity sector for analysis. Microgrids provide the flexibility of being inclusive; they can easily integrate energy storage. Additionally, while the Ontario electricity sector has a mechanism for energy storage to be integrated at a utility scale, it did not have one developed for microgrids. Therefore, microgrids were chosen to illustrate the policy barriers for disruptive technologies in Ontario. The intension was to highlight that a more inclusive mechanism to value the benefits of emerging technologies like microgrids could facilitate the integration of multiple technologies. 


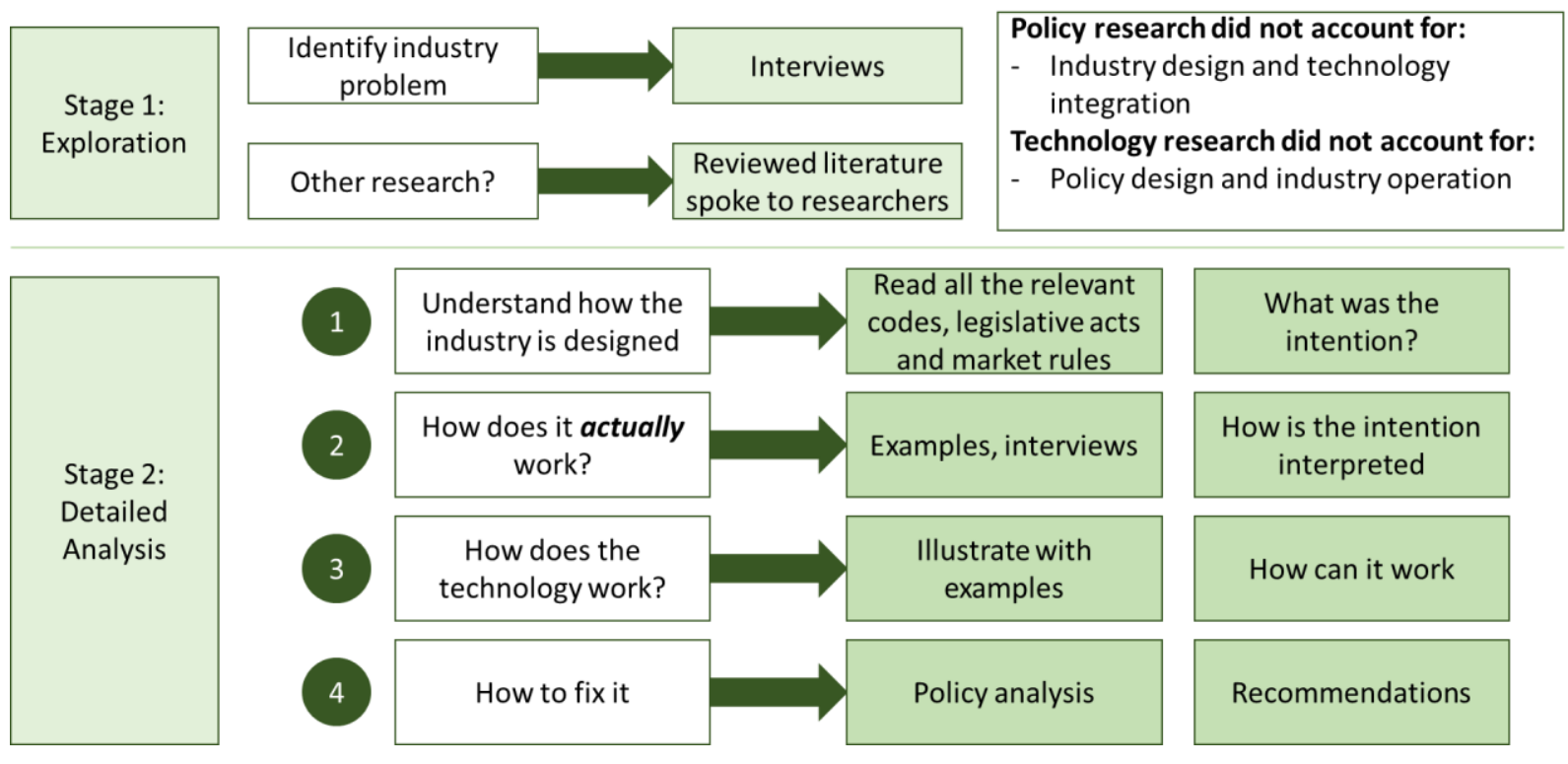

Figure 1: Author's methodology for research

The technology selection of microgrids was determined to be a useful mechanism to forward a discussion regarding policy barriers. However, since there was no existing market mechanism to value microgrids, it was considered important to highlight two cases: one in which a microgrid was fully integrated to showcase the value of the technology and second where it faced policy constraints to highlight the resistance the technology faced in being adopted. Further details about the cases can be found in chapter 3. The PowerStream microgrid was chosen to illustrate the potential of the technology while the Zibi microgrid was chosen to illustrate the constraints that microgrids can face. Additionally, the PowerStream microgrid is embedded within the utility grid while the Zibi microgrid was intended to function on a private campus. Having two different types of management structures, one as a utility and another a private campus, allowed the study to compare the two and highlight key fundamental 
differences that can be addressed to help diffuse these technologies These

recommendations are elaborated on in chapter 5. One key value that microgrids can add to the grid is emissions reductions by better organizing the grid and integrating other technologies.

This thesis often references smartphones to illustrate how technologies like microgrids function. The key reason to choose an illustrative example was that the discussion presented in this thesis needed to be able to demonstrate key differences in three areas, how technologies are engineered and developed, how they are governed and regulated and how markets value and integrate them. To avoid presenting a large amount to technical engineering information or technology diffusion constraints, and to make the study more accessible, smartphones were drawn upon to simplify specific discussion elements. Smartphones were chosen as an illustrative tool due to key similarities in how technology components in smartphones interact because a similar interaction between components takes place in microgrids. Additionally smartphones were considered to be a relatable technology due to their widespread presence. The references made in this study are strictly to reflect on how a smartphone can bring together tools like email access, contact sharing, provide directions, become an internet browser etc. the interaction of all the various tools depends on the user and can be customized to user preference. If those functions are separated into a device that manages email, another that manages internet access then while those devices may still provide access to those functions, the convenience of accessing them through one integrated technology is impeded. This behavior is analogous to a microgrid where it is the integration of existing technology 
components that creates the value for the microgrid, the connection of energy storage to generation etc. Both the microgrid and a smartphone can be customized to the user preference.

A second reason to use a smartphone comparison is that it is a technology that was not in widespread use until recently. The first iPhone was released in 2007 (Honan 2017). The development of the industry from the first generation technology to achieving market saturation has taken place within a very fast time frame, approximately 10 years. A Massachusetts Institute of Technology review estimates that smartphones may be the fastest technology to achieve market saturation (DeGusta 2017). In this study, the potential of technologies to mature faster than legislation can adapt was illustrated through the development of smartphones. This thesis does not imply that smartphones and microgrids would see equivalent speeds in technology diffusion nor does it undertake a comparative analysis of the two technologies. Rather it uses smartphones to help facilitate the technology related discussion pieces. It is also noteworthy to mention that the industries within which both technologies operate, electricity for microgrids and telecommunication for smartphones, have different regulatory structures and policy issues. While telecommunications is a regulated industry, the development and operation of smartphones from an engineering perspective is not regulated. Essentially, a regulator does not determine how the email service of the phone will be integrated with the internet browsing function. While in the case of a microgrid, the individual functions are regulated, essentially meaning that the regulator impacts how electricity generation is 
connected to energy storage. These key functions were drawn upon for comparison to facilitate the discussion.

The following section highlights that climate policy has become an important consideration for policy makers.

\subsection{Influencing priorities, climate change}

The rise of an emergent reality that carbon emissions are warming the planet is creating the value for renewable generation technologies, a response by the electricity industry to adapt to this new need. The global acknowledgment of climate change and its impacts, as reflected in the signing of the Paris agreement (United Nations 2017b), speaks to the cultural shift that is driving the development of new technologies. It is beyond the scope of this paper to lay out the key issues that climate change will bring to bear though it accepts the need for a global coordinated effort to move to low carbon economies. On the heels of the withdrawal of the United States from the Paris agreement, the challenges facing the planet in reducing greenhouse gas emissions (GHGs) will require even more cooperation. Failure on the part of policy makers to integrate these technologies and taking action on climate change can have catastrophic consequences for the planet as highlighted in a recent article published by the New York Times (Gillis 2017). Gillis presents a scenario where inadequate response to climate change would result in sustained droughts, mass migration from equatorial countries and other catastrophic breakdowns in both the natural and social environment. Technology development alone 
cannot address this challenge. A larger response from policy makers who help govern these industries will also be needed.

Policy makers have recognized the broader cultural shift towards addressing climate change. Manifestation of this thinking can be seen through the implementation of policies like the Feed in Tariff (FIT) programs adopted by Ontario in the early 2009 (Ontario Ministry of Energy 2017a). The FIT program was designed to increase the amount of renewable energy on the Ontario grid. The key underlying assumption in the development of FIT programs in Ontario and globally has been that an increase in the amount of renewable electricity generation on the grid will result in a reduction of GHGs; GHGs being the gasses contributing to global warming. Evidence of this association can be inferred from the language in the Green Energy and Green Economy Act of 2009 (often called the "Green Energy Act" 2009). The preamble to the act highlights that the government of Ontario is committed to increasing the adoption of renewable energy to 'use cleaner sources of energy' and to promote a green economy. Green economy refers to an economy that has an overall focus on reducing the levels of resource consumption, harmful emissions and minimizing all forms of environmental impact. (ECO Canada 2010). With only a few technologies that could define an alternative to traditional high emitting electricity production and aid in the government's mandate to use cleaner sources of energy, electricity, wind and solar generation became naturally associated with the idea of GHG emissions reduction. 
Policy frameworks failed to address the underlying motivation to reduce GHGs but rather articulated that objective by promoting a specific technology solution. Additionally, their inability to distinguish between any two MW of electricity produced, essentially 'locked in' the definition of electricity generation to a time when a generation was inherently linked with an element of controllable production. Without additional technological solutions or changes to how the electricity system worked, $1 \mathrm{MW}$ of solar would not be interchangeable to $1 \mathrm{MW}$ of coal since electricity produced by coal could be matched to the time of use while solar would be generated when the sun shines. This form of prescriptive policy, which defined a technology solution has had a number of unintended consequences, the following section explores these challenges.

\subsection{Unintended consequences}

The inability of policy frameworks to adapt to a fundamental difference between intermittent and traditional electricity generation created a false equivalency between the management needs for all technologies that defined electricity generation. The unintended impacts of this false equivalency have been studied in Europe where the integration of renewables led to a small increase in carbon emission in Germany in 2015 (Martin 2016). In Germany, coal power was used to mitigate the impacts of intermittent renewables on the grid. Coal or natural gas electricity production is flexible and can be used to manage fluctuations in the grid caused by renewable generation, because it is able to ramp up or down quickly, unlike nuclear facilities that require a long time to ramp up. Energy storage devices like batteries can ramp up or be used to compensate for fluctuations caused by renewable generation very quickly. In Germany, without 
articulating the broader motivation of reducing emissions and by creating a mechanism to increase renewable generation only, the technology became an end in itself. Overcoming the operational constraints of intermittent sources caused a rise in the use of higher emitting generation technologies. Learning from these lessons and employing reforms can help enable changes that will lead to more improved solutions, as seen in Germany's new ambitious plans for the reduction of GHGs (Appunn 2017). Similar trends in GHG increases have not been seen in Ontario, largely resulting from an abundance of hydroelectricity and a nuclear electricity base. However, over production of electricity has been a concern for Ontario and can be attributed to the difficulty in controlling the supply of intermittent sources. This has had unintended consequences such as paying other jurisdictions to take the additional electricity from the grid and paying producers to not produce electricity when supply exceeds demand (Bordeleau 2011).

In industries such as electricity where technology innovation has outpaced the ability of policy to adapt, additional unintended consequences and industry reshaping scenarios have emerged. One scenario, dauntingly phrased the 'Utility Death Spiral,' discusses the concept that as more consumers adopt distributed renewable generation they will begin to become energy independent and unplug from the utility grid (Lacey 2014). Utilities are regulated and make revenue based on the amount of electricity they sell minus the cost of operating the distribution grid. As more consumers unplug from the grid, utilities would be forced to raise prices to cover the costs of maintenance. As the cost of electricity rises, more consumers would be incentivized to invest in renewables and unplug. The resulting impact is that the utility business model itself would cause a collapse in the industry. A 
similar phenomenon to the utility death spiral is being witnessed in the cable TV industry as the proliferation of internet and streaming sites is causing a decline in profits as more consumers unplug from their cable subscriptions.

A policy framework where all generation of electricity is considered equivalent cannot properly articulate the value of technologies like energy storage and microgrids, which do not fit neatly within the existing definitions of the electricity markets. This restricts their diffusion into established, regulated industries. These technologies fill a critical need that would help create a better equivalency between any two MW of electricity while also helping to create a more resilient electricity grid (Tao et al. 2011). In order to develop policy instruments that would value these technologies properly, policy makers must first recognize the inherent changes that have taken place in how technologies can interact. Part of that value for energy storage and microgrids lies in the inherent link between the intermittent nature of specific renewable generation sources and the need for reserve electricity to ensure proper supply. Microgrids and energy storage technologies are the natural technology solutions to create a true equivalency between intermittent renewables and traditional forms of electricity generation. They are the 'on demand' version of the nature of electricity consumption. Additionally, these technologies can better manage emerging issues related to grid resilience and help integrate smart grid technologies and electric vehicles (EVs). 
Within the current policy framework, energy storage and microgrids stand to be both the lynchpin to the green economy and the disruptor of the existing industry. They solve the issue of intermittency but they operate unlike other technologies currently on the grid and require new types of management mechanisms. Electric systems are purposefully designed to resist disruption to ensure that they can withstand a variety of scenarios and continue to provide safe and reliable electricity to consumers. It is an industry designed to be able to centrally control and operate the grid. In an industry where unpredictable changes in quality, supply or consumption of electricity can have far reaching ramifications for the larger grid, and for those connected to it, disruption is a risk. This highlights the conflict between a culture that is inherently risk averse, now being faced with the challenge of finding a mechanism to integrate technologies that are new, innovative, dynamic and can respond to changes in the grid faster than it was ever designed for, while ensuring reliability. This paper studies the past policy frameworks within the electricity sector to reveal key challenges that require the attention of policy makers. It further considers why and how policy makers should reform the sector by highlighting the arguments from Mariana Mazzucato in The Entrepreneurial State, Mark Jaccard in Sustainable Fossil Fuels and Clayton Christensen in The Innovators Dilemma. The following section outlines the key components addressed in this analysis.

\subsection{Masala — the spices that make the study}

For policy makers to address the issue of how to value new technologies, they will need to return to the question of why programs like FIT were introduced to begin with. Without addressing the underlying intention of why a policy is introduced, a policy can 
be technically accomplished without meeting its objective. For example, the IESO meticulously tracks the amount of renewable energy being generated on its website, and this information is updated hourly (IESO, n.d.). However there is no indication of how much emissions reductions have been achieved as a result of adopting these technologies. The Ontario Government, in its Climate Leadership Plan, has highlighted its intention to reduce GHGs in Ontario (Ontario 2017b). As part of that broader strategy, tools like EVs will be deployed. It is here that an important distinction in the provincial government's objective is realized: the Ontario government is committed to reducing GHGs. This is a motivation further strengthened by their commitment to the Pan Canadian Framework. The Ontario government, through the Climate Leadership Plan, has committed to reduce emissions and promote the development of a clean technology $\left(\right.$ cleantech $\left.^{1}\right)$ sector. It has further expressed a commitment to use specific tools to achieve that objective, one of which as stated above is EVs. This broader commitment to reduce GHGs needs to be better articulated within the electricity system to properly value and make use of technologies that can help realize this objective but are constrained by a policy framework that does not account for their benefits. A cohesive strategic approach that would identify the amount of GHG reductions required rather than specifying technologies for adoption would free industry leaders to adopt solutions more suited to achieve the broader end objective. Such an approach can highlight the value of integrating technologies into ecosystems like microgrids, while also helping create a more resilient grid.

\footnotetext{
${ }^{1}$ Cleantech and clean technologies are defined as technologies that produce less pollution as compared to current alternatives or no pollution at all (OECD 2017)
} 
Within the context of decarbonization and grid resilience, Ontario accounts for $23 \%$ of Canada's total GHG emissions as illustrated in Figure 2. A view at the Ontario economy reveals that electricity is only $5 \%$ of its emissions profile; with a high reliance on nuclear and hydro, Ontario has a largely non-emitting base of power (IESO 2017b). Is then to be inferred that Ontario does not need to reform its electricity sector? Far from it. Ontario's electricity sector is about to experience a form of industry overlap as the humble transportation sector will provide a new form of disruption on wheels. The electricity grid stands to be a critical enabler to achieve GHG reductions through policies aimed at electrifying transportation. The concerns about electricity sector reform will continue with the increased addition of EVs. Are EVs transportation, deployable energy storage, load, energy dispatcher or microgrid on wheels? To an enthusiastic engineer an EV may be the Swiss army knife of electricity. However, it is more critical to understand how an EV would be defined by an enthusiastic policy maker and how integrating EV infrastructure is going to impact the resilience of the grid. 


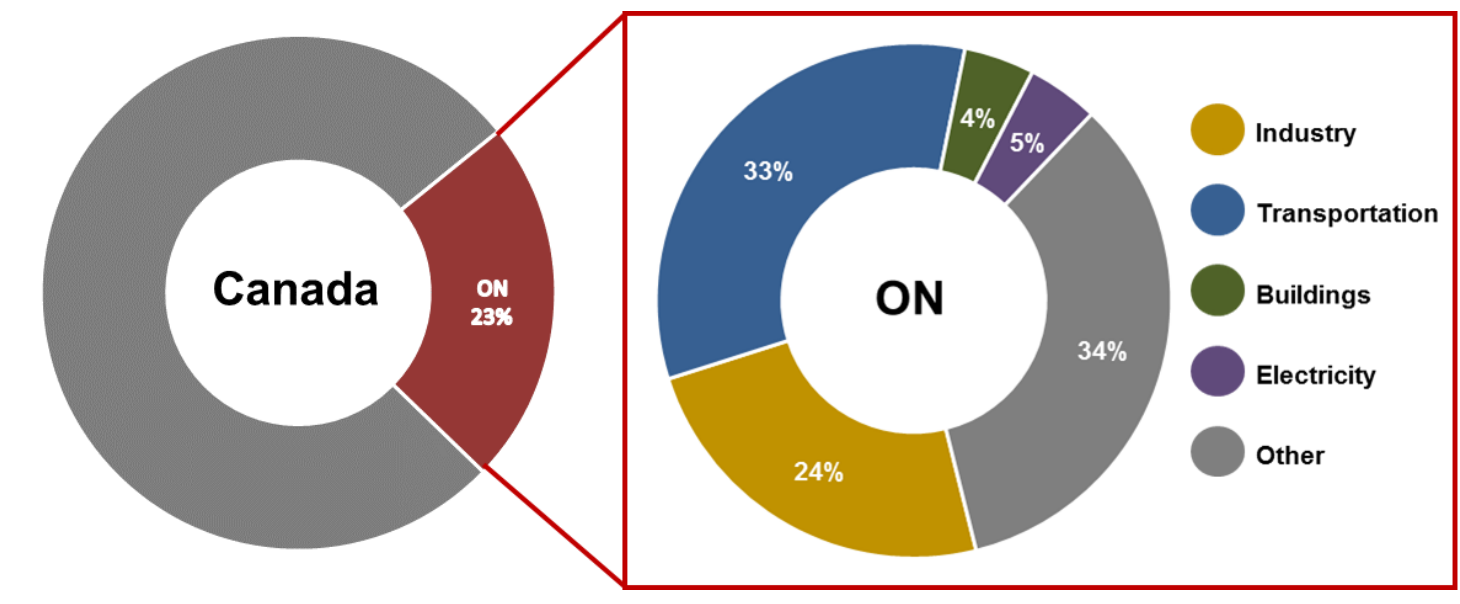

Figure 2: Ontario emissions summary illustrated from Environment and Climate Change Canada, NIR, Table A10-2 and Table 12-2 (May 14, 2017)

This thesis highlights the key policy challenges that are being faced within the electricity system in its effort to reduce GHGs in Ontario. It is a study of the Ontario electricity system within the context of integrating microgrids. The central argument guiding this study is that policy makers need to be explicit about the intention of their policies rather than the tools used to achieve them. A prescriptive policy framework that specifies specific technological solutions will be constrained in achieving its intentions because in the absence of the intent, the prescription becomes the objective. Without the intended purpose of reducing GHGs, increasing renewable generation became the policy objective. In technology driven fields, prescriptive polices run the risk of impeding effective technology diffusion and adoption. Technological solutions develop faster than policies can change. This is especially critical in regulated industries because governments greatly impact the market. Microgrids are a key technology solution that can facilitate the safe 
integration of other technologies like renewable generation, energy storage, and EVs, to name a few, in a safe and resilient way and achieve the government's mandate to reduce emission. While microgrids can be leveraged to solve many issues facing the electric grid, key policies in the management of the electricity grid must be changed to realize this potential. To showcase the conflict between the current policy framework and this technology ecosystem, this paper analyses two case studies of where two utilities have recognized the need to integrate microgrids, and brings to light the challenges that were faced during their deployment or development. These case studies will be used to show how specific policies around the placement of energy storage, the integration of renewable generation and the limitations on regulated entities like utilities can limit the efforts of the Ontario government in achieving their climate goals. Within the broader context of reducing GHGs, this paper will focus on carbon reduction. Carbon reduction is a recognized objective of the Paris Agreement and serves to articulate one key objective for policy makers as it is the largest contributor to GHGs. It is acknowledged that other forms of pollution reduction may be critical to the overall health of the planet and Ontario. These would include efforts to reduce water pollution or gases contributing to smog production, as was the primary objective that directed the coal phase out (Ontario Ministry of Energy 2017c). This study is not a holistic analysis of GHG reduction policies, but rather a study that highlights the unintended consequences that may contribute to industry disruption and prevent policy makers from achieving their objectives if policy frameworks do not evolve with the underlying changes that are occurring in the electricity sector. It is therefore recognized that decarbonization is the 
key policy goal for the Ontario government, as per the Ontario Climate Change Action Plan. (Ontario 2017b)

It is within the backdrop of decarbonizing the electricity grid that the Ontario electricity system will be analyzed. It is acknowledged that governments have many priorities to balance when creating policies. These may range from job creation, air quality and health and maintaining economic growth to name a few. While these policy objectives would be considered along with decarbonization policies for the province, this thesis restricts its analysis to only studying effective decarbonization policies and technology development. It is considered that the analysis presented in this thesis could be used to analyze other policy objectives as for any effective policy its intended purpose should be stated. If decarbonization policies are intended to also create jobs, then that goal should be stated rather than creating a market for renewable generation without consideration how renewable generation would result in job creation. The analysis presented here isolates the government's objectives of decarbonizing the grid and considers the policies to achieve that objective to reveal the challenges that governments will face to achieve their goals as a result of how the sector is designed and managed.

The Ontario government's objective to reduce emissions in the province and in the electricity sector is highlighted in the stated objectives of the Green Energy Act ("Green Energy Act” 2009) and the 2013 Long-Term Energy Plan (Ontario 2017c). The preamble of the Green Energy Act states the government's intention of 'promoting a green economy'. A green economy is generally understood to be an economic model of growth 
that, among other things, aims to reduce carbon emissions and other environmental risk factors (United Nations 2017a). Additional evidence of the government's objectives to address emissions is noted in the explanation for how directives can be used. Directives are a vehicle through which the government can tell the IESO what policies need to be implemented in the electricity sector. Within this section the act specifies that the Minister can use directives to address greenhouse gas emissions. The act does not specify any emission reduction targets or emissions reduction in general, however this intention is inferred from the promotion of a green economy, the many references to renewable technologies, conservation programs and the references to 'cleaner sources of energy'.

Further evidence of an underlying policy objective to reduce emission can be noted in the 2013 Long-Term Energy Plan. The Long-Term Energy plan begins with the Minister's message to indicate the motivations of building and maintaining a 'clean, reliable and affordable electricity system’ (p.g.2). It further highlights investments made by Ontario in developing 'energy technology, innovation and smart grid solutions' while highlighting the use of smart meters and demand response programs as evidence of technologies that are making the Ontario grid 'modern, clean and reliable'. 'Clean' being an inference to non-polluting as interpreted within the context of the message where it brings up climate change initiatives through the coal phase out, smart-grid technologies, renewable generation and conservation programs and being enablers to achieve that mandate. While the plan makes reverences to 'affordable energy' as a goal, it concentrates heavily on environmental issues and technologies that have been integrated to help their development. The sections that reference developments in integrating renewable 
technology make links to the MWs of renewable energy that has been connected to the grid (p.g.6). The coal phase out and nuclear power are also highlighted for their role in helping reduce greenhouse gas emissions. The Long-Term Energy Plan is also the only document reviewed that made references to emissions reduction forecasts (p.g.44). The document does not tie any specific program or technology with emissions reductions targets. An analysis of these two documents, The Long-Term Energy Plan and the Green Energy Act, in combination with informal interviews, is used to support the argument that the Ontario government has an intention to reduce carbon emissions and greenhouse gasses in an effort to create a green economy. This key objective will be used to provide the context within which this thesis will analyze the electricity industry and specifically microgrid integration in Ontario. Microgrids will be used to highlight a scenario where a technology that can help achieve emission reductions, faces policy constraints towards integration.

The two case studies that will be used will serve to show how current policies can create obstacles for industry players in their efforts to achieve this decarbonization objective. The first case to be analyzed will be PowerStream (known as Alectra as of 2016) and their microgrid demonstration project. At the core of this endeavor was PowerStream's motivation to demonstrate how microgrids could be used to increase resilience for a community and test how a microgrid could be deployed (PowerStream 2017). The second case highlights the evolution of an idea by a developer to create a net carbon neutral development. Zibi Developments in partnership with Hydro Ottawa have been designing the electricity architecture (Windmill 2017b). At the core of the Zibi project is the 
motivation to showcase the possibility of creating a carbon neutral and sustainable community. This community would articulate many of the objectives that the Ontario government has highlighted in decarbonizing the grid. The Zibi project highlights a case where the motivations of private sector industry players align with the government. The PowerStream example similarly highlights a utility that is motivated to also help the province reduce carbon. These two cases will be compared and analyzed within the Ontario electricity system to reveal the key policy challenges that will restrict the government's efforts in achieving its climate objectives in the electricity sector.

The next chapter will analyze why policy makers need to consider changes to help diffuse technologies. This analysis will build from the ideas that help define the investments made by governments in innovations by Mariana Mazzucato in The Entrepreneurial State (Mazzucato 2014). It will then consider the key motivations for the state in making those investments by introducing the concepts that Clayton Christensen highlights in the Innovator's Dilemma (Christensen 2011). Finally, the thesis will consider how to assess Christensen's Innovators Dilemma within the context of governments by analyzing public policy motivators as presented by Mark Jaccard in Sustainable Fossil Fuels (Mark Jaccard 2005). 


\section{Chapter: Framework; guests at a tea party}

To develop the framework from which policies in the Ontario electricity system will be analyzed, this paper will consider the key concepts that have been discussed in Chapter 1 After considering how decarbonization policies were created and implemented in Ontario this paper will consider the question of why and how the current policies should be changed. These fundamental questions have been articulated as follows:

1. Why should the government be motivated to support new innovative technologies?

2. What key considerations do policy makers need to make in the development of judicious policy?

3. What are some key challenges that government faces in adopting disruptive technologies?

The following section is an overview of the framework that was used in this analysis and the key links between the key ideas considered.

\subsection{Framework overview}

A detailed analysis of each of the components for the framework used in this thesis are highlighted in section 2.2 to 2.6 while Figure 3 is a short summary of the main components used in the framework. To answer the question of why governments should even consider changing policies that influence the adoption of disruptive technologies Mariana Mazzucato's The Entrepreneurial State was studied. The main arguments 
regarding the government investing in the development of technologies was considered and was analyzed to apply to clean technologies in the electricity sector. Though it was agreed in principle that governments who invest in technologies should receive some return on their investment, the arguments for financial pay back alone or as the preliminary criterion were not considered to be applicable. This disagreement was largely as a result of the recognition that governments do not make policy decisions for financial returns primarily but tend to have broader policy objectives that motivate action. To consider how governments should measure their payback or return on investment (ROI) as Mazzucato argued, Mark Jaccard's analysis was considered from Sustainable Fossil Fuels. Jaccard's framework was considered because it isolates the policy objective of reducing environmental impact in the economy while balancing economic impacts. Jaccard's arguments held central the idea of reducing environmental damage as a measure for effective environmental policies. This central argument was considered and applied to this study in the form of reducing emissions as the main policy objective of environmental policies in Ontario. Mazzucato's ROI was considered to be analogous to how Jaccard analyzed the effectiveness of policy objectives. 


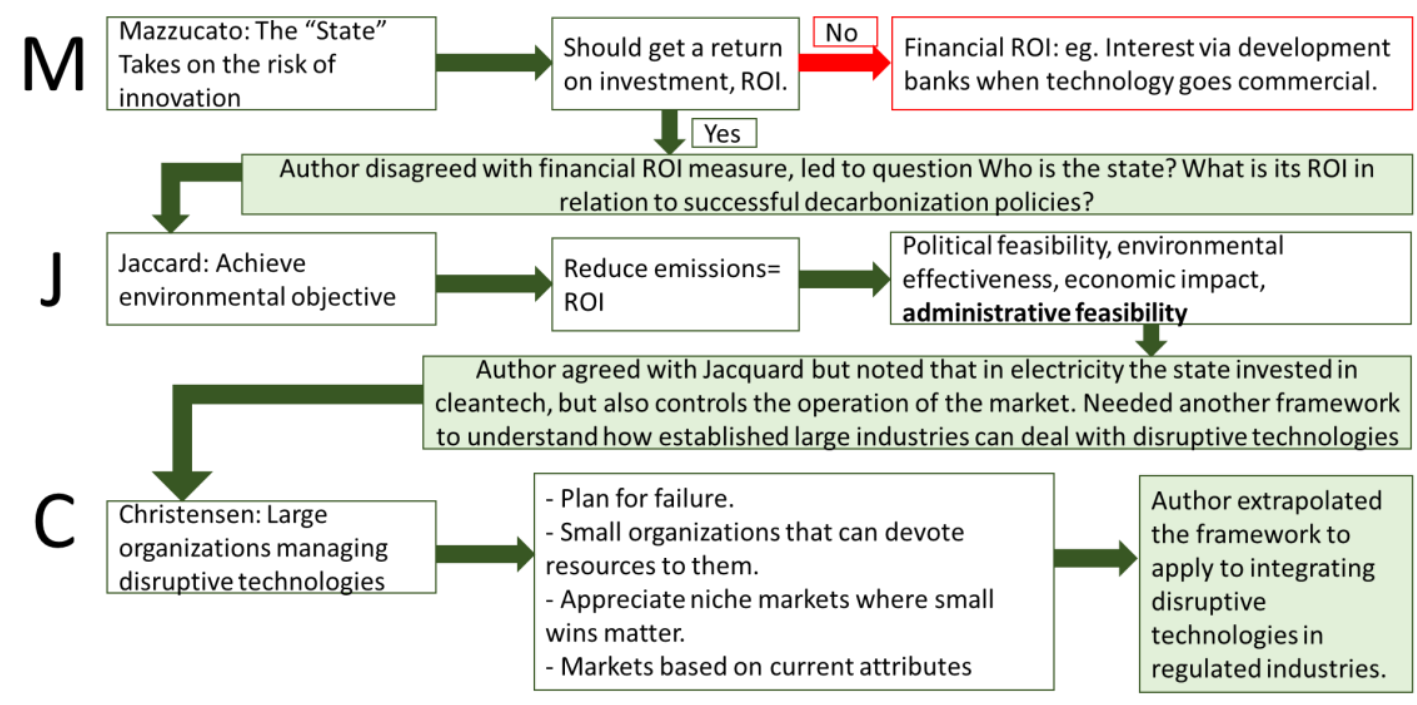

Figure 3: Author's summary of the framework used for analysis

It was considered vital to select a metric for measuring policy success that would have the broadest application. This consideration was made from Jaccard's argument that an economy-wide metric would allow for broad application without being prescriptive in the tools needed to achieve that metric. Thus, in the context of environmental policy, emissions reductions would be a broad metric that would apply to the entire economy. In addition to its wide appeal, this metric would allow more technologies that could achieve that metric to be valued properly because they would no longer need specific markets to be created for their integration but would rather be integrated in a market, based on their ability to effectively reduce emissions. Such an approach would allow technology integrators to balance emissions reductions with technology development and integration costs without the need for governments creating specific markets or programs that would value high cost technologies that may not provide the best emissions reduction. The underlying argument would be that a market for emissions reduction would be more 
efficient then creating one for renewable generation, another for energy storage and yet another for conservation. This would then enable integrators to determine the most economical means through which emissions reductions could be achieved by selecting the most appropriate technology solution to apply.

Another key component of Jaccard's model was the administrative feasibility of applying the policy. Jaccard's argument regarding administrative feasibility was also considered through the perspective of governments controlling the operational aspects of the electricity sector. While often governments are considered during a discussion of policy objectives, in the electricity sector it plays two roles: the first being the political role of determining the strategic objectives of the sector; the second of managing and operating the electricity markets and infrastructure. The question of administrative feasibility of policy in Ontario required a consideration of how the sector could operationally change to integrate new technologies that could facilitate the stated environmental policy objectives. The remaining consideration for the framework to be completed was regarding how large, bureaucratic, regulated industries could adopt disruptive technologies. To answer this final piece, Clayton Christensen's work in Innovators Dilemma was considered.

In Innovators Dilemma Christensen considers the challenges disruptive technologies face when their market potential is evaluated by large established companies. Disruptive technologies, being technologies that are technically well developed, may not have all the attributes valued by existing markets, but do not pose technology development risks. The 
technologies considered in this thesis in the form of microgrids aligned to the definition posed. Microgrids are a configuration of existing, developed technologies and thus do not pose technology risk. Christensen's analysis focuses on large companies that have well established processes and internal objectives to meet. Additionally, as defined by Christensen, good managers in large companies are tasked in maintaining these internal processes and objectives. Therefore according to his analysis even if executive management signal a change in direction towards disruptive technologies, the nature of the existing management in those companies would not be ideal to implement such a shift.

Christensen's analysis resonated with the electricity sector in Ontario. The electricity sector functioned a bit like a large company where the Ministry of Energy would set the tone and direction, not unlike executive management; the IESO would act as the middle management of the electricity sector setting a vision for executing the Ministry's vision while maintaining the normal operation of the company; and the Ontario Energy Board would function like long standing company rules and practices for internal operation. The main difference between Christensen's analysis and the electricity sector was that for Christensen, the key analysis was motivated to help large companies undertake changes on finding markets for disruptive technologies, while in this thesis the critical question is how the markets could be effectively valued because the electricity sector is regulated.

Christensen's approach completed the framework and was adapted by using Jaccard and Mazzucato's arguments to fit government policies in regulated industries. Within 
regulated industries, where the market design is controlled, it was vital to have a metric that could create a market that would effectively value the policy objective. One central argument in this thesis is that technologies develop at a faster rate than policies can adapt. Therefore, creating separate markets for each technology and evaluating them in the context of the existing market design was deemed to be administratively challenging and ineffective. In other words, creating a patchwork of programs to add storage, microgrids, renewables, etc., is not the inherent objective of environmental policies. To apply Christensen's framework to a regulated industry like electricity, it is adjusted by considering the policy objective or ROI of environmental policies in Ontario to be reduced emissions. Thus, the success of these policies in Ontario would be a measure of how effectively the electricity sector would reduce carbon emissions. This would create a mechanism in which disruptive technologies could demonstrate their value and be integrated. This framework would be applied to the discussion of microgrids to illustrate one disruptive technology and the challenges different integrators would face in implementing it.

A disruptive technology is a technology that consists of developed technologies but often lacks specific attributes that are currently valued in the market. Microgrids are used to demonstrate the limitations of the current market and electricity sector in Ontario; their value is discussed in section 3.9. This thesis acknowledges that microgrids would be a technology that could be better valued for its ability to help with emissions reduction but does not advocate for any specific technology. It only uses microgrids to illustrate the conflicts in the existing market design when integrating technologies that can be key 
enablers in achieving emissions reductions but do not fit neatly into the existing policy and regulatory frameworks.

The following sections are a detailed analysis of each of the frameworks used along with the key arguments that were considered.

\subsection{Motivating Mazzucato}

To determine why governments are motivated to adopt and support new technologies we turn to the work of Mazzucato, an economist writing about innovation policies as they relate to governments supporting the development of technologies. She presents us with The Entrepreneurial State, an entity that invests in the development of new technologies and industries. At the heart of Mazzucato's argument is the notion that the state enables the development of new technologies by the 'socializing of risk,' only to have private industries then build from that foundation and create a culture of 'privatization of rewards'(Mazzucato 2014). Essentially what Mazzucato is indicating is that investing in creating new technologies, carries with it a high risk of failure during the initial stages of development. She argues that during the high risk stage governments fund technology development because they have a higher ability to absorb the financial risk. When technologies have been developed to the point that private sector can appreciate their commercial value, private sector players then take over and benefit from the governments investment by taking the technology to market. Mazzucato's argument is evident in the cleantech sector where the government has continued to fund the development and demonstration of these technologies in Canada through agencies like Sustainable 
Development Technologies Canada (SDTC). However, only limited investment from the private sector is shown. A recent study done by Gaddy et al. lends further support to Mazzucato's argument by revealing that either due to technology risk or lower margins venture capital (VC) firms tend not to invest heavily in the cleantech sector (Gaddy, Sivaram, and O'Sullivan 2016). Gaddy et al. argue that VCs are more suited to invest in software firms as they require lower capital and come with a promise of higher returns. In contrast, much of cleantech is capital intensive and has a long lead time before VCs can realize their return on investment (ROI). Mazzucato argues that if the state is taking on the technology development risk, then the state should benefit from that investment. However, there is a central conflict at play when the state does not earn direct returns on its investment. Mazzucato offers three options for this:

1. Royalties from commercialization of technologies that were funded by the State

2. Income contingent loans and equity in companies that are borne from the State's investment

3. Development banks that can be leveraged to develop technologies with repayable loans

While considering Mazzucato's argument, it is vital to question who 'the state' is. Mazzucato presents the state as a homogenous coordinated entity. This assumption is evident in the offered mechanisms for ROI realization. Consider the effectiveness of these mechanisms from the lens of who would receive the money from their 
implementation. Would these be implemented to benefit the federal government's investment in the technologies? If so which agency and how would they be distributed? Let us take for example Mazzucato's illustration of the agencies involved developing the platform technologies that were critical components of the first generation iPod. A platform technology is a technology that is used as a basis for the development of other technologies. For example, in the case of the iPod, the touchscreen display was a platform technology that was critical in the development of the overall product. Figure 4 illustrates the many agencies involved in the development of these technologies. These agencies highlight the heterogeneous nature of Mazzucato's state. However, one could argue that in how her ideas are presented, there is an implicit idea in the state is a homogeneous coordinated entity, centrally funding innovations. 


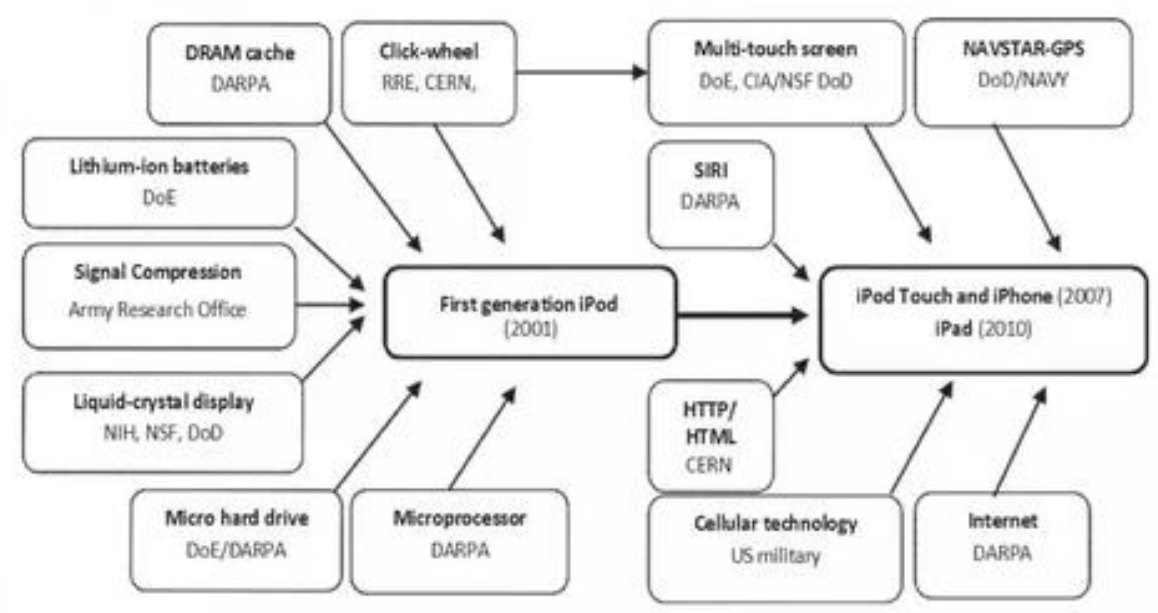

Figure 4: iPod platform technology development contributions, Figure 13 from Mazzucato, M. (2015, p. 116), The Entrepreneurial State: debunking public vs. private sector myths, Anthem Press: London, UK, ISBN 9780857282521, US edition (Public Affairs). ${ }^{2}$

Rather, as shown in Figure 1 above we can see that the state is in fact a collection of government agencies and in different government jurisdictions all with various mandates. A further actor missing from Figure 4 is the universities that were co-funded by state level contributions or other municipal funds.

Take for instance government funding for research programs in Canada at the Federal level. Figure 5 illustrates some of the key agencies involved in supporting scientific research in Canada. Institutions like the National Science Engineering and Research Council (NSERC) support science funding and provide grants for academics and the private sector in support of science research. NSERC supports research at Canadian universities and colleges that are also being supported by provincial governments.

\footnotetext{
${ }^{2}$ Reproduced with permission from the author
} 
Ontario's own Ministry of Research, Innovation, and Science had a budget of \$1,794

million to spend on academic research and industry supporting programs ("Ministry of

Research, Innovation, and Science" 2017).

\section{Exhibit 1.2: Canada's Science and Innovation Ecosystem}

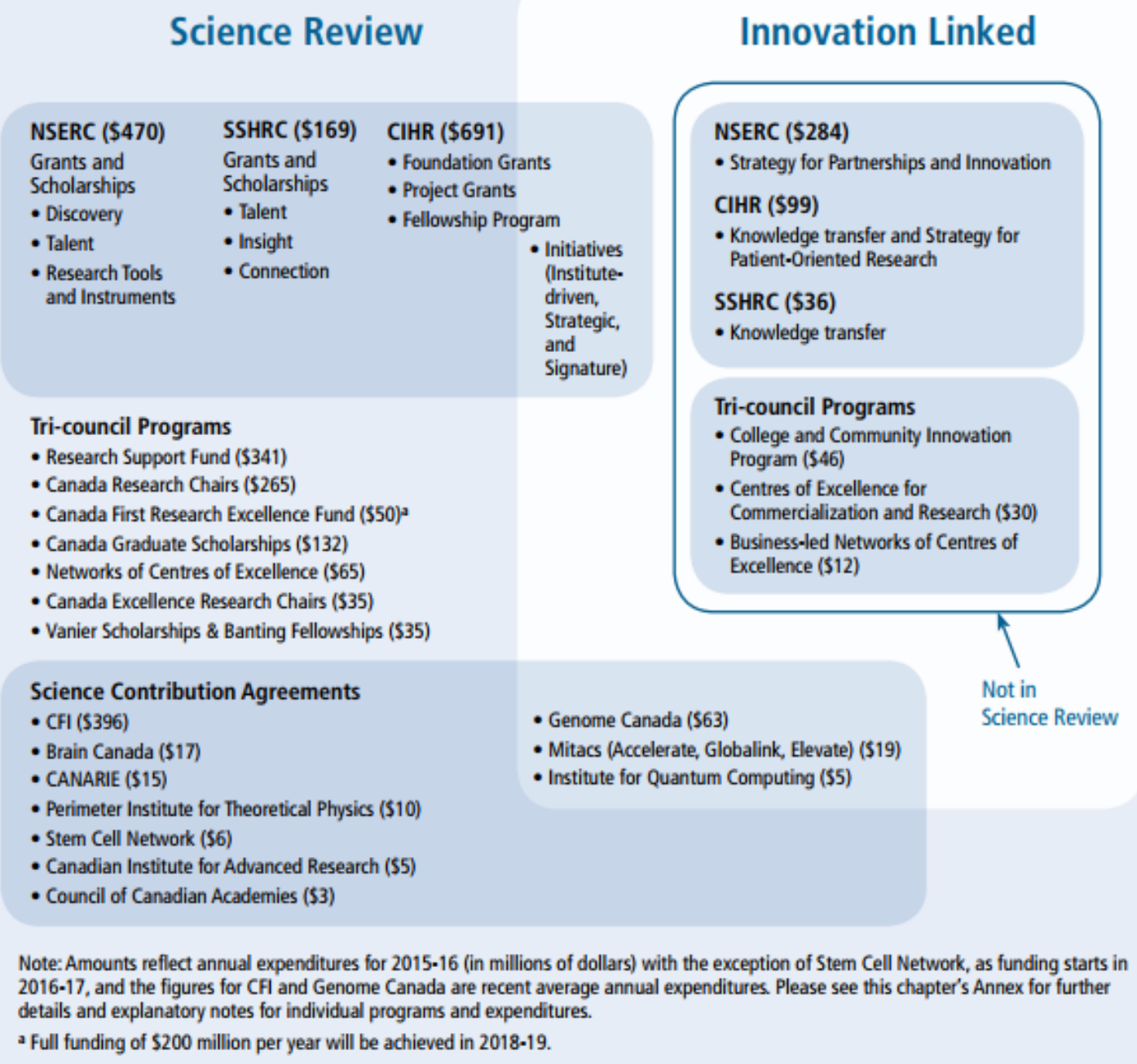

Figure 5: Federally supported programs for science innovation taken from the Fundamental Science

Review (Advisory Panel for the Review of, Federal Support for Fundamental Science, and Advisory

Panel for the Review of 2017) 
Given Mazzucato's argument for the need of the state to receive some ROI, the questions that need to be answered remain — which state and what does return on investment mean for that state? If the state is not getting sufficient ROI through GDP growth and taxes, then why does the state, at multiple levels, engage in the thankless work of investing in high-risk innovation?

Let us take for example the cleantech sector. As Mazzucato argues, fundamentally it is governments taking the risk on innovative technologies in industries like cleantech. The 2017 Canadian Budget is a clear indication that the current Canadian government believes that cleantech is one of key industries that will fuel future GDP growth (Canada 2017a). Investments made federally to help commercialize cleantech innovations through the Business Development Bank (BDC), the Export Development Bank (EDC) and Sustainable Development Technologies Canada (SDTC), indicate the federal government's focus on a new industry as the engine of economic growth. A similar sentiment is echoed by the creation of Mission Innovation, an international financial commitment made by 22 governments to invest USD $\$ 30$ billion per year, by 2021 , in commercializing the cleantech sectors ${ }^{3}$. Here in the cleantech sector, we see a different state emerge, one not silently funding innovation only to hand off the reward to VC firms. Rather one actively investing in the commercialization and adoption of technologies through organizations like Mission Innovation. Thus, again, one must

\footnotetext{
${ }^{3}$ The withdrawal of the US government from the COP21 is recognized. However the continued support of state level governments, municipalities' and non-government actors' continued investment in cleantech is also considered vital to fighting climate change. Further the arguments in this paper remain relevant for those government actors to realize their ROI (Roberts 2017)
} 
wonder why the state (or various levels of states) continue to commit to investing billions into innovations that VC firms have not taken up.

Two key concerns arise by assuming that the state is homogeneous and ROI, as Mazzucato indicates, should be monetary, the first being that the government's overall objectives are misunderstood and the second this misunderstanding implies that the responsibility of the state ends after a technology is developed. In the conversation of electricity and cleantech, the state is not merely responsible for the development of technology, but it is also the regulator of that industry. If one part of the state has invested in that technology and taken the risk, another is restricting its diffusion and hindering the realization of the benefits from the technology it helped develop. The state is preventing itself from achieving its own ROI. Additionally, the state is not motivated by the need to amass taxes. Taxes are a form of revenue that allows the state to operate to achieve its ultimate goal of governance. That governance includes ensuring the economy's health and ensuring the safety of its citizens and environments.

Mazzucato argues that the state must be able to achieve some ROI by proposing potential avenues like development banks or repayable loans to realize this goal. Mazzucato presents innovation as a critical responsibility of the state given the number of technologies that the state has helped fund. However the answer to the question of why would the state take on the risk of innovation if it is not getting the needed ROI, remains incomplete. Mazzucato's focus on a financial ROI ignores the true nature and role of the state. To better understand what an accurate representation of the state's ROI would be, it is important to consider what the motivation is behind the state's investment in 
innovation. The following section considers the role of the state to help reveal the policy objectives that may be influencing its investment in innovation. It further considers the factors influencing public policy to define how ROI should be measured for policy makers. It considers the current and historical motivations that led to the development of climate policies in Ontario. After establishing the political backdrop in which policy makers are working, the framework established by Mark Jaccard in Sustainable Fossil Fuels will be introduced to measure the success of public policy in regards to clean economies.

\subsection{The politics of policy}

To answer the question of how ROI for the State should be measured, one must consider what the role of the State is and what would be a measure for its success. While the private sector invests in innovation to make profits and to generate higher revenue, these motivations are not consistent with the need for the State to invest in these technologies. As Mazzucato points out, it is the need for profit that creates the distinction in risk appetite between the state and the private sector. Take for example the microprocessor that was a critical component in the development of the iPod. The microprocessor's development, as Mazzucato mentions, was aided by significant contributions from Defense Advanced Research Project Agency or DARPA. Mazzucato also mentions that DARPA was interested in funding technologies that could aid in "producing superior defense technologies' (Mazzucato 2014). It is clear that the microprocessor, along with other technologies initially funded by DARPA, has significant applications in other industries such as advanced computing as well as the development of the iPod. However, 
the state's initial interest in developing this technology was not monetary. Mazzucato similarly points to clean technologies like wind and solar generation that were developed with significant contributions from the state. She fails to provide a motivation here for why the state would choose to fund these technologies without another motive. It is here that we look to Leslie A. Pal to provide guidance on the motivations and reasons for why the State is taking on such risk.

Leslie A. Pal (2013), a researcher of policy reform, in Beyond Policy Analysis introduces the concept that governments, unlike the private sector, are motivated to institute policy for a multitude of reasons. These reasons may range from defense and security to creating sustainable economic growth to reducing GHG emissions. A government's 'ROI' is not measured by the economic payback alone, but rather the success of the underlying policy in achieving the policy goals that led to the respective investment. These objectives can include reduced GHG emissions, regional economic growth, increased security of citizens, etc. Let us return to the example of the microprocessor that was instrumental in the development of the iPod. The critical question to answer for the success of DARPA's involvement is not whether Apple Inc. is paying DAPRA some form of royalties for developing the technology but rather, what superior technologies for defense applications were facilitated by funding the microprocessor. The answer for the microprocessor and DARPA's success in relation to that policy may reside in redacted documents that may not be accessible to this researcher for security reasons. However, one may infer that defense technologies like guided missiles and drones, to name a few, rely significantly on certain advances in computing that would be facilitated by technologies like 
microprocessors. The success of any policy may be better served by measuring how effectively it achieved the strategic governance issue it was developed for. The focus of this paper to analyze policy effectiveness in a slightly less classified area than defense, GHG reduction.

To analyze the effectiveness of policies in relation to decarbonization in Ontario it is important to note that electricity policy in Canada falls within a provincial jurisdiction while the effort to decarbonize the economy is a federal and provincial collaboration. Thus the definition of state will include the agencies and departments responsible for executing decarbonization policies in relation to the Ontario electricity system. To better understand how the effectiveness of these can be measured, the arguments made by Mark Jaccard are considered in section 2.4 below. This is because Jaccard presents us with the key elements vital to assessing successful environmental policies. In Sustainable Fossil Fuels, Jaccard highlights that the State is creating policy which is 'an effort by public authorities to induce actions by consumers, businesses and other levels of government'. The first key consideration to understand is what is important to policy makers as they develop decarbonization policies. The following section considers these underlying motivations.

\subsubsection{What matters to policy makers}

In Ontario, the Green Energy and Green Economy Act, often referred to as the Green Energy Act, articulated the political motivation to create a 'green economy' ("Green Energy Act" 2009). The act highlights the government's motivation to remove barriers 
towards integrating renewable generation, increasing energy conservation and introducing programs that would be aimed at promoting this green economy. The act does not explicitly mention decarbonizing the grid, though the implication of a green economy indicates a broader objective of creating economic growth through sustainable economic practices that aim to reduce environmental risks (United Nations 2017a). In addition to these general concepts however, the act refers to specific technologies. The technologies that were referenced in the Green Energy Act, such as renewable generation, were mature and proven technologies that could achieve GHG reductions. In explicitly referencing these technologies the province limited itself to only the proven technologies available at that time, without creating a path to integrate technologies that were still being proven and could help achieve significant GHG reductions once they became commercial. Being prescriptive in which technology should be used to achieve GHG reductions, is considered to be a result of having only limited mature technologies that could be integrated. As further investment in this sector created more technologies, there has been an increase in the types of tools that are now available to achieve GHG reduction. These include new energy storage technologies, microgrids and new smart grid technologies. A more sophisticated technological landscape has led to a more sophisticated understanding of sustainable technologies and the broader language policy makers used to describe their goals. Evidence of this evolution can be seen in the premier's message that introduces the current Ontario Climate Change Action Plan which makes reference to the larger cohesive government strategy to tackle the impacts of climate change by building a 'low carbon economy' and promoting a 'clean-tech sector' (Ontario 2017b). These shifts that now highlight the policy intention of reducing carbon 
no longer make a reference to one specific type of technology that will be used to achieve them, rather they reference a abroad 'clean-tech' sector. This shift illustrates an understanding that beyond renewable generation, technologies like EVs, energy storage, microgrids among others can also be used to reduce emissions.

While public policy makers have become more sophisticated in articulating strategies by using goals like creating 'low carbon economies' rather than naming specific technology objectives like 'add renewable generation' the existing policy frameworks have not been modernized to account for this change. This evolution in policy direction is important because technology solutions will vary between jurisdictions. In Ontario, where a large part of the grid is decarbonized due to a large nuclear energy base and large hydro capacity, renewable generation may not be the ideal solution for GHG emissions reduction. In contrast, Alberta, where a large portion of the electricity grid is carbon emitting, may require larger amounts of renewable generation to be integrated to decarbonize the grid. Distinguishing between the policy objective and the policy tool is critical to allow for a regionally specific strategy that can best achieve the state's mandate.

By providing clarity between the tools and objectives, policy makers can create more flexibility in how policies can be effectively implemented. They will thus provide a mechanism to realize their policy objectives. Since the government's success is not reliant on revenue alone, but rather the success of the policy mandate, it is important to understand how successful policy is implemented and measured. The next section 
analyzes a framework proposed by Jaccard to evaluate sustainable energy policies and considers its relevant application to the Ontario electricity market.

\subsection{Judicious Jaccard}

Jaccard, in Sustainable Fossil Fuels, presents four key questions that are critical in assessing the success of effective sustainable energy policies. These questions are:

1. What is the political feasibility of this policy?

2. What is the environmental effectiveness of this policy?

3. What is the economic impact/efficiency of this policy?

4. What is the administrative feasibility of this policy?

These questions are useful in thinking about aspects that a government could consider when designing and implementing policies because they help to articulate how policy is created and implemented in government. They help to understand the key differences between the private and public sector. This paper considers these four questions to measure the Ontario government's ability to achieve its goal of effectively fighting climate change while promoting a cleantech sector as per the Ontario Climate Leadership Plan in the electricity market (Ministry of Energy 2017). The electricity market is a regulated market that operates within the jurisdiction of the provincial government. Through several organizations like the Ontario Energy Board (OEB) and the Independent Electricity System Operator (IESO), the provincial government controls the electricity market through regulations as well as codes and market rules that define how the electricity market operates and which technologies are allowed on the grid. The role of 
the individual agencies will be explored in depth in Chapter 3. However, it is important to understand that while one agency of the government may have invested in the development of cleantech, other government agencies control the mechanism for their diffusion by controlling the market.

To understand the role of different levels of government in helping to diffuse cleantech, consider how a technology may receive a license to operate in their industry. Viewed from this lens, technology developers must meet a variety of policies that are determined by state and non-state actors. In the electricity sector, the government through the IESO must first create a market in which a technology can be used. Technologies must be able to prove their viability in these markets by demonstrating that they can meet the regulatory requirements to operate in these markets: they have the required permits to operate safely, they have the requisite license and they fulfill a market need. Other requirements to operate in an industry may be to meet industry established codes and standards. Take for instance a technology like photovoltaic (PV) panels that can convert solar energy into electricity. A PV panel technology would first need a market to sell into, such as the IESO Feed in Tariff (FIT) that would value renewable generation as outlined in the IESO market rules ("Market Rules \& Manuals Library - IESO” 2017). A market alone would not be sufficient; anyone installing the panels would need to abide by the codes that govern embedded generators, such as placement of meters, as outlined in the OEB Distribution Code (Ontario Energy Board 2015a). Further installation could require receipt of permits from the cities. The PV panels would need to interface with other technologies like inverters and would need to also abide by industry standards, such 
as standards set by the International Standards Organization (ISO) to ensure safe operation and integration. The government creates the electricity market, regulates the market, influences industry standards, provides certifications and develops the codes for operation within that market. Figure 6 illustrates how technologies like PV panels may interact with policy in reference to their ability to get a license to operate within the industry.

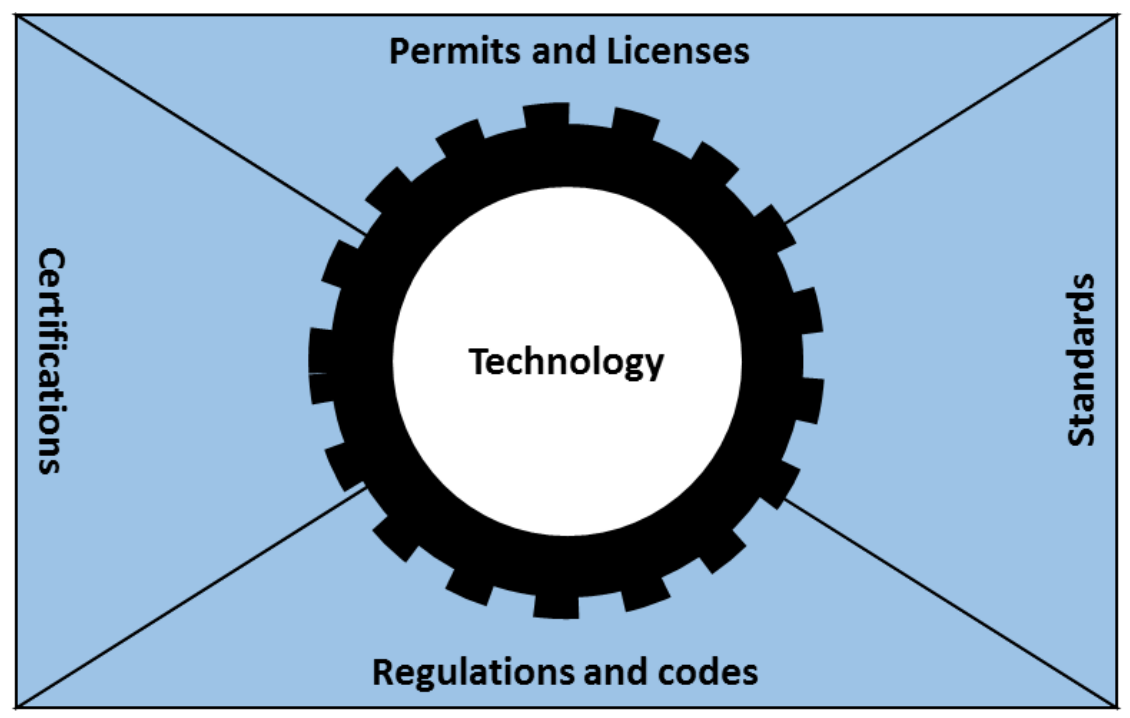

Figure 6: Author's illustration of technology-policy interface

Technologies must with conform and adhere to policies to operate within a given industry such as electricity. It is just as important to understand that policies that govern those industries are a function of the operational or administrative needs of that industry as well as the politics of the day. In this instance, it is vital to understand and separate the operational needs of the industry as well as analyze the political agenda that is shaping the policies of the day. The interaction of these two policy influences impacts how technologies can diffuse within the context of electricity markets. For the purpose of this paper, industry standards and non-government codes will not be deeply analyzed. Rather 
this paper focuses on some of the policy tools that are within the government's control. While it is acknowledged that industry associations and standards bodies may develop standards that can inform regulations governments adopt, it is beyond the scope of this paper to analyze standards development in a non-government context. This study will rather focus on those policy tools (regulations and codes) that are within the state's power to influence, because these policy instruments impact the government's ability to achieve its own objectives of promoting clean technologies and decarbonizing the grid.

Furthermore, regulations and codes are policy instruments that are directly in the purview of the provincial government to change. Promotion of clean technologies, in reference to decarbonizing the grid, implies that these technologies, when diffused or integrated within the current electricity system, can help to facilitate the province's broader objective of fighting climate change. Since the provincial government itself creates the codes, regulations and market rules, it directly impacts the ability of clean technologies to integrate on the grid.

Jaccard's four key questions are critical in analyzing how the Ontario government can measure the effectiveness of its policies in reference to achieving its goals because they provide the context within which environmental policies are made. Jaccard's analysis can be applied in the Ontario context by grouping his key arguments into two main questions: what political driver is influencing the creation of a policy and how to most effectively implement that policy. The sections following first consider the political backdrop that is influencing the creation of the government's agenda, and then considers its administrative feasibility. This paper concentrates its analysis on the operational effectiveness of the 
decarbonization policies in relation to the electricity system while recognizing that part of the government's broader strategy is influenced by political change.

\subsubsection{Political feasibility, a policy window opens}

The first key question to address from Jaccard's framework is regarding the political feasibility of sustainable energy policies. To answer this question we must consider the underlying political changes that have taken place in Canada in reference to climate change policies (Chahal et al. 2017). The election of the federal Liberal government in Canada in 2015 came with a distinct shift in policy regarding climate change. The signing of an agreement at the $21^{\text {st }}$ Conference of the Parties (COP 21) punctuated the beginning of a federal- provincial collaboration in Canada within the context of fighting climate change. In a significant departure from past practice, the Canadian delegation that attended COP 21 included representatives from most of the Canadian provinces (Scrimshaw 2017). In Canada, this coordination was further solidified through the Pan Canadian Framework on Clean Growth and Climate Change, a provincial/federal commitment to address the issues related to climate change, which most provinces and territories agreed to (Canada 2016). On the international stage, this coordination was signified through the signing of the Paris agreement.

With key provincial governments supporting new climate initiatives, Canada is witnessing the opening of a policy window. A policy window is essentially an unexpected opening in the policy process that creates the possibility to influence the direction of a process (Leslie A. Pal 2014). Further evidence of this policy window can 
be witnessed through key environmental initiatives like the nationwide announcement of the coal phase out at the federal level in Budget 2017. The national phase out of coal is an initiative that required critical support from provinces like Alberta that have a large coal base to their electricity systems (Press et al. 2016). Additional commitments are indicated in the budget through commitments made to promote cleantech sectors with provincial and federal support and the concentration on initiatives to increase the adoption of EVs. Environmental sustainability has moved from the periphery and has taken center stage in many political agendas at the time of writing (2017). In Ontario, this shift is noteworthy and its impact can be witnessed through the change in policy in the Ontario Conservatives and the position taken by Patrick Brown the current leader of the party. While the conservatives may disagree on the policy tools needed to fight climate change there is now an acknowledgment in the leadership that climate change needs to be addressed (Taber 2016).

The opening of this policy window answers Jaccard's question of political feasibility. There has emerged a desire to support sustainable development strategies like decarbonization in both the province of Ontario and the broader Canadian economy. The range of policies being implemented to realize these goals speak to the support and political will behind these initiatives. The Ontario government has joined California and Quebec in implementing a cap and trade program to cut emissions (Ontario 2017a). It has announced initiatives to promote the diffusion of technologies like EVs, smart grid and energy storage. It is recognized that realizing the objectives set forth in this policy window will require governments to carefully consider how to remove barriers and 
modernize regulated markets like electricity. To understand the operational considerations that will be required for policy makers to achieve their objectives, it is important to consider Jaccard's remaining questions about environmental effectiveness, and environmental and economic feasibility. The following section considers these questions in reference to the electricity system in Ontario and develops the key considerations that will be used to measure the effectiveness of policy for this paper.

\subsubsection{Implementing policy: walking the walk}

Jaccard argues that some policies like regulatory changes, may have good environmental impacts and be easy to implement since they are more operational in nature. He does not analyze specific industries individually. In electricity markets, changes in regulatory environments signify fundamental changes in the market which are largely controlled by the provincial government. Take for instance the OEB regulations that specify how utilities that distribute electricity can make money (Ontario Energy Board 2015a). The OEB specifies that utilities can only operate in front of the meter. As the meter is the point of transaction where electricity goes from the distribution network inside the home, the utility is not allowed to operate or influence the use of electricity once it has entered a home. One suite of technologies that can help decarbonize residential electricity falls is classified as smart grid technologies. These technologies have the potential to reduce emissions by giving utilities control over management of appliances like water heaters to use electricity when there is an excess and suspend their use when electricity demand is high. An easy method for controlling these devices would be to allow the utility to operate behind the meter, with the customer's consent, and control the water heaters as 
needed. Unfortunately, this classifies as a 'behind the meter' application and is not currently allowed in the Ontario electricity system. Such a regulation not only limits the ability of technologies to be implemented but also constrains the effectiveness of technologies that have been supported in their development by funding from other levels of government. Reform in regulations can help both the diffusion of new technologies while also contributing to the ability of governments to meet their emission reduction targets.

The policy being analyzed in this paper relates to decarbonizing the Ontario electricity grid. Within that context, changing regulations are critical in realizing the environmental effectiveness of any policy. The Ontario electricity system is burdened by legislative acts, regulatory rules, and codes that require modernization before any environmental policy can be effective. This recognition leads us to the importance of Jaccard's question regarding administrative feasibility. As Jaccard mentions, the administrative feasibility of these changes would be difficult as changing legislative acts and codes and rethinking market rules is a challenging task. However, this paper argues that if any environmental policy is to be successful it must adapt to the technological changes that have taken place within that industry. A shift has taken place in how policy objectives have been articulated by policy makers, moving from a prescriptive definition such as 'increase renewable' to a more holistic strategic approach like 'decarbonization'. This shift needs to find its way into legislation and regulations that control the electricity markets. The challenge facing such a shift lies in the nature of electricity markets and the government's role in relation to those markets. While the state has invested in the creation of key clean 
technologies, it is also mandated with ensuring the safe operation of a large electricity grid that is essentially operating as designed. Customers are getting safe reliable electricity on demand. What then is the impetus for the state to take on the administrative challenging of changing the electricity market?

The answer to Jaccard's two questions about environmental and economic effectiveness shed light on what the government's mandate is. The Ontario government has a dual goal of ensuring economic growth in the province while also ensuring environmental risks are mitigated by implementing decarbonization policies. The state, broadly including the Canadian federal government alongside provincial governments, has invested in clean technologies for years. Evidence of this investment is noted in the 2017 budget through agencies like Sustainable Development Technology Canada (SDTC) that have invested over $\$ 900$ Million in Canadian cleantech firms. This paper recognizes the ROI for the state in relation to the electricity sector to be measured by the state's (provincial and federal) own mandate of promoting cleantech and decarbonizing the economy, specifically the electricity system. It is important to note that cleantech, as a sector, is defined as any technology that includes environmentally sustainable technologies. These technologies are not restricted to generation of electricity only but include technologies such as energy storage and microgrids, as well as other sectors like water treatment and waste management to name a few. The impetus to undertake the challenging administrative task of modernizing the grid lies in the government's mandate to decarbonize the grid while also promoting a cleantech sector. The government's success 
in achieving these mandates will be measured by the economic payback of growing the economy and reducing GHGs from the grid.

Part of the government's motivation in seeing cleantech sectors grow is that it has been funding innovation in the sector for some time through agencies like SDTC and programs like NSERC. Returning to Mazzucato's argument for ROI, the state has invested in this sector because there was a recognition of the need to promote clean technologies that can help decarbonize the economy. Thus, the state took the risk that VC firms were unwilling to take and helped develop these new technologies. Both the entrepreneur and the innovator, the state has funded research in the sector and with the opening of a policy window has the opportunity to realize an environmental payback on its investment from reducing emissions and an economic payback by promoting the cleantech sector.

Jaccard's question of administrative feasibility is linked to Mazzucato's missing definition of the state. The outstanding question that remains is what is standing in the path of the state realizing its ROI? What is the administrative difficulty in implementing the requisite policy? Neither Jaccard nor Mazzucato helps us understand this operational question that seeks to answer why one agency of the government would fund disruptive technology while another would adhere to regulations that would stand in the way of the diffusion of that technology. In the electricity sector, where the state would need to amend regulations to create markets for new technologies, there is an inherent dilemma since the incumbent system is operating as designed. Electricity is being generated and consumed without interruption. The state is getting contradictory messages about when 
and how to implement changes. The innovator state guided by a policy window is creating policies to decarbonize the grid. Evidence of this is seen through the recent budget where BDC, EDC and SDTC were provided funds to help commercialize clean technologies (Canada 2017a). The administrative, or operational, state is operating a system and a market that recognizes the existence of new technologies but does not have a mechanism to integrate them. Evidence of this is seen in the Ontario electricity sector where the IESO is trying to plan for the long-term development and decarbonization of the grid but does not have a clear mechanism to value technologies like microgrids or energy storage. The monumental shift needed to change the current system to adapt to not only safe and economical production, transmission, distribution and consumption of electricity, but also to balance environmental effectiveness will be significant. However, without this administrative change in the market, the policy window will close without realizing effective policy. Christensen could answer this Innovator's Dilemma, by saying firms that would not adjust to market change would lose market share and possibly be displaced by other innovative companies (Christensen 2011). In electricity and regulated industries, the market shift is hinged on the policy shift being implemented in a risk averse, safety driven structured and regulated market controlled by various groups within 'the state'. The innovator, the entrepreneur and the regulator, the state is not unlike a large company faced with disruptive technology in Innovator's Dilemma.

In the following section, Christensen's Innovator's Dilemma is considered from the context of the government responding to disruptive technologies. His arguments are analyzed and adapted to understand how governments can build effective policies to 
integrate innovative, disruptive technologies in the electricity sector to ensure that the government's environmental and economic policies can be effectively implemented.

\subsection{Challenging Christensen}

Clayton Christensen explores the question of why well-managed companies fail when faced with disruptive technologies in the Innovator's Dilemma. He considers the evolution of technologies like the disk drive and analyzes the reaction of incumbent, established companies. Christensen argues that poor management is often not a component of failure when it comes to the inability of large companies to manage disruptive technologies; in fact, good management may be a contributing factor to why large companies cannot respond to disruptive technologies fast enough. Christensen defines good management as effective stewards of the company, tasked with ensuring that the company continues to operate smoothly. He argues that for a large company to operate effectively, good managers throughout the organization would resolve conflicts and disruptions to the organizations' operations before they can have significant impact. Good managers would ensure that the core organization continues to operate smoothly leaving executives and higher-level managers to determine the strategic direction of a company. When considering technology development, effective managers would evaluate the investment in research and development against the market size. For a large organization with an existing customer base, these managers would solicit the feedback of existing customers to evaluate if there is a market for the product. A small market would not be an attractive investment to a large organization. Large organizations and their corresponding management structures are well suited for continuous improvement 
in technologies. An example of such development would be the continued improvement of smartphones. Once the industry is established, large companies can effectively size the market and seek customer feedback on which attributes of the technology to develop.

Christensen's definition of good management applies within the electricity system. The electricity system is divided into four main markets: electricity generation, frequency regulation, voltage control and reactive power, and black start facilities. The electricity market is explored in depth in section 3.6. These markets are controlled my government through the IESO who manages the electricity market in Ontario. Take for consideration the market for electricity generation. Traditionally the IESO has purchased electricity from large generators through contracts for large scale nuclear power plants or hydro power plants. The traditional markets have been in the hundreds of MW range. This large- scale electricity would be transmitted on the transmission grid, which is also controlled and managed by the IESO. The sector is engineered to move large amounts of electricity, centrally produced in large amounts, and is managed by large institutions that ensure the system runs optimally. According to Christensen's definition, good management in the electricity sector would ensure the smooth operation of the electricity grid where large amounts of electricity is centrally produced and then distributed to customers.

Christensen proceeds to evaluate how good managers would consider disruptive technologies. Disruptive technologies are technologies that are simple and largely consist of 'off the shelf' components. They are often simpler versions of previous technologies 
and often lack attributes that current markets value. Take for example a battery connected to the grid. A battery can provide some electricity, voltage control and reactive support, frequency regulation and act as a small black start device. As an electricity source, it can store some amount of electricity but is not as effective as electricity generation. Nor can it provide the other market needs at the same. In a microgrid an energy storage device can facilitate smooth operation of all the components, but would not be an ideal source for any single market need. One key distinguishing feature for energy storage would be that it can be dispatched quickly. It can go from storing electricity to supplying it very fast.

When considering disruptive technologies, Christensen argues, that the sales potential is not evident. Thus, good management would not consider such a technology to be a good investment. For the IESO managing large contracts in the market, a small energy storage device does not have significant value. It cannot manage enough electricity for the IESO to effectively evaluate its potential in the system. However, from the perspective of a distribution grid, a small amount of energy storage, situated near a small microFIT or FIT solar generator for instance, could easily manage the fluctuations on the distribution grid and can be an effective asset. The constraints in the utility business model that restrict their ability to integrate certain technologies will be explored in detail in sections 3.5 to 3.8 .

The electricity sector is responsible for production, distribution, and transmission of electricity - a commodity that must be produced within moments of the time of consumption. Excess supply of this commodity must be removed from the grid to ensure 
smooth operation and to avoid adverse effects such as black outs and the unexpected loss of electricity to consumers. The various technologies on the grid must be operated in balance and harmonized to ensure the safety of consumers, operators and any entities connected to it. The significance of the impacts that loss of electricity can have on the system can be evidenced by the gravity of the response to the 2003 blackout of the north eastern North American grid. Both the Canadian and US government federal governments launched a collaborated investigation along with several provincial and state level governments to understand how a software bug in the grid in the US Midwest caused the loss of electricity for an estimated 55 million people across the two countries (U.S.-Canada Power System Outage Task Force 2004). A 2010 study done by the OEB revealed that, on average, Ontario experiences only 4.78 unplanned power outages per year (OEB 2010). It can be argued that the low number of power outages in Ontario are evidence that the system is managed well. Chapter 3 will shed further light on how much effort and coordination goes into managing the electricity system and ensuring reliability.

This paper argues that the electricity system, like Christensen's large companies, is managed well to fulfill its intended design purpose of providing Ontario with safe and reliable electricity. It was not designed, nor is it managed, to adopt clean technologies like microgrids or energy storage solutions that are disruptive. There is an emergent need for decarbonization that is resulting in policy makers having to retrofit disruptive clean technologies on the grid. Christensen argues that the good management of large companies, similar to the electricity sector, is ill suited to manage the growth and integration of disruptive technologies. Christensen provides us with seven key indicators 
that can help identify why management in large companies is not suited for disruptive technology. These indicators are used to analyze management of the electricity sector and to highlight that Christensen's framework in Innovators Dilemma applies to a regulated market like the Ontario electricity sector. Christensen's seven points to understand the inherent conflicts for large companies when managing disruptive technologies are listed below as they appear in The Innovator's Dilemma (p. 258-260). They are then explored in depth and used to evaluate the electricity sector.

1. Products that do not appear to be useful at present, may serve customer needs in the future. Therefore, expecting customers to lead organizations towards innovation may not serve the companies' end goals.

2. Disruptive technologies that may appear to have small markets and revenue potential may not be funded as they would appear to have a limited contribution to the company's goals.

3. Successful companies match technologies to markets, but disruptive technologies may not have established markets and thus their impacts may be overlooked.

4. Managers in successful companies are adept at ensuring the companies survival by meeting current market needs. Managing disruptive technologies requires a set of skills that successful companies do not need for their operational needs.

5. Information needed to get executive buy in for major investments in disruptive technologies may not exist in reference to disruptive technologies.

6. A blanket technology strategy cannot be used to manage both disruptive and sustained technologies. 
7. Established companies may not understand the value proposition of disruptive technologies since they would rarely invest in them during the development phase. This would create large barriers to adoption.

To understand how Christensen's analysis can be borrowed to understand the problems facing the electricity system and microgrids, we return to his definition of disruptive technology. Christensen describes disruptive technologies to be straightforward innovations that consist of off-the-shelf components that were put together in a simple architecture. He contends that these technologies offer less of the attributes that a customer in an established market would want and thus these technologies are valued more in emerging markets and have niche applications. While an in-depth analysis of the definition of microgrids is presented in Chapter 3, consider a microgrid from the perspective of Christensen's definition. A microgrid is essentially, as Tao et al. describe it, a collection of existing technologies such as energy storage, renewable generation etc. Microgrids can be customized for specific needs but a combination of a small electricity generation device, with an electricity storage device and an inverter would classify as a microgrid (Tao et al. 2011). The individual components that are part of the microgrid would be largely established technologies that do not need any modification, a microgrid is merely a re-organization of existing technologies. The closest proxy to a microgrid would be the existing electricity grid. Where the current grid would serve the province of Ontario, a microgrid could be adapted to serve a small residential complex or a university campus. Christensen's definition is echoed here as it is unclear what advantage a microgrid would serve in the established grid. Thus, most current applications of a 
microgrid have been niche and designed to attract new emerging markets like isolated communities and consumers faced with electricity disruption. Microgrids are therefore considered to be disruptive technologies by Christensen's definition. His first two considerations largely contend that disruptive technologies are unique, and typically their market potential is unclear. These considerations are evidenced in the uncertainty around what value microgrids could bring to the electricity system. A recent analysis by Navigant Consulting, a firm leading the research on microgrid adoption, values the global microgrid market to be large but does not specify what the market needs for microgrids may be and how to realize it (Navigant Consulting 2016).

Christensen's third and fourth point speak to the difference in companies' ability to manage disruptive technologies in a given market. He contends that successful companies match technologies to markets and good managers in large companies are skilled at ensuring that the current market needs are met. Here it is important to consider that in the electricity market, the company is a proxy of the government. To apply Christensen's framework the electricity sector is considered to be similar to the large company that Christensen is evaluating. The government is not only matching the technology to the market need, but also creating the market and regulating it. Take for instance the market for energy storage as was highlighted in the introduction. The government considered intermittent renewable technologies to be equivalent to traditional generation technologies, and as any good manager would do, it matched the current market need with the technology. The electricity market matched the function of electricity generation to the market of electricity generation. However, without recognizing the intermittent 
nature of the renewable generation, the market could not value the attributes of energy storage. The provincial government in relation to the electricity system is not only a proxy for Christensen's large company operating within the system, it is also a proxy for the market that is valuing the technology. The government's mandate is not only economic but also environmental. Unfortunately, the market for managing the changes on the grid resulting from integrating renewables was not created. A large electricity system adept at managing supply and demand of electricity was not able to distinguish the difference between the management needs of intermittent renewables and traditional generation. This unintended consequence in electricity markets highlights the central thesis of the Innovator's Dilemma, i.e. why do well-managed companies fail to adapt to disruptive technologies? A different set of management skills and market design is needed to create markets and manage these technologies.

Christensen's fifth insight that it is difficult to get executive buy in to invest in disruptive technologies speaks directly with Mazzucato's arguments in The Entrepreneurial State. The state has already invested and mitigated the risk of technology development. The question with regards to disruptive technologies in the electricity markets is not about technology development, but of technology adoption. The state in recognizing the need for environmentally sustainable technologies has already invested in their development. The policy that drove the development of these technologies was motivated by an environmental ROI. These technologies are largely looking for new markets that can value their adoption. Christensen contends in his sixth point that a blanket technology policy cannot be used to manage disruptive technologies. This insight is evident in how 
governments have funded the development of these technologies. The adoption of technologies that have incremental benefits to existing markets has largely been left with the government bodies operating the electricity system. These would include new transformers or meters, but essentially these new technologies fit within the existing framework and design of the grid and are new versions of an older design. Similar to how an iPhone 8 is a new version of an iPhone 7-it may have some design updates but is not a new disruptive product, but is rather a form of sustained innovation that improves a previous version. This paper does not intend to minimize the improvement in social status that would be elicited with prompt adoption of the iPhone 8 close to release. It is merely using the technology to illustrate the difference between types of innovation.

Large companies are well managed and positioned to work to create better versions of existing products as there is a clear market for that product and existing customer insights can be used to select features like better camera and battery life. In contrast, disruptive innovations lack large or clear markets and thus their development tends to be done in smaller companies or organizations that can value wins in small markets. The development of cleantech in Canada has seen such an approach applied by governments. Cleantech development in Canada has been supported through smaller units and agencies of the government (federal and provincial). Agencies like SDTC as well as provincial government ministries like the Ontario Ministry of Research, Innovation and Science have funded the demonstration and development of these technologies. While the development of these technologies follows Christensen's advice, the diffusion of those technologies now falls within other large government controlled areas. This again speaks 
to the bureaucratic nature of large firms. Within government this bureaucracy extends into the area of jurisdiction. The complexity arises as one agency may be responsible for funding the development, but its adoption lies within another jurisdiction. An energy storage technology could be funded through its development at the federal level but its integration and market would exist on the provincial level. As Christensen analyzes private firms, the development and adoption of the technology would depend on one small firm. A company would develop the technology and then look for markets in which it could sell. Within the context of governments and regulated industries, Christensen's idea of creating smaller units decouples the responsibility of development, adoption and market. From the market adoption perspective, governments control the markets of regulated industries. Thus, Christensen's idea will be adapted to apply to governments by considering how the electricity sector may be organized to create smaller units which would serve localized markets that can value technologies like microgrids and facilitate their adoption.

Finally, Christensen recognizes that large established companies would not invest in research related to disruptive technologies since these technologies would not fit within an existing market and therefore could not have high ROIs. To evaluate a technology's ROI the company would need to consider the existing market, consider what customers want and how much they are willing to pay for the technology. Given that disruptive technologies are often not suited in current markets and often lack attributes found in technologies that serve the traditional market, disruptive technologies would have poor financial ROIs. Within the context of the Ontario electricity market and microgrids, this 
consideration follows similar to Christensen's argument that it would be difficult to convince executives to invest in disruptive technologies. Governments at both provincial and federal levels have signaled their desire to integrate these technologies with the intention to decarbonize the economy. Beyond a framework to analyze the difficulties that large companies may face when dealing with disruptive technologies, Christensen also offers solutions on how companies can foster and integrate these technologies. This framework will form the basis of how this paper will analyze potential solutions for electricity markets in Ontario. This paper considers the perspective that the electricity market is an interconnected large firm, and Christensen's four questions will be adapted to form the framework that will be used to analyze the electricity sector. His four key pillars of advice to large companies are as follows:

1. Give responsibility for disruptive technologies to organizations whose customers may need them so that resources can flow to them.

2. Create organizations small enough that the small wins from niche markets that would value disruptive technologies could create excitement within the organization.

3. Plan for failure and allow for an iterative process when integrating disruptive technologies. 
4. Find early markets for the disruptive technologies based on their current attributes. The qualities that may make these technologies unattractive to mainstream markets are valued in new markets.

Within the context of the electricity market in Ontario, the key question that this paper serves to answer is how disruptive technologies like microgrids can be integrated into regulated industries like electricity. Christensen's advice is interpreted within this context to guide the analysis of this study. The above pillars will be interpreted as follows:

1. Who are the customers and niche markets that can value microgrids and how can a mechanism be created to empower these players in the existing electricity market to implement this technology?

2. What mechanism should be created in the current electricity markets that could leverage small gains in GHG reductions most effectively?

3. What changes need to be made to the existing market structures to allow for policies to evolve and adapt to technological changes?

4. What markets or customers can value the existing attributes of disruptive technologies rather than waiting for disruptive technologies to adapt to existing markets?

With the key ingredients in place, the following section will summarize the framework that will be used to analyze the Ontario electricity system and its ability to integrate 
microgrids. The following framework will further provide the key considerations that will be used to recommend changes to the existing system.

\subsection{The final word: recipe for masala chai}

Before considering what policy barriers exist in the adoption of disruptive technologies, this paper began by considering how technologies evolve over time. It then analyzed why policy makers should adopt disruptive technologies by considering the fundamental changes that have occurred within the electricity markets. Mazzucato's arguments are vital in providing us the driver for adopting disruptive technologies. She argues, as does this paper, that governments have invested in the creation of disruptive technologies and they should receive some ROI on that investment. To understand the definition of ROI within the context of government, this paper then looked to Jaccard, who helps articulate the role of the government while providing some insight into how effective environmental policies should be created. Jaccard's work helps to establish the context within which this paper analyses ROI. ROI for the government would be a measure of how effectively the economy has been decarbonized.

It is within the backdrop of federal and provincial policy mandates to reduce emissions, that ROI will be measured as the amount of effective emissions reduction through the electricity system - the electricity system being the enabler to decarbonize the economy by facilitating other sectors like transportation to be electrified. Jaccard's arguments, while considering administrative feasibility important, do not give insight into how this can be measured or analyzed within the context of integrating disruptive technologies on 
the electricity system. Here the arguments of Christensen were considered to highlight that creating policies to integrate clean technologies is not sufficient or effective for disruptive technologies because initial markets for disruptive technologies remain niche until markets adapt. Christensen's arguments will be extended to the actual market as well in this paper because electricity is a regulated industry, and thus the government is responsible for the creation and administration of that market. This thesis considers the government to be an enabler of both disruptive technology development, as argued by Mazzucato, and also disruptive technology adoption.

This paper will apply this framework by first establishing the context of the electricity industry in Ontario. It will highlight how the industry is structured and operated in Chapter 3. It will conclude in the next chapter with an introduction to the two microgrid case studies in Ontario. Chapter 4 will use Jaccard's argument to highlight the administrative difficulties that are faced with integrating disruptive technologies on the electricity system in Ontario through the Hydro Ottawa microgrid. Christensen's advice will be considered through the integration of the PowerStream microgrid. The administrative and operational challenges of these two microgrids will be compared to emphasize how barriers challenge the ability of governments to realize Mazzucato's ROI in the form of emissions reduction. In Chapter 5 the questions of how policy makers can adjust to these changes will be considered by returning to Mazzucato, Jaccard and Christensen's arguments within the context of the changes needed within regulated industries to facilitate the adoption of disruptive technologies. The four key insights used 
by Christensen to advise large companies in the management of disruptive technologies will be considered within the context of technology diffusion in the electricity sector. 


\section{Chapter: Context the market and technology}

This chapter will provide an introduction to the electricity grid, its structure as well as the key players that are responsible for managing the Ontario electricity system. It will also provide an overview of the Ontario electricity markets. These concepts will be used to define what microgrids are and highlight two cases in Ontario where utilities have been instrumental in the development and deployment of this technology. The next section will begin with an introduction to the electricity grid as it is designed.

\subsection{Electricity grid overview}

Ontario's electricity grid is part of the North American electricity grid which is over 100 years old (Brown and Sedano 2004). It is considered the largest machine ever built ("The Largest Machine Ever Built," n.d.). It was designed to move electricity from the source of generation to its end user. Until recently electricity was generated in large power plants to capitalize on economies of scale. This electricity was then moved from the generation site, through high voltage transmission lines, to a distribution network. Once the electricity reaches the distribution network it is transmitted through the utility grid to the end consumer.

It is noteworthy to mention that electricity must be generated near the time of consumption and a difference in the amount of supply vs the demand can cause technical issues on the grid. Thus, the grid is carefully managed to avoid significant variations. Furthermore, all electricity generation does not operate the same on the grid; for instance nuclear energy production cannot be easily changed to respond to fluctuations since 
nuclear energy requires significant time to either ramp up production or ramp down. Natural gas plants can more flexibly respond to grid conditions by ramping up quickly. Renewable generation also varies with the type of source. Geothermal energy is a constant source of energy while solar or wind would be functions of weather conditions. Tidal energy is often reliable as it responds to natural, often predictable patterns. The electricity grid balances these various types of generation sources and their respective behaviors to provide stable, reliable electricity. Figure 7 illustrates a simplified view of how electricity is generated, transmitted and distributed in the existing grid. The grid can be defined in four main parts: electricity generation, electricity transmission, electricity distribution and electricity consumption (Brown and Sedano 2004).

Electricity Generation: The production of electricity in power plants. Traditionally refers to large-scale production such as nuclear, large hydro and thermal heat production.

Electricity Transmission: The transport of electricity from the generation site over high voltage lines to the distribution network.

Electricity Distribution: The distribution of electricity to the consumer. Electricity distribution includes receiving the high voltage electricity from the transmission grid, converting it to a lower voltage and then delivering it to the consumer through the lower voltage distribution network.

Electricity Consumption: The use of electricity to do work. Consumers on the distribution grid include industrial users, large consumers and residential consumers. 


\section{Electricity generation, transmission, and distribution}

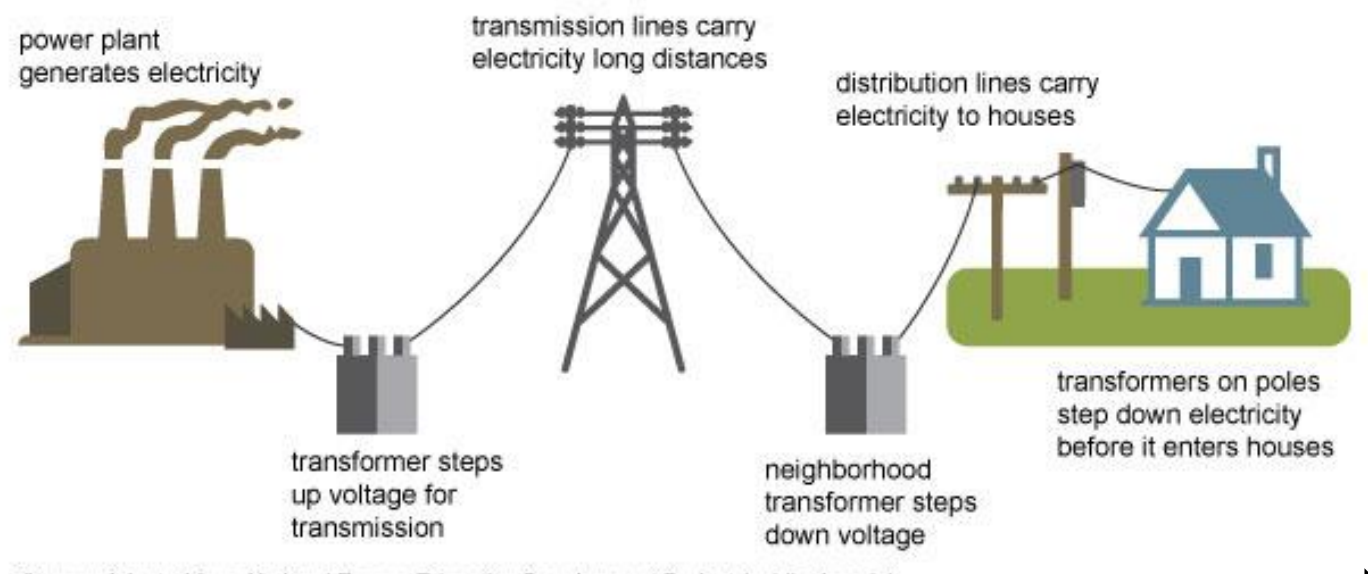

Source: Adapted from National Energy Education Development Project (public domain)

Electricity flow is in one direction

Figure 7: Flow of electricity Image adapted from "How Electricity Is Delivered To Consumers -

Energy Explained, Your Guide To Understanding Energy - Energy Information Administration,”

n.d.

The electricity grid was designed to move electricity in one direction, from generation to end consumer. Until recently, with the introduction of distributed renewable generation the utility grid has not had to adjust to bi-directional electricity flow. Essentially, while the grid can easily send electricity to a consumer, it was not designed to accept electricity from the end user. An example of this would be to accommodate the addition of FIT contracts; distributors would need to make adjustments to their grids to accept the electricity from the generators if the generator is within the utility distribution network.

The cost of the upgrades would then be passed on to the customer and the generator requesting a connection. While mechanisms exist for consumers to feed electricity back into the grid, the distributor was not designed, from an economic or technical standpoint, to accommodate this need (Ontario Energy Board 2015a). The distribution network of the 
grid is primarily designed to distribute the electricity from the transmission grid to the consumer. It is not well equipped to accept electricity from consumers or from smaller generation sources on its network (Brown and Sedano 2004). This idea will be further explored in Chapter 4 within the discussion of microgrids. Managing the grid is a significant operational task that requires several players to work in close coordination.

The grid's management can be considered as being divided into two main activities: the operational or administrative component of ensuring that the grid is stable and political strategic management of the grid. While each organization is discussed in depth in this chapter further below, the division between the organization and the functions they perform relative to each other are illustrated in 8 .

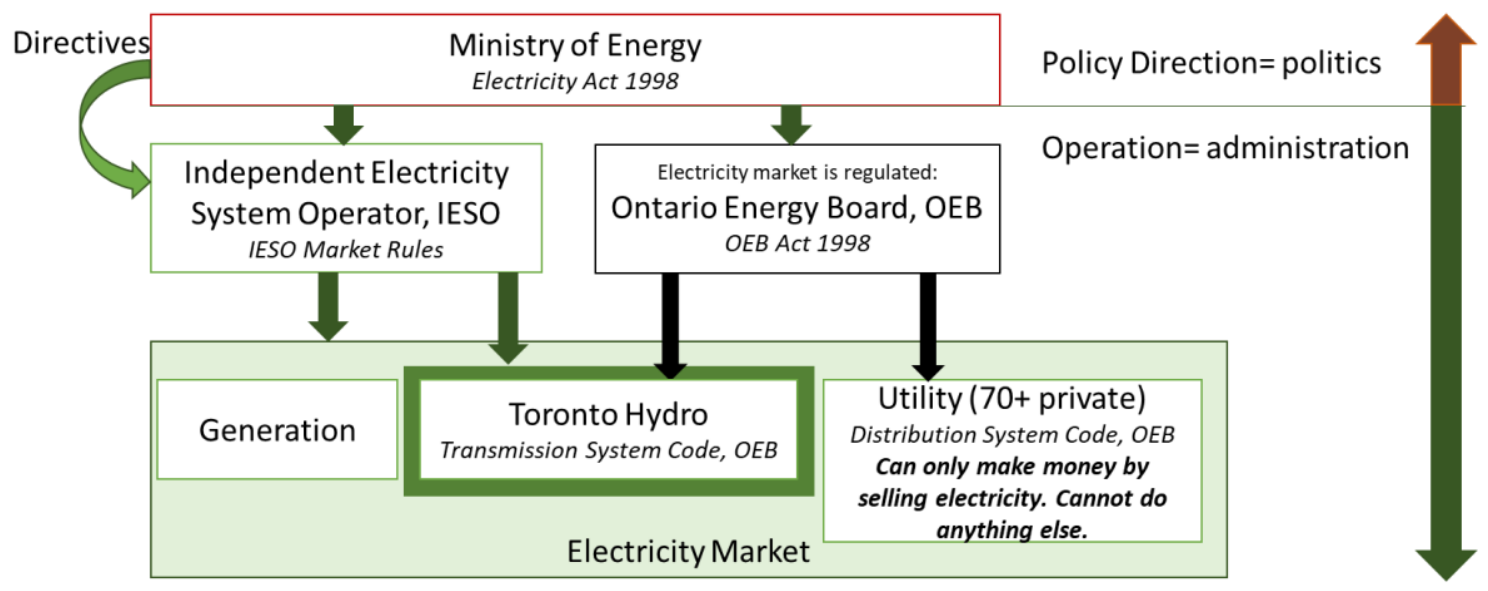

Figure 8: Author illustration of Ontario electricity sector

The Ministry of Energy sets the tone and agenda for the priorities of the government in power. It also sets the strategic direction for the other industry players; similar to how executive management including the governing board in a company would set the 
strategic direction and vision for how a company is managed. The ministry is the political part of the electricity system; it is intended to represent the views of the party in power, and by extension the constituents of Ontario.

Once the ministry sets the agenda, the IESO is tasked with executing this vision. The IESO develops and executes the Long-Term Energy Plan for Ontario, which is intended to be a collaborative vision of how to develop and manage the Ontario electricity sector. It is developed through consultations between the key organizations, government agencies and market players involved in the electricity system. The IESO also creates and maintains the electricity market in Ontario. The OEB is mandated to regulate transmission companies and utilities. The OEB largely determines how utilities and transmission companies operate and how they can generate revenues. Hydro One is the dominant transmission company in Ontario and its role is to move large scale energy production into the utility grid. An analysis of the transmission grid is beyond the scope of this thesis because this thesis considers the impact of technologies like microgrids and energy storage that will be integrated onto the distribution grid. Utilities are regulated monopolies that are responsible for moving electricity from the transmission grid and distributing it to end consumers. Other key stakeholders are end consumers such as Zibi developments, noted in Figure 9 below, who would interact with the distribution grid.

Before discussing the electricity sector of Ontario in detail, it is considered vital to have an understanding of the meter as a point of transaction in the electricity system. The meter is explored at length in section 3.7. However, it is also introduced here within the 
context of the electricity grid overview to understand how the system manages the transactions and exchange of electricity to the customer. Once the electricity passes through the residential customers' meter, the Ontario electricity sector no longer has visibility of how the electricity is consumer or managed. Residential and / or other customers may have additional electricity management technologies in their homes or on campuses but the sector would be effectively blind to how those applications were applied. Additionally, electricity is sold and accounted for through the meter. A residential home would have one meter, a campus would also have one meter. The electricity 'in front' of the meter, or within the utility's grid is managed by the utility, the electricity 'behind the meter' is not managed by the utility but is expected to be consumed once it passes the meter. Consider the location of the meter to the microgrid in Figure 9 for the two cases analyzed in this study:

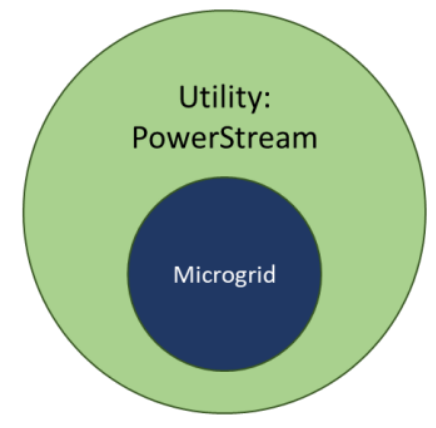

Microgrid is embedded in utility grid.

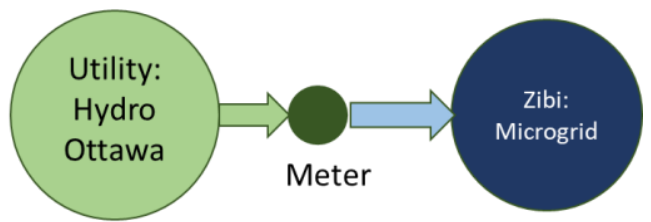

Microgrid is embedded in residential development

Figure 9: Author's representation of the meter in the case studies

The PowerStream microgrid, as shown in Figure 9 is embedded in the utility's own grid. From the management perspective, this means that PowerStream can create technology 
connections between how it consumes, generates and manages electricity. The Zibi microgrid is different from the PowerStream microgrid as Zibi is considered to be a private developer. Thus, from the perspective of the electricity sector, Zibi is a campus that consumes electricity. The development will have one meter, which means that past that meter, Zibi can manage how it consumes electricity. However, electricity generation would require a separate meter to allow the electricity sector to account for how much electricity is generated. This key difference between PowerStream and Zibi limits the type of technologies the Zibi can connect within its development. PowerStream, as a utility, manages its own grid while also providing support to help manage electricity in the Ontario system. One function that PowerStream provides is an account of how much electricity is consumed on its grid. For Zibi, this function would be provided by Hydro Ottawa. Hydro Ottawa would be responsible for informing the IESO how much electricity was being consumed on its grid, this information is vital to the safe operation of the grid. If Zibi connects generation to its microgrid without a separate meter, Hydro Ottawa would not know the true consumption of Zibi, which creates significant management issues for the IESO as are discussed in section 3.7.

The meter as a management tool for the electricity sector is mentioned here to put into context the responsibilities of the various stakeholders in the electricity sector as well as provide an operational view for why those functions are important. As the key stakeholders are introduced it is vital to consider that the utility is operationally the closest stakeholder to the customer. The Ministry of Energy, OEB and IESO do not interact directly with most customers. There is only one exception however; namely 
where large consumers of electricity may be connected to the IESO grid. These entities may include large, energy intensive consumers of electricity such as industrial consumers. The following sections will take a closer look at each of the individual stakeholders starting with the Ministry of Energy.

\subsection{Ministry of Energy, where the dreams are dreamt}

The ministry of energy sets the tone and agenda for the energy sector within Ontario, which includes the electricity sector. Its policy mandate comes from the electorate by the election of a provincial government and that government's platform. The ministry is intended to work in collaboration with industry partners in determining the appropriate course of the agenda and plan on how to execute that agenda. The IESO is tasked with planning the long-term energy plan for the province (Ontario 2004). The ministry has the latitude to issue directives to the IESO for specific requests. The directives can be on a range of issues and can be on a range of topics extending from conservation programs to FIT and MicroFIT (IESO 2017c). The long-term energy plan is intended to be a reflection of how the sector is changing and what is in the best interest for the province.

Some industry experts reflect that while the long-term energy plan is developed as a collaborative effort between the ministry and key stakeholders in the electricity markets to provide the sector with reliable direction, the issuance of directives have complicated the landscape (Anonymous 2017). Directives may be interpreted as the government's tool to address changes in the industry. However, they are ill equipped to address these changes strategically as they are often prescriptive, where rather than stating the policy 
objective they state specific action (eg: directives that mandate specific amounts of renewable or storage rather than GHG reductions) are and may adversely impact the operational cohesion of the long-term energy plan. For instance, the directive issued on April 5, 2016, specifically directs the IESO to procure $600 \mathrm{MW}$ of wind, and $250 \mathrm{MW}$ of solar photovoltaic capacity, up to $50 \mathrm{MW}$ of hydroelectricity and $30 \mathrm{MW}$ of bioenergy (Ministry of Energy 2016). Specific tools that are expected to manifest the goal of "clean, reliable and affordable energy future" are mandated to be procured.

It is a curious conflict that the same act that mandates that the IESO "conduct independent planning for electricity generation, demand management, conservation and transmission" is used to override that plan and mandate an amount of generation be brought online in the form of a directive (Ontario 2016). The electricity act itself highlights the competing priorities within the state. There is a division between the politics of creating clean energy policies and the operational or administrative requirements of the electricity grid. The ministry, in an effort to signify a policy direction, specifies a technology solution to meet its mandate. This however limits the IESO's ability to effectively plan for decarbonization, and renders it the position of merely executing directives and ensuring the safety of the grid.

As noted throughout this paper the policy under scrutiny at the heart of Ontario's electricity policy is that of decarbonization; however, policy makers have been prescriptive in which technologies to use as to achieve this mandate. The impact in Ontario of such a detachment between the policy direction and tool has made the 
unfortunate implication that renewable energy is expensive and not suited to Ontario (Corcoran 2017). While a large number of opinion pieces and articles published with anecdotal evidence suggests that environmental policies in Ontario have led to this increase, there remains to be any substantial evidence-based analysis of the market (Global News 2016). Issues concerning the cost of maintaining a 100 year old machine, the capital needed to build and refurbish nuclear facilities, or even the creation of an electricity market, would have impacts on the electricity prices. However, these concerns are largely left out of such articles. Evidence of this can be seen when the electricity market was reformed in Ontario. Its initial design was efficient as it responded effectively to market signals- when demand for electricity was high, the price of electricity would also increase. This was illustrated when the market went into effect in 2002 and the province experienced a very hot summer. The temperatures resulted in a high demand for air conditioning while electricity supply was constrained from lack of rain to provide hydro to limited nuclear power. The resulting high prices forced the province to shut down the market in a response to public outrage (Winfield 2012). In a time when solar power is experiencing an unprecedented decline in rates, the perceived coupling of renewable generation with high prices endangers the government's ability to meet its policy objectives of decarbonizing the grid as it may lose support from its electorate.

While directives may be a response to development of new technologies or an emergent policy objective, they render the long-term energy plan ineffective. Such interference in the electricity system disables the ability of those charged with energy planning and grid operation in the province to effectively execute the long-term energy plan and manage 
the grid, while ensuring that policy objectives are effectively met. The IESO executing a directive to increase renewable adoption is not equivalent to the IESO being able to effectively plan for or aid in the decarbonizing of the grid. It is not the objective of this thesis to advocate for a specific technology to achieve GHG reductions. Rather this paper seeks to highlight that a more efficient market design, where the end objective of decarbonization is valued would be more able to integrate technologies that are suited to achieve that policy goal. A thoughtful consideration of the policy objectives can help to restructure the market to facilitate the integration of technologies that are most able to reduce emissions. Rather than creating a mandated amount of renewable generation, energy storage or smart grid contracts and paying for each of those individual programs through separate contracts, valuing GHG reductions from the grid would open the market to more technologies. Additionally, valuing GHG reduction in lieu of individual programs would also open technology integrators to find the most economic path to achieve those targets.

The IESO plays a unique role in the electricity market, as it is one of the only institutions that plays the administrative / operational role while also being the closest to the management and strategic vision by virtue of its interaction with the Ministry of Energy. The following section attempts to introduce the many responsibilities of the IESO, the Executor in Chief. 


\subsection{IESO, jack of all trades and master of....all?}

It may be a research project in itself to fully understand what the IESO does and its role in the electricity system. The IESO plans and manages the electricity system, and directs and executes directives related to the electricity system. If the Ministry of Energy is the CEO then the IESO is the company. The electricity act lays out the foundations of the IESO as follows:

The objects of the IESO are,

(a) to exercise the powers and perform the duties assigned to it under this Act, the regulations, directions, the market rules and its licence;

(b) to enter into agreements with transmitters to give it authority to direct the operation of their transmission systems;

(c) to direct the operation and maintain the reliability of the IESO-controlled grid to promote the purposes of this Act;

(d) to participate in the development by any standards authority of criteria and standards relating to the reliability of the integrated power system;

(e) to establish and enforce criteria and standards relating to the reliability of the integrated power system;

(f) to work with the responsible authorities outside of Ontario to co-ordinate the IESO's activities with the activities of those authorities;

(g) to operate the IESO-administered markets to promote the purposes of this Act;

(h) to engage in activities related to contracting for the procurement of electricity supply, electricity capacity, electricity storage, transmission systems or any part of such systems and conservation resources;

(i) to engage in activities related to settlements, payments under a contract entered into under the authority of this Act and payments provided for under this Act or the Ontario Energy Board Act, 1998;

(j) to engage in activities in support of the goal of ensuring adequate, reliable and secure electricity supply and resources in Ontario;

(k) to forecast electricity demand and the adequacy and reliability of electricity resources for Ontario for the short term, medium term and long term;

(1) to conduct independent planning for electricity generation, demand management, conservation and transmission; 
(m) to engage in activities to facilitate the diversification of sources of electricity supply by promoting the use of cleaner energy sources and technologies, including alternative energy sources and renewable energy sources;

(n) to engage in activities in support of system-wide goals for the amount of electricity to be produced from different energy sources;

(o) to engage in activities that facilitate load management;

(p) to engage in activities that promote electricity conservation and the efficient use of electricity;

(q) to assist the Board by facilitating stability in rates for certain types of consumers;

(r) to collect and make public information relating to the short term, medium term and long term electricity needs of Ontario and the adequacy and reliability of the integrated power system to meet those needs; and

(s) to engage in such other objects as may be prescribed by the regulations. 2014, c. 7, Sched. 7, s. 3 (1); 2016, c. 10, Sched. 2, s. 3.

This paper, thankfully, does not undertake an exhaustive analysis of the IESO. After a reading of the relevant legislative acts along with interviews with industry experts, this paper concludes that the heart of the IESO mandate is to ensure the safety and reliability of the electricity system. With those two fundamental principles in mind the IESO plans the operations (yearly and daily) of the electricity grid. It helps in the development of the long-term energy plan, along with the directives of the Ministry of Energy, irrespective of whether those directives may conflict with its planning. As an example, if the IESO is directed to bring on $50 \mathrm{MW}$ of solar energy online, irrespective of the need, the IESO will execute the mandate and bring online $50 \mathrm{MW}$ of solar energy. It will then manage that electricity with the purpose of ensuring the reliability and safety of the electricity grid. Here we consider the impact of how directives limit the goal of decarbonization. If the IESO is given the mandate to decarbonize the Ontario electricity grid along with the authority to do so independently, then the IESO would analyze the grid, consider which technologies would most effectively reduce emissions and deploy those technologies on 
the grid. These may include a combination of some renewable generation, microgrids, specific smart grid technologies, energy storage etc. However, if the IESO is issued the directive to add $50 \mathrm{MW}$ of solar energy, the IESO will execute the directive even if decarbonization would be better achieved by deploying $50 \mathrm{MW}$ of energy storage, or simply reorganizing the grid through microgrids. The $50 \mathrm{MW}$ of solar energy, as mandated, would be brought on line and the IESO would ensure that the $50 \mathrm{MW}$ of solar energy was safely integrated to the normal operation of the electricity grid. The OEB is considered by this paper to be a critical partner in the government's ability to achieve its emission reduction policies. The following section is an introduction to the regulator.

\subsection{OEB: regulating the regulator}

The Ontario Energy Board, OEB, is mandated to regulate the players in the electricity market and to ensure that the customer is treated fairly. The OEB Act specifically lays out the board's mandate including the following key conditions:

1. To protect the interests of consumers with respect to prices and the adequacy, reliability and quality of electricity service.

1.1 To promote the education of consumers.

2. To promote economic efficiency and cost effectiveness in the generation, transmission, distribution, sale and demand management of electricity and to facilitate the maintenance of a financially viable electricity industry.

3. To promote electricity conservation and demand management in a manner consistent with the policies of the Government of Ontario, including having regard to the consumer's economic circumstances.

4. To facilitate the implementation of a smart grid in Ontario.

5. To promote the use and generation of electricity from renewable energy sources in a manner consistent with the policies of the Government of Ontario, including the timely expansion or reinforcement of transmission systems and distribution systems to accommodate the connection of renewable energy generation facilities. 2004 , c. 23 , Sched. B, s. $1 ; 2009$, c. 12, Sched. D, s. 1; 2015, c. 29 , s. 7. 
It is here that one must fill in the blanks. The OEB must approve the business activities that regulated businesses in the electricity market undertake (Anonymous 2017). Currently utilities make money from moving the electricity from the transmission grid to the end user over the distribution grid. The more electricity that the utility moves, the more revenue it makes. The OEB also regulates the profit margin that a utility can make. For example, if Toronto Hydro wanted to pilot a program to study and measure the impact of EV charging infrastructure on the grid, this would not fall within their regulated business of distributing electricity to the consumer. Toronto Hydro would need to submit a request to the $\mathrm{OEB}$ to be able to recognize these costs and pay for them with a rate increase. The OEB would then determine if the cost is a requirement or not and thus either approve or decline the request. While it is written in the OEB Act that the OEB will consider decarbonization efforts, specifically "smart grid and renewable generation," when making decisions, numerous industry insiders who were interviewed for this paper have noted that in practice the OEB largely considers the price mandate (Anonymous 2017). Before any technology is integrated onto a system, it undergoes testing to ensure that it has been de-risked. This process would involve a pilot program in which one could study the interaction of that technology within the existing infrastructure to understand what types of technical challenges could arise from integrating the technology, how it can interfere with the existing system etc.

Thus a pilot program, such as the one proposed by Toronto Hydro in 2011 to "understand the design, specification, standards, metering, communications, security, privacy, and 
billing and data requirements related to EV charging" would seem like a prudent forward thinking measure that would facilitate the eventual increase in EVs that the province has committed to (Ontario Energy Board 2011). Utilities would be the natural place on the grid where these charging stations would reside, embedded close to the customer. However the OEB would have to approve these measures for utilities to undertake such integration programs. Unless the OEB agrees that the activity is necessary for the business it will not approve the increase in price. Pilot programs to test the viability of technologies on the grid need to be undertaken before the technology can be widely integrated, in order to ensure smooth deployment. It is important to understand how EV charging infrastructure will interact with the grid, before widely deploying the technology to meet the Ontario government's mandate of increasing EVs in Ontario. If utilities cannot test these technologies on the grid because they are not part of their regulated business, they will remain hesitant to integrate them because they do not know how the technologies will interact on their grid, which they are responsible for.

The OEB stands to be a key partner towards decarbonization of the Ontario electricity sector. If utilities are paid for reducing emissions on their grids, then they may be able to invest in technologies that would help them achieve that target. For example, EVs present a unique opportunity by offering a unique set of attributes. In an EV there is a small amount of stored electricity that can be dispatched into the grid, and it comes with its own management system that can leverage smart grid technologies to help. An EV can essentially be defined as a microgrid. Connected onto the grid, the various combinations of EV attributes can be virtually combined to help remove excess electricity from the 
grid, add electricity to the grid and help with managing the grid. However, these attributes would not find their way into a utility's current regulated business unless one merely defines an EV as a load on the system. The OEB can facilitate the decarbonization of the grid by allowing utilities to value decarbonization.

Additionally, as the grid ages, repairs and upgrades are required, but the utility needs to have the OEB approve the cost of the repairs and determine which costs it can pass down to the customer, thereby limiting their ability to adapt to the changing ecosystem of technologies needed to upgrade the grid. As more technologies become available to consumers, they may facilitate 'cord cutting' - a phenomenon seen in telecommunications with landlines and cable TV, where the ease of internet empowers customers to leave behind a technology they feel they no longer need. The cost of the remaining infrastructure then spreads out over a smaller consumer base, motivating more to cut the cord. As more and more customers would migrate off the grid, utilities fear their business models would no longer be relevant. This is more notoriously known in the industry as the Utility Death Spiral (Lacey 2014); a daunting term in an industry driven by safely and reliability.

It is also noteworthy to consider the language in the OEB act, which includes an emphasis on price protection, the use of smart-grid and renewable sources of electricity. Again, policy for decarbonization manifests itself without any reference to the end objective but rather as specific tools, further addressed in Chapter 5. However, this raises the question: where would EVs and microgrids be placed? The OEB is essential to the 
process of decarbonization because it regulates utilities and transmitters. The next section will highlight in detail the role utilities play in the electricity ecosystem. However, it is vital to note that approval of each increase in price based on the defined criteria in the OEB act renders a form of handcuffs on the utility businesses.

It is acknowledged by this paper that electricity prices in Ontario have risen to a point of becoming a politically sensitive issue, especially in rural Ontario. However, it is perplexing to note that the electric grid requires upgrades, and upgrades to older machines tend to be of the expensive kind such as the refurbishment of nuclear plants like Darlington that can carry a price of $\$ 12.8$ Billion (CBC News 2017). All technology requires maintenance and periodically component replacement. If strategically done, the maintenance period can actually boost efficiency by integrating new improvements. The current Ontario electricity system requires similar maintenance, but due to the politicization of electricity in Ontario, investments in upgrading the system are challenging (Hui 2010). As an engineer, I once worked to ensure that the Canadian C-130 Hercules aircraft fleet, the oldest fleet in the world at the time (older than Egypt's fleet), flew without incident due to a team of dedicated engineers and technicians working to ensure timely maintenance and upgrades. The last of the aircraft retired and became an immediate addition to the aviation museum where it no doubt joins aircrafts younger than itself at the time of retirement (Pugliese et al. 2016). It is curious that while getting new tires for a vehicle or upgrading a water heater in a home are considered investments, upgrading new meters in the electric grid that can enable better technology integration, while the meters need upgrades anyway, seem to be non-essential. The choice of 
upgrading the grid is not one between higher rates and status quo, but is rather one between higher rates now for uninterrupted electricity or much higher rates later after the equipment has become obsolete. It is always more expensive to buy a new airplane than invest in maintaining the old one. The cost of replacing a part of an aircraft will be lower than replacing the aircraft. The question remains, how will this investment be applied? A question that evokes the fundamental issue in Jaccard's analysis: what is politically feasible is often not environmentally or economically the most efficient. Unfortunately for electricity in Ontario, this has become a politicized issue and not one of operational management.

The above players in the electricity ecosystem are vital in understanding the impacts of the decarbonization policy in Ontario. There are some players that were considered and researched during the development of this thesis but, while they remain critical in their own right, they were not key to understanding the interaction of decarbonization policies as they related to microgrids. Not wanting to leave anyone out entirely, below is a quick introduction to them and their role in the system:

Ontario Power Generation: Owns and operates generation facilities in Ontario including nuclear, hydro, biogas, wind and thermal. (Ontario Power Generation 2017) Hydro One: A crown corporation that owns and operates the transmission grid as well small parts of the distribution grid. It is important to mention that the province has sold majority share of hydro one in an effort to both raise capital for transmission upgrades 
and also to increase efficiencies through private ownership, as outlined by industry specialists.

\subsection{The utility: all 70+ of them}

The utility is also known as a local distribution company in Ontario. However, the term utility appears more globally and is thus used in this paper. For this paper the term utility can be used interchangeably with the term local distribution company or distributor. The utility grid was intended to deliver electricity from the transmission grid to the customer. In Ontario the utility landscape is fragmented with over 70 utilities serving the province and they greatly vary in size (Ontario Ministry of Energy 2017b). Toronto Hydro and the recently merged Alectra (PowerStream, Hydro One Brampton, Enersouce and Horizon Utilities) are two of the largest serving over 500,000 customers each. The large number of utilities in Ontario is a legacy from how the system evolved and not a function of strategic planning. Over a third of the utilities in Ontario serve fewer than 13,000 customers. There are a few drawbacks to having so many players, the first being that administrative costs per capita are much higher. Each utility controls a specific area or jurisdiction, and the sheer number of utilities restricts how many resources are shared. Utilities have their own substations, each jurisdictional point is metered, thereby there is a fair amount of duplication in equipment. Another key drawback: larger utilities have the funding to do more research and development $(\mathrm{R} \& \mathrm{D})$ and to undertake more proactive upgrades to their infrastructure. Examples of this include Toronto Hydro piloting EV charging stations as mentioned earlier and the PowerStream microgrid that is part of this study. The vast majority of utilities in Ontario are restricted from undertaking projects 
that would be aimed at adapting to a decarbonized grid largely because their funding is limited due to a small customer base and any increase in delivery charges would have to be approved by the OEB.

More consolidation in the utility landscape is likely to happen as the smaller utilities will continue to lag behind in upgrading their grids to accommodate the expected decarbonization policies that the province has committed to in its Climate Leadership Plan. The province acknowledges the need for reform in the sector and proposes vast consolidation in the utility space to increase efficiencies and modernize utilities (Ontario Ministry of Energy 2017b). However, consolidation alone will not be sufficient in achieving the utility of the future. The regulatory framework and the expectation from the utilities will also have to change significantly. A more in-depth analysis of the changes needed will be carried out in Chapter 5. It is noteworthy to mention that in the current system, the utility is largely the pipeline of electricity from the transmission grid to the consumer. Its current revenue base comes from the amount of electricity that it sells to its customers.

With an understanding of the key actors in the electricity space, it is important to also have an overview of the key market issues. The following section is an overview of the IESO market and how it operates along with the key considerations for understanding 
where technologies like microgrids can be impacted or play a role in the grid. Given an introduction of the key players, it now important to introduce the game.

\subsection{The IESO market, an electrifying game}

The IESO manages the electricity market just as a conductor ensures that a piece of music is being played in harmony. It does require that the instruments all submit reports of how long they can play for a day or so in advance, since no one wants to be caught offguard if the violinist is having a bad day. As noted above, the fundamental guiding principle for the IESO is ensuring the reliability and safety of the electricity system. The IESO is responsible for all operations on the IESO controlled grid, in addition to administering the IESO market. The IESO controlled grid is essentially the high voltage transmission grid. Figure 10 is a simplified view of the electricity grid and the IESO controlled markets. 


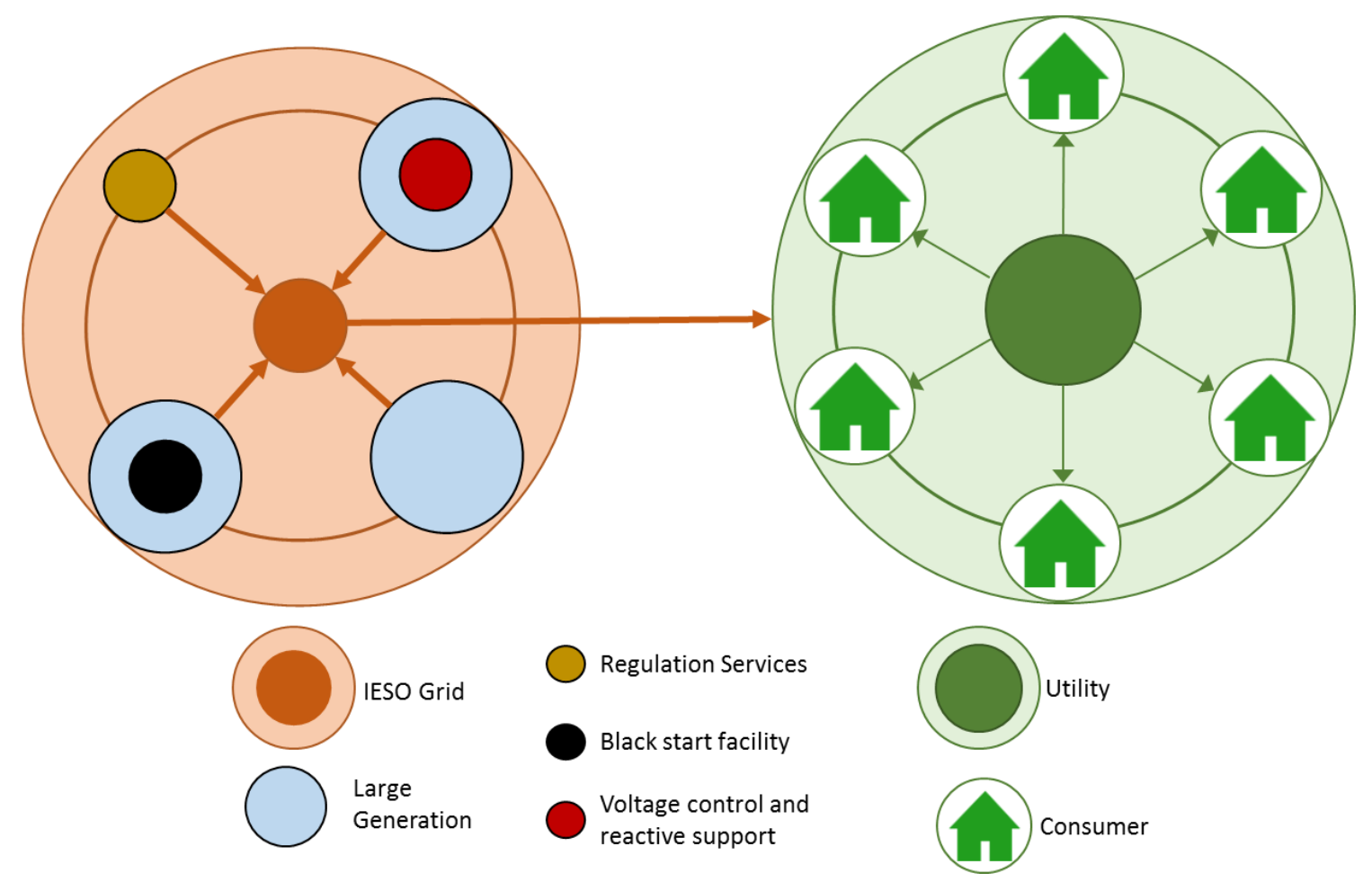

Figure 10: Author's illustration of the IESO and distribution grid

To reliably manage the electricity grid, the IESO has 4 main markets:

1. Generation

2. Voltage control and reactive support

3. Black start facilities

4. Regulation service

Each of these markets is elaborated on here:

\subsubsection{Generation:}

The IESO manages the generation capacity in the province. It is tasked with balancing the demand and supply of electricity (Ontario 2004). Figure 10 illustrates most of the generation capacity on the transmission side, in reference to contracts with larger 
generators like Ontario Power Generation that supply electricity at high voltages directly to the transmission grid. The impact of FIT and other decarbonization policies has not been illustrated in the figure and is reserved for the analysis section in Chapter 5, to highlight the impact of the policy environment on the industry. For simplicity the figure only illustrates the design intent of the electricity system before decarbonization policies took effect. A generation facility is signified on the figure with a blue circle connected to the transmission grid.

\subsubsection{Voltage control and reactive power}

Voltage control and reactive power are ancillary services that are traditionally provided by generators. They are required to maintain voltage control and reactive capacity to ensure the safe operation of the grid. Reactive power fluctuations can occur due to the length of distance that electricity travels over the transmission and distribution lines. Fluctuations in reactive power can cause corresponding fluctuations in voltage. Imagine water travelling long distances through a pipe - the amount of distance travelled may result in a drop in pressure over the length of the distance travelled, requiring additional pumps to ensure the water pressure is what is needed at the end. Similarly, injections of reactive power may be needed to ensure voltage is kept steady over the distances travelled. A generation site that is also providing voltage and reactive control to the grid is indicated in Figure 10 with a red circle inside a blue one. The red signifies that the 
generator in question is providing reactive and voltage control and the blue signifies that it is providing generation.

\subsubsection{Black start facility}

A black start facility is a generation facility that can start without requiring any external electrical supply. Some generation facilities may need an external supply of electricity to begin to work, such an example could include a requirement to start a small generator or nuclear facility. These facilities would need the electricity grid to provide some power or have a reserve of power in the form of batteries or small diesel generators to begin producing electricity. These facilities may be needed to help electrify a portion of the grid. In the event of a blackout these facilities would be called upon to begin restoration efforts and return the grid to service. These are signified as blue generation facilities with a black circle on the center in the figure.

\subsubsection{Regulation services}

Regulations services help to maintain balance between load (electricity consumption) and electricity generation in the grid. Regulation services market continues to evolve with the addition of renewable generation and other distributed loads within the system. As EVs begin to diffuse through the grid, these services will need to be added to accommodate the disruption they may cause (IESO 2017a). For instance, along with EVs diffusing through the system, there is increasing amounts of research on fast charging stations. These fast charging stations will have unique load profiles that will draw a considerable amount of electricity from the grid in a short period of time. They will cause additional 
disruptions to the current system and consequently require additional capacity.

Regulation services are indicated on the figure with an orange circle.

The IESO markets are summarized in Figure 11.

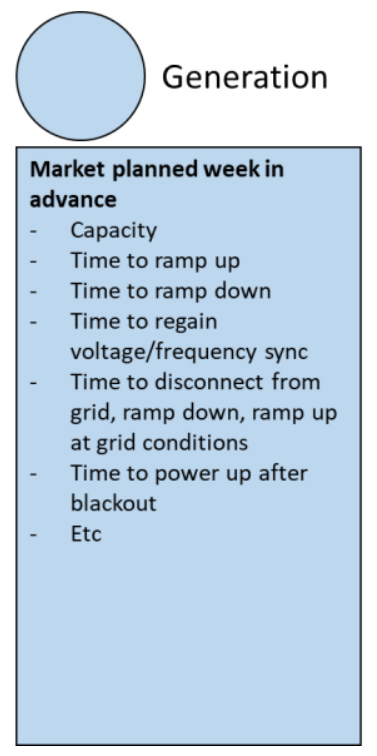

\begin{tabular}{|c|c|c|}
\hline $\begin{array}{l}\text { Market planned } 48 \text { in advance } \\
\text { Regulations services help to } \\
\text { maintain balance between } \\
\text { load (electricity consumption) } \\
\text { and electricity generation in } \\
\text { the grid. } \\
\text { Impacted by: } \\
\text { - Amount of load connected } \\
\text { - How quickly load is } \\
\text { drawing electricity from } \\
\text { grid } \\
\text { Directly impacted by: } \\
\text { - Fast charging stations. }\end{array}$ & $\begin{array}{l}\text { Market planned at contract, } \\
\text { requires regular update: } \\
\text { A black start facility is a } \\
\text { generation facility that can } \\
\text { start without requiring any } \\
\text { external electrical supply } \\
\text { Critical for: } \\
\text { - maintaining grid reliability } \\
\text { when conditions fluctuate. } \\
\text { Bringing the grid back } \\
\text { online after a power } \\
\text { outage. } \\
\text { Time needed to bring the } \\
\text { grid back on-line after } \\
\text { outage } \\
\text { Sequence of re-electrifying } \\
\text { grid }\end{array}$ & $\begin{array}{l}\text { Market planned at contract, } \\
\text { requires regular update: } \\
\text { Reactive power fluctuations } \\
\text { can occur due to the length of } \\
\text { distance that electricity travels } \\
\text { over the transmission and } \\
\text { distribution lines. Fluctuations } \\
\text { in reactive power can cause } \\
\text { corresponding fluctuations in } \\
\text { voltage } \\
\text { Critical for: } \\
\text { - maintaining grid reliability } \\
\text { when conditions fluctuate. } \\
\text { - Preventing unintended } \\
\text { blackouts }\end{array}$ \\
\hline
\end{tabular}

Figure 11: Author summary of the key IESO markets

Like all markets, electricity has a point of transaction. To understand the operational / administrative need to measure, record and manage the players on the grid, it is important to understand this point of transaction.

\subsection{The meter: the point of no return}

The meter in the electricity system is the point of the transaction-it does all the accounting. For a utility, the meter is where the electricity is passed from the distribution grid to the customer and is where the transaction is completed along with where the visibility for the utility ends (Ontario Energy Board 2015a). Take for instance an average 
independent home. Here, the meter would account for how much electricity was consumed by the house and consequently sold by the utility. Buildings and campuses often have one meter that can be sub-metered by another unregulated entity (Ontario Energy Board 2015b). Sub-metering is considered to be a 'behind the meter' activity and not part of a utilities business as currently defined by the distribution code (Ontario Energy Board 2015a). Essentially in a multiunit building, once the electricity has passed through the building meter, the utility has fulfilled its role. For the individual bills that are received for electricity in these units, a third party vendor would sub-meter the units (Ontario Energy Board 2015b). The sub-metering vendor is obligated to register with the IESO. Figure 12 is an illustration of the differences in where the utility can operate and where the sub-metering vendor can operate. For a regulated utility or distributor, submetering is going on behind the meter and due to privacy concerns utilities cannot operate behind the meter. For example, in Figure 12, Hydro Ottawa would transmit the electricity until it has been passed through a campus meter, such as one for Carleton. From that point either a third party, or in the case of Carleton ${ }^{4}$, the university itself, would sub-meter the campus to allow building maintenance services visibility into the electricity use for each building. Although sub-metering would allow the campus to understand its own energy use, the campus would pay one bill to Hydro Ottawa. Hydro Ottawa would only see the overall electricity consumed by Carleton University; they would not have insight into the electricity use of each building, nor would they bill each building. They would bill Carleton as one meter. Sub-metering services through third parties are an added cost to the electricity bill that the consumer will see. Utilities can

\footnotetext{
${ }^{4}$ Confirmed through Carleton building services
} 
have unregulated businesses that may operate behind the meter and provide additional services like sub-metering. So, what are the limitations of the unregulated business that a distributor can engage in? "Nothing, they can open an ice-crème stand if they want" (PowerStream 2017). However, there must be clear separation between the regulated and unregulated arms of the utility. They can open a business that operates behind the meter and helps campuses with smart-grid applications, but this business must be separate from its regulated business of moving electricity from the transmission grid to the consumer (Hydro Ottawa 2017). The meter facilitates ease in accounting, and like all effective accounting, it complicates operations.

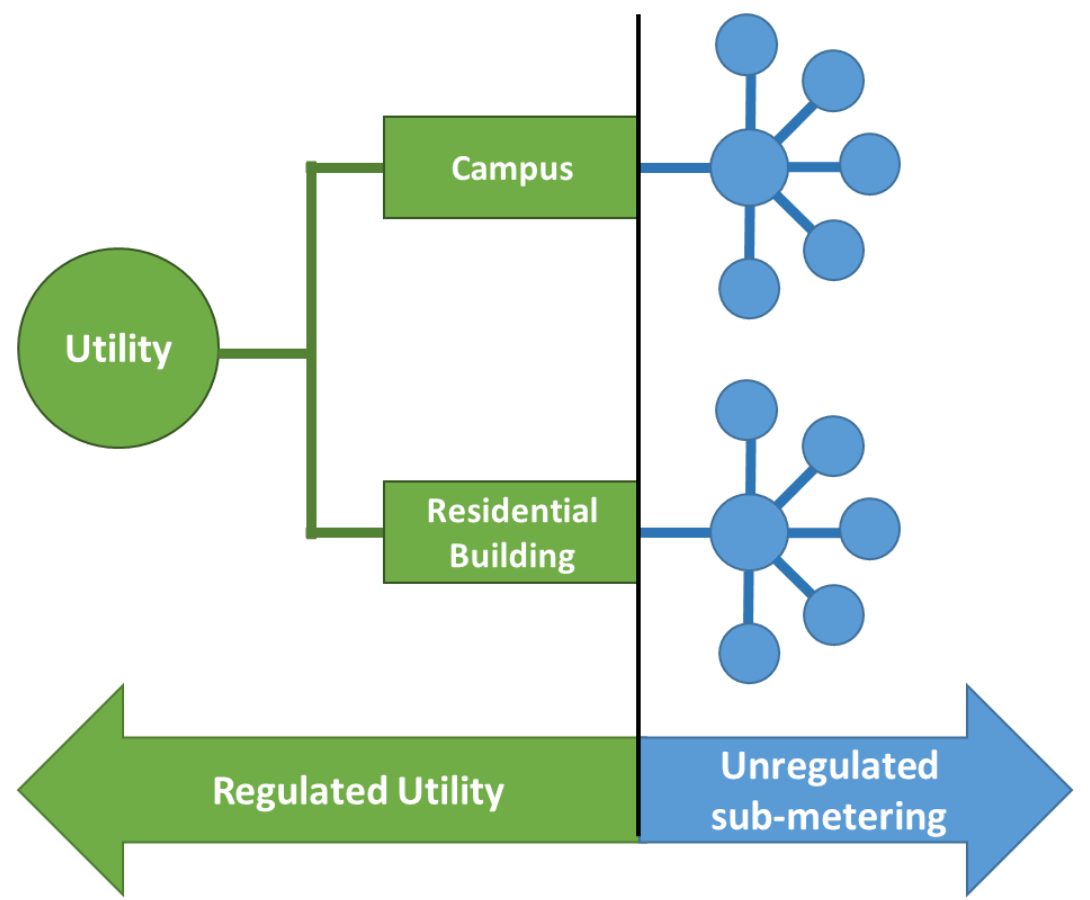

Figure 12: Author's illustration of difference between utility meter and sub-meter. 


\subsection{Metering renewable energy programs:}

Metering is a critical part of the electricity system with regards to ensuring mandated programs run effectively. Take for instance the FIT, MicroFit and Net metering programs offered by the IESO described below and as illustrated in Figure 1313.

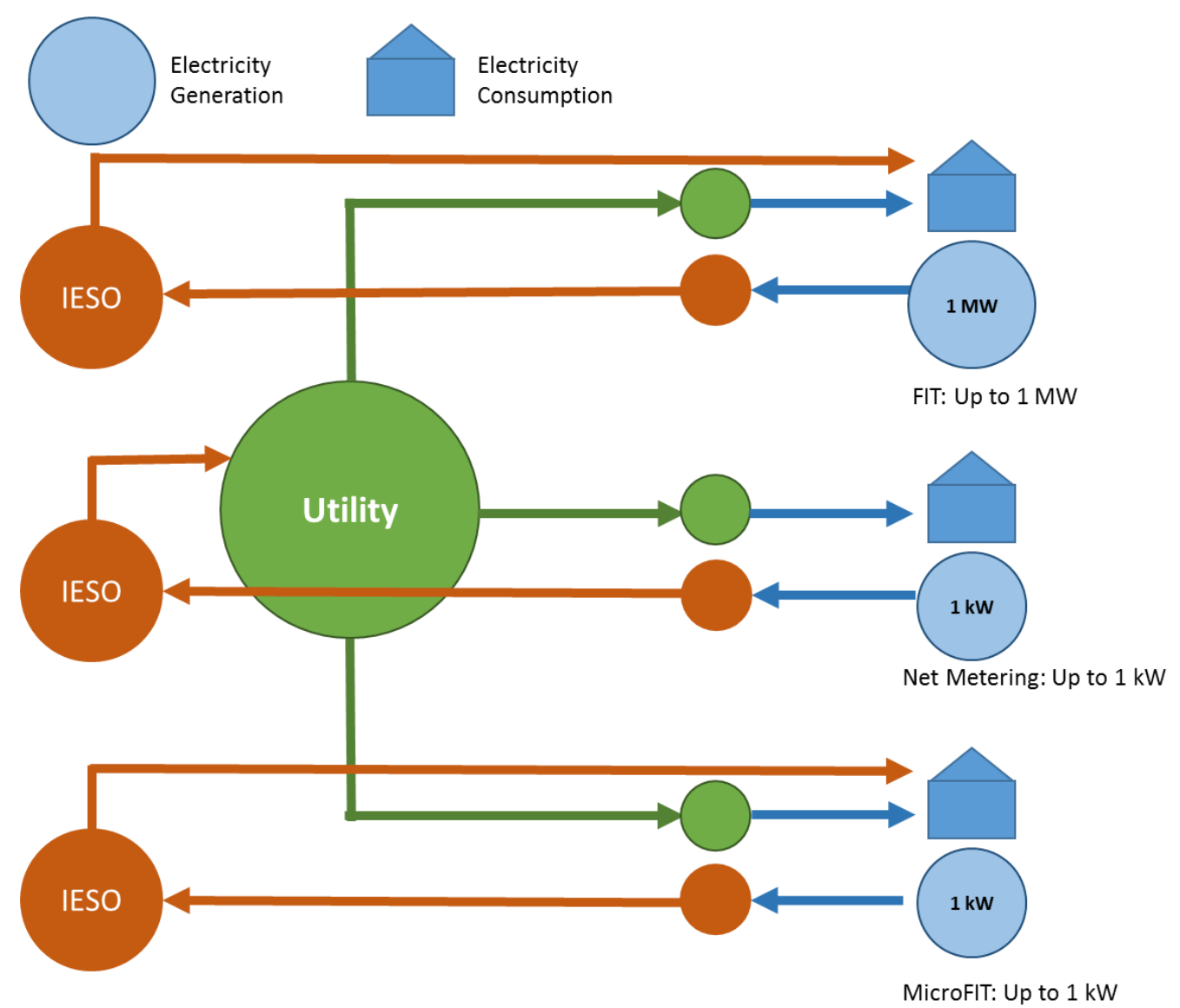

Figure 13: Author illustration of three IESO programs in relation to the meter

Feed in Tariff, FIT - In Ontario, FIT generation facilities are less than $1 \mathrm{MW}$ and microFIT are less than $1 \mathrm{~kW}$ in size and embedded in the distribution system as they are on lower voltage lines ("Market Rules \& Manuals Library - IESO" 2017). These facilities are registered with the IESO and have contracts that specify what kind of generation 
facility they are (solar, wind, etc.). Additionally a facility registered as a FIT facility, a facility that can has a contract to generate and sell renewable electricity under a FIT contract with the IESO, cannot be a 'behind-the-meter project'(IESO 2015). Effectively if a solar facility is registered as a FIT facility with the IESO but is considering to add energy storage to the facility or wind on the same FIT facility and then sell into the grid, that is considered a behind-the-meter project.

The inherent intention is that if taxpayers are paying for 'renewable generation' (as explicitly laid out in the electricity act) then there must be clear visibility that the electricity generated came from the specified source of renewable technologies, as defined in the electricity act and the contract with the IESO. The IESO and the utility do not have visibility behind the meter; essentially if a FIT facility has a contract to generate $1 \mathrm{MW}$ of solar electricity, that facility would be metered so the IESO would know how much electricity was generated. The IESO cannot look behind the transaction point of the meter into the generators' operation; they cannot go 'behind the meter'. Therefore, they would use the meter to inform them of how much electricity was generated and then they would rely on the existing contract they have to pay the generator based on the contract rate for solar energy. The IESO currently has no other way to ensure that the electricity being produced is from the source being claimed, thus it relies on the contract and the meter.

If a generator with a FIT contract produces solar electricity and stores that electricity in an energy storage device because when there is low demand and adequate supply, only to 
sell the electricity from the batteries into the grid when the demand was higher and there was shortage of supply that would effectively be a 'behind the meter application'. Since the IESO does not have visibility behind the meter, this configuration would be disqualified from a FIT contract. Now consider that in Ontario, with a strong nuclear base load, the periods for low demand are often evenings, a time when the nuclear baseload can satisfy demand. The output from these facilities cannot be easily changed due to technological constrains. Demand is often higher in the day time, when stored renewable electricity could be dispatched from batteries to meet the fluctuating demand. From a policy perspective, this may be an effective means to decarbonize the grid, but from the political perspective this would be an effective line of questioning for an opposition party to state that the electrons that were sold under this policy were not green. Green electrons of course elicit a general sense of well-being upon consumption.

Consider for example, the accounting for solar FIT as illustrated in 13. A facility registered as a FIT facility in the distribution grid would require two meters. The first meter would be used by the utility to bill the facility for its electricity consumption. The second meter would be required to keep track of how much solar electricity was generated for the IESO. The FIT facility would be a consumer of electricity on the utility grid, but would also have a generation contract with the IESO. Thus, the electricity generated by the solar facility would need to be accounted for separately as the IESO would need to pay the FIT generator for producing that production. 
MicroFIT- It is here that one considers the simple dreams of city councilor David Chernushenko which he highlights in his documentary 'Powerful,' where he purchased a solar panel and a simple battery over 10 years ago in the hopes to connect them to his house. It would be years before he could use the solar panel as there was no mechanism for him to feed it into the grid or use it for his own consumption; the distribution system would not support it (Canada 2017b). With MicroFIT, homes could generate electricity upto $10 \mathrm{~kW}$ of electricity and feed it back into the grid, encouraging green civic engagement. The electricity generated by MicroFIT would also need to be metered separately. If the homeowner with the solar panel wanted to use the electricity themselves, they would want to opt for the net-metering option.

Net metering: Net metering is designed for consumers who want to generate their own electricity (up to $10 \mathrm{~kW}$ ) and lower their own electricity bills. Consider this from the perspective of the meter. A net metering facility would have two meters, similar to FIT and MicroFIT. The difference would be that now the consumer would see a credit on their bill rather than a direct transaction with the IESO. Essentially the IESO would compensate the utility, and the utility in turn would compensate the consumer.

Consider the desire of civic minded, idealistic students wanting to produce and use green electricity on a campus like Carleton, through a program like the Green Revolving Fund against the need for visibility of electricity consumption behind the meter. For such a campus, the energy consumption would have a large impact on the grid, as compared to an average home. If Carleton opted to generate its own electricity using solar panels for 
its own consumption without separate meters, the utility would see lower demand as would the IESO, and would adjust their supply and demand forecast accordingly. Neither the utility, nor the IESO knows why the demand is low. They would not know that solar panels are off-setting the consumption. It bears restating here that the grid is very closely managed. Significant changes in demand or in supply can impact the reliability of the grid. On the off chance that there is a cloudy day in Canada, the energy generation for the campus will be reduced dramatically. The grid would see an increase in demand corresponding to the campus need. Neither the utility, nor the IESO could have anticipated such a dramatic shift and thus the reliability of the grid could be compromised. Even idealism requires heat on a cloudy Canadian winter day.

The meter in the above scenario would limit the ability of the IESO and the utility to respond to significant fluctuations on the grid. The above scenario also describes a typical microgrid application. The lack of visibility is a key restraint in the diffusion of a technology like microgrids. The next section presents the definition and possible applications of a microgrid.

\subsection{Microgrids}

Microgrids are essentially smaller versions of the electricity grid. Their function can vary depending on the needs of the customer. Microgrids can be adapted to resolve a variety of issues on the grid including increasing grid resiliency, reducing carbon emissions by increasing renewable energy adoption, and powering remote communities to name a few (Tao et al. 2011). According to Tao et al. (2011) there are a few key components of a 
microgrid: it must encompass some distributed generation, be connected to the distribution grid, have an end user, include energy storage devices and must have the ability to connect with the larger grid to optimize its performance under a variety of conditions, including operating in islanded mode. What Tao et al, are essentially describing is a number of potential configurations not unlike the difference between a smartphone and a laptop. All smartphones come with a default set of functions that are capable of performing specific tasks. Each user customizes their phone based on their needs. While some may have plans that allow for texting, others may consider largely data specific applications. The apps one downloads on to the phone customize what it can be in reference to the individual's needs. While one may be able to use a smartphone to access applications like the internet or work specific applications, it would be easier to use the laptop for such functions. The smartphone can easily interface with the laptop through a wireless connection and leverage the power of either. In a similar fashion if a microgrid were a smartphone with the best plan possible, it would conform to Tao et al's definition. It would produce electricity, be capable of storing that electricity, be able to change the services it provides the larger grid depending on the conditions of the larger grid, and in the case of power outage or other needs it would be able to islandessentially separate from the larger grid and operate independently from it.

Microgrids can be grid connected or remote. Remote microgrids exist in areas that lack connection to transmission grid, traditionally remote areas. In Canada, these tend to be in Northern communities that generally have a small local grid and are not connected to the overall North American grid. In these cases, electricity is generated, typically, through 
diesel generators and then travels over a local microgrid to provide electricity to the local communities (Royer 2013). Where some fuel can be transported by road, many communities rely on fuel to be transported by air. To pay for this additional cost for electricity production, governments are required to subsidize the cost to the consumer (Standing Senate Committee on Energy, the Enviornment and Natural Resources 2014). While remote microgrids have a high potential for playing a role in local decarbonization policies, as they are independent from the larger electricity grid they face different policy constraints than grid connected microgrids. This paper restricts its analysis to the policy issues faced by grid connected microgrids while acknowledging that remote microgrids face a different set of policy and jurisdictional issues that need further consideration and study.

Within grid connected microgrids there is an inherent difficulty in arriving at a consolidated definition because the technology definition does not align with how the policies within the industry are structured. The inherent question at the core of what a microgrid is would be, "what do you need it to do?" As a technology, microgrids can be designed for a variety of customer needs. Additionally, they can respond to the needs of the grid dynamically. Microgrids as a technology would not have a specific function based definition. Take for instance a microgrid designed to integrate solar energy. This microgrid may be designed with a certain capacity of solar panels and battery storage. If the larger grid would experience changes in frequency or voltage, unrelated to the solar panels, this microgrid could respond to address those fluctuations. Additionally, if there is an unexpected power outage, batteries can be used to electrify the grid or provide 
power for a certain period of time. The interaction between the larger electricity grid and the microgrid that allows them to be connected while also having the potential for the microgrid to be self-sufficient through local electricity production that can be supplied to the larger utility grid would be classified by Tao et al. as exhibiting the behavior of an ideal citizen. Another microgrid could be designed to integrate EVs and would have no generation integrated in it, but could still be capable of providing electricity through stored electricity. This flexibility in a technology definition is not unique; rather, many technologies are not defined by their component functions. One does not consider a smartphone to be merely picture storing device, nor does it value it merely as a device to connect to social media. In fact smartphones as a technology can be used to address a number of consumer needs depending on the applications that are used.

Taking the technology perspective, microgrids are best understood as a reorganization of existing electricity technologies. For instance, an EV with its internal control system could be used in conjunction with a small solar generation device for a small community or building to generate, store and use electricity as needed. A small microgrid, such as one with an EV connected to the grid may also be referred to as a nanogrid (Hardesty 2014). A collection of nanogrids, in the form of houses or buildings equipped with solar roofs and EVs, can add up to a microgrid. Currently there is no industry standard definition of either a microgrid or a nanogrid, with regards to size or capacity. Critically for this paper the distinction between nanogrid and microgrids does not materially impact the discussion about policies. Figure 14 is an illustration to show the differences between a microgrid and a nanogrids. This thesis considers the potential of virtual microgrids to 
help reorganize the grid. Virtual microgrids would essentially be created by digitally connecting components on the grid through smart-grid components. As an example, if multiple EVs are connected to the electricity grid, during a time of day when there is an excess supply of energy, these EVs could be leveraged to recharge to and thereby rebalance the grid by taking excess supply. This virtual connection between the grid, the EV and the generation sources would classify as a virtual microgrid. This thesis will not make a distinction between nanogrids or virtual microgrids but will rather consider them as part of the definition of microgrids. While microgrids can be connected to the transmission network, this paper will narrow its focus on the low voltage distribution network. Many of the policy constraints discussed in this paper contend with distributed renewable technologies that are embedded within the distribution network, as well as EVs that will need to be integrated on the distribution network. Therefore this paper will concentrate its focus on microgrids embedded in the distribution network.

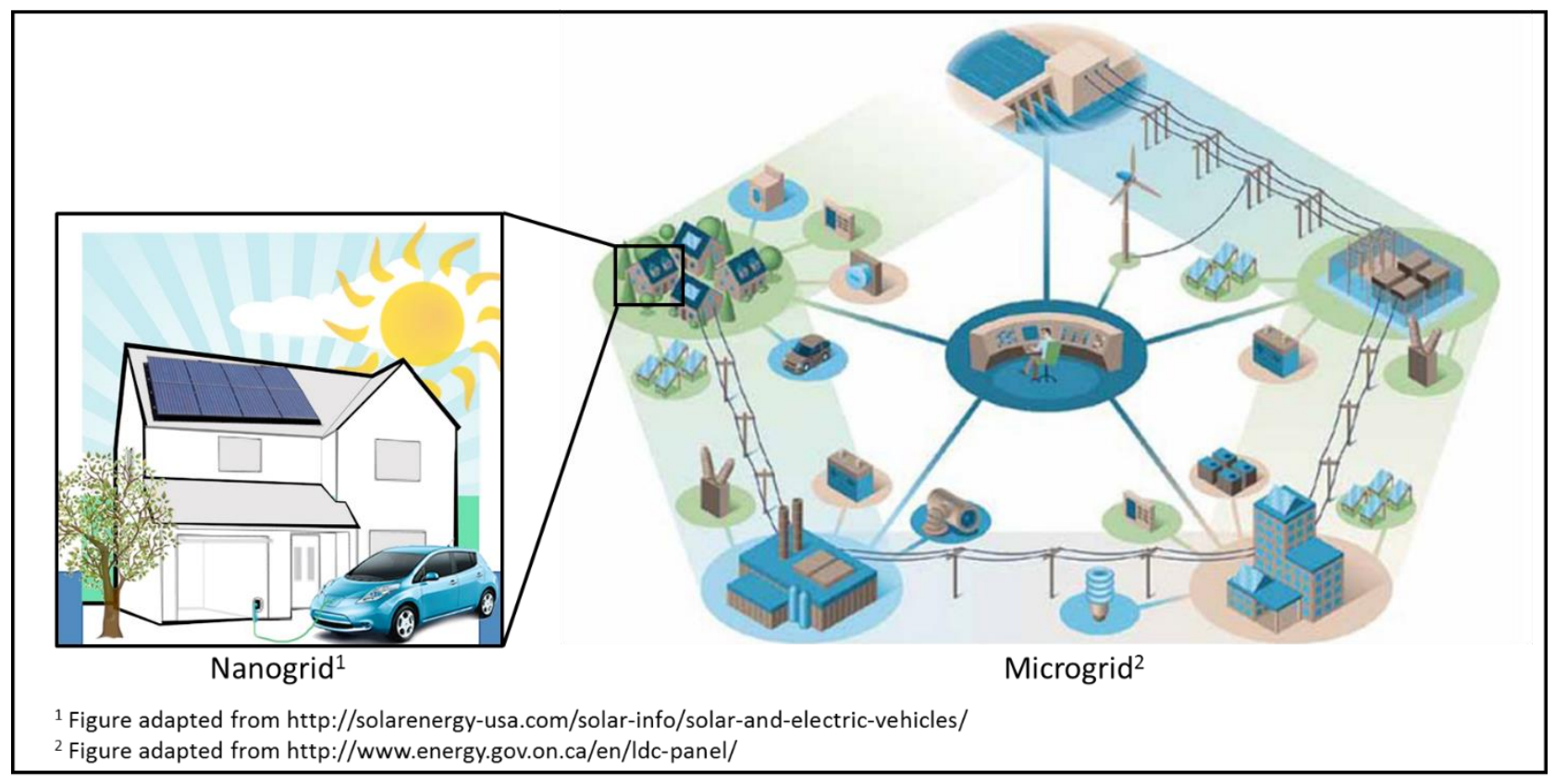

Figure 14: Illustration of a nanogrid relative to a microgrid 
Within the context of Ontario, consider how the technology goals in the Climate Leadership Plan could work together as a microgrid interacting with the larger grid (Ontario 2017b). As part of the climate leadership plan, Ontario has dedicated itself to increasing the adoption of renewable vehicles by subsidizing their purchase, subsidizing the installation of EV chargers and installing EV chargers on major highways. A home owner with an EV may elect to install a bi-directional charger that would be capable of drawing electricity from the grid and also feeding electricity back into the grid (Wald 2013). The home owner may also have a solar panel. Connecting the solar panel to the home and the EV charger would essentially create a nanogrid (see Figure 14 for an illustration). This nanogrid would be capable of generating electricity during the day, using the electricity in the home and then charging the car with the rest. If the EV is charged, then the excess electricity could be fed into the grid. In the event of a power outage, the home would be able to island, draw power from the EV, or the nanogrid could feed electricity into the larger grid as needed. A collection of these nanogrids could be virtually connected to help provide power to a small community, as a virtual microgrid. A community could also invest in small distributed generation like wind and an energy storage device to add further assets onto their microgrid and improve their resilience. While Tao et al have a broad definition of microgrids, for this paper a microgrid would include a nanogrid. Additionally, this paper considers the potential of virtual microgrids to be critical as future technologies are introduced into the economy. Thus the definition of microgrids will include technologies distributed throughout the grid, that can be 
connected through smart grid technologies to achieve the same functionality of a microgrid.

This paper argues that there is a conflict between how technologies may be defined by technology makers and policy makers. To highlight this difference consider the impact of regulations and policies that currently exist and their interaction with a technology like microgrids. Take for instance that a microgrid is designed to increase the amount of renewable generation. It includes a renewable generator, an energy storage device and a load in the form of a small community of houses. The design objective would be that the storage device would store excess electricity from the generator after the homes in the community have consumed what they need, any excess would be sold to the grid. From the perspective of the policy and regulatory environment, the regulated distributor can only transmit the electricity from the transmission grid to the homes as illustrated in Figure 10. All electricity that is generated by the renewable sources must be sold to the IESO, not the regulated utility as indicated in Figure 13, and it is unclear who would maintain ownership of the energy storage device in this scenario. These respective functions would need to be metered separately. The existing policy frameworks would view the microgrid as renewable generation, storage and distribution, and not as a consolidated system. The architecture needed to account for a microgrid, would require each function of the microgrid to be valued separately. While, as a collection of components, a microgrid could provide value in all four of the IESO markets (generation, frequency regulation, voltage regulation and black start facility), independently, each function would have to participate in a separate market. By competing in separate 
markets the components of a microgrid will not be able to provide the same value to the grid. It is the combination of the technologies that provides the added value. By changing perspectives from the technology to the policy framework, the potential value of the microgrid is considerably diminished. The case studies that follow this section illustrate the difficulty in valuing a microgrid within the current Ontario policy framework.

\subsection{Case studies: a tale of two cities}

This chapter will introduce the two cases that will be analyzed to understand the policy barriers that stand in the way of the diffusion of microgrids.

\subsection{PowerStream, also known as Alectra}

PowerStream recently merged with Enercource and Horizon Utilities to create Alectra utilities, and acquired Hydro One Brampton (Alectra Inc. 2017). For simplicity, this paper will use the name PowerStream to speak about the microgrid demonstration project as the microgrid project was deployed prior to the merger by PowerStream. Furthermore, some of the source materials to describe the project along with other references in the media are made in reference to the PowerStream name.

The main motivating driver for PowerStream in designing the microgrid demonstration project was a recognition to evolve (PowerStream 2016). PowerStream realized that key technologies like distributed generation, energy storage and EVs were changing the landscape for utilities and they would have to adapt to these new technologies. During the development of any technology, it is critical to undertake a process of real world testing. 
The steps here encompass research on the existing knowledge, designing a new technology, building a prototype and testing it in real world environments and then using those results to improve the product until a unit capable of sale can be designed. These steps follow how technologies are typically developed and how their development is measured through Technology Readiness Levels, typically referred to as TRL levels, that were initially developed by The National Aeronautics and Space Administration (NASA), to measure the maturity of the development of space faring technologies (Mai 2015). PowerStream wanted to understand how a microgrid would react in a real scenario in an environment under its purview, how the individual components in the microgrid could be coordinated and its interaction with the grid itself. They used this underlying principle to design a microgrid that could test a variety of scenarios and further enrich their knowledge in applying the technology. Figure 15 is a schematic representation of the components in the PowerStream microgrid. 


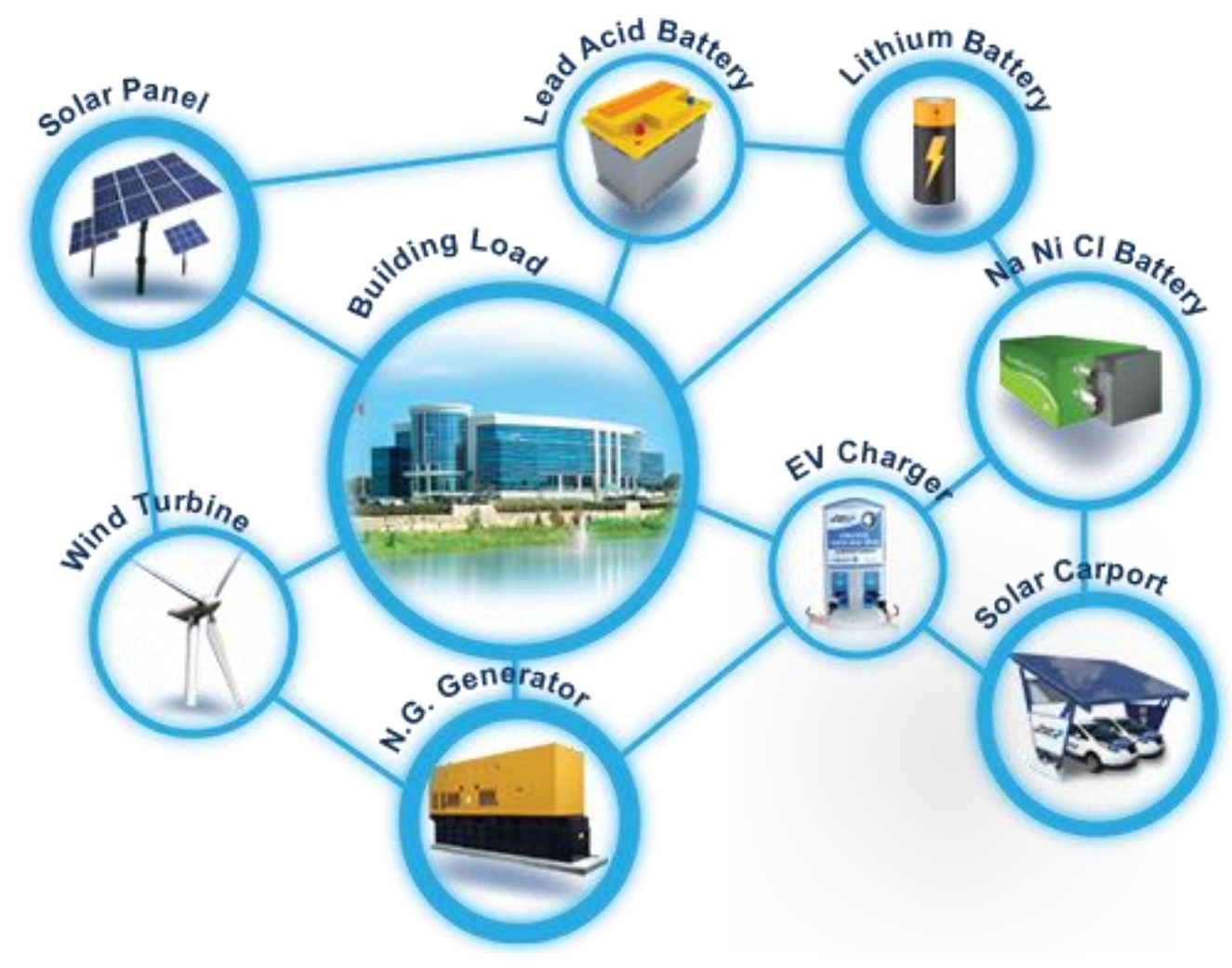

Figure 15: Schematic of PowerStream Microgrid ${ }^{5}$

The components shown in Figure 15 are described in relation to the microgrid and their respective functions in Table 1. From the components, it can be inferred that PowerStream tested a variety of operational and economical scenarios that would be critical for any application of a microgrid.

\footnotetext{
${ }^{5}$ Reproduced with permission from PowerStream
} 
Table 1: PowerStream Microgrid Components

\begin{tabular}{|l|l|}
\hline Component ${ }^{1}$ & Function \\
\hline Solar Carport & $\begin{array}{l}\text { A cover for a car with a solar panel as the roof. Generates } \\
\text { electricity and shelters the car }\end{array}$ \\
\hline EV Charger & Provides charging for electrical vehicles \\
\hline Natural Gas Generator & Generates electricity from natural gas \\
\hline Wind Turbine & Renewable electricity generation \\
\hline Solar Panel & Renewable electricity generation \\
\hline Inverter & $\begin{array}{l}\text { Converts the DC electricity generated by the solar panels to AC } \\
\text { for integration with other components on the grid }\end{array}$ \\
\hline Sodium Nickel Chloride Battery & Energy storage suited where space is not a concern. \\
\hline Lithium lon Battery & $\begin{array}{l}\text { Energy storage typically found in electrical vehicles and } \\
\text { applications where space is a concern. }\end{array}$ \\
\hline Lead Acid Battery & $\begin{array}{l}\text { Traditional energy storage similar to batteries in most non } \\
\text { electric vehicles. Suited where space is not a concern but price is. }\end{array}$ \\
\hline
\end{tabular}

${ }^{1}$ Component list from company website: https://www.powerstream.ca/innovation/micro-grid/micro-grid-project.html

It is beyond the scope of this paper to evaluate how PowerStream measured its success from the operational integration of the microgrid within its system to the valuation of the economic cases that were studied as part of their analysis. The detailed metrics of their evaluation for success would be technical and include considerations of how long the microgrid could operate independently, how easily it could deal with the viability of the different loads that would draw electricity from the microgrid. This paper accepts that the technology was integrated as intended based on PowerStream's internal assessment. This paper restricts its analysis to the policy constraints that PowerStream faced while executing the microgrid and in its operation. It is noteworthy to mention that the demonstration has brought into focus the desire for more projects like PowerStream in the industry for additional evaluation and study. This paper considers the PowerStream microgrid to be a successful demonstration of an integrated microgrid within a utility. It further recognizes that as one of the few microgrids integrated into a distribution grid, 
learnings from this project have garnered much attention in the industry as PowerStream has been invited to share their insights at conferences like DistribuTECH and by organizations like MaRS Discovery District. This paper will focus on the process and challenges that were faced by PowerStream in developing and implementing the microgrid within the framework that was developed in Chapter 4 .

The PowerStream microgrid is designed to test the application of microgrids within a distribution network. It was designed to power a small load at the PowerStream headquarters in Richmond Hill. The microgrid was providing power to the building cafeteria and an EV charging station. The total design load was expected to an average of $7 \mathrm{~kW}$ and a maximum of $9 \mathrm{~kW}$ (PowerStream 2017). For comparison an average domestic fridge uses $.5 \mathrm{~kW}$ of electricity (Toronto Hydro 2017).

\subsection{Zibi developments aka Hydro Ottawa}

Zibi developments began as an idea of Windmill Developments. The guiding principlefor the development can be best illustrated through the words of Jeff Westeinde,

"Decreasing the environmental footprint of our built environment is critical to humankind's continued survival and enjoyment on our planet. Windmill is leading by example in real estate development and proving that greater sustainability is not only achievable, but advantageous on numerous levels (Windmill 2017a)

Where PowerStream illustrates a utility aware of its need to evolve, Windmill illustrates the same self-improvement motivation in a developer. The assessment in this paper will focus on the evolution of the Zibi concept as it progressed from idea to application within the development project. It will walk through the initial plans and how critical changes 
had to be made to the system. Hydro Ottawa was a critical partner for the development and much of this context will follow their experiences. An in-depth analysis will again follow in Chapter 4.

The plan for Zibi was guided by the principles laid out in the One Planet Community framework aimed at creating a network of the earths greenest neighborhoods (Windmill 2015). The development straddles the Ottawa/Gatineau city lines - both divisions in two separate cities and two provinces, or more aptly phrased, a jurisdictional nightmare scenario. For electricity and heat, the development proposed as part of its masterplan using the Kruger plant on site as a combined heat and power plant with an estimated 13.2 MW of potential heat available. In addition to the production of electricity, the developers want to ensure efficient use of electricity through many smart-grid features that can automatically control the timing of specific loads, such as when dryers are used, automatically dim certain lights when not in use and ensure the most efficient use of electricity.

Initially, Windmill has proposed designing and operating the electricity infrastructure of the development on their own. However, Hydro Ottawa believed there was an opportunity to partner with the developer. In Hydro Ottawa, Windmill saw the opportunity to leverage their technical expertise and reputation to build a safe and reliable electricity network that was designed to meet their unique requirements. In Windmill, Hydro Ottawa saw the opportunity to work in an area that they expected would be a growth opportunity for their business (Hydro Ottawa 2017). The following section 
analyzes the two microgrids to highlight key differences in the policy barriers that were faced by both projects. 


\section{Chapter: Analysis, the entrepreneur's fate}

In this chapter the two Zibi and PowerStream microgrids will be analyzed to highlight Jaccard's argument regarding administrative difficulties that are faced with integrating microgrids on the electricity system in Ontario. These administrative barriers will be considered within the context of how they impede the government's ability to realize Mazzucato's ROI in the form of emissions reduction.

The two microgrids presented are unique in that they operate beyond the scope of what a regulated distributor is expected to do. Essentially, the PowerStream case is unique because the distributor would not be paid for the investment or for operating the microgrid, the utility would have to absorb the cost of the demonstration. The Hydro Ottawa case is unique in that Hydro Ottawa had to rely on its unregulated business to be able to work with Zibi for behind-the-meter smart grid applications. For clarity, two factors that are critical in the analysis will be briefly explained here:

A few key differences in the PowerStream and Zibi ${ }^{6}$ cases are highlighted in Table 2. In the PowerStream case, the microgrid remained on the utility's own network. This gave PowerStream latitude in testing out the technologies as they intended, rather than having to contend with various players in the system. PowerStream did have to invest their own capital into the project, but since it was intended to test the concept of microgrids, this was considered to be an investment into a future area of the business: services. The

\footnotetext{
${ }^{6}$ Zibi developments has faced significant zoning challenges from contested land right claims by Indigenous peoples that are beyond the scope of this paper (Porter 2017). This paper analyzes policy barriers in relation to the technologies used within the electricity sector.
} 
largest hurdle faced by PowerStream was in dealing with legal issues related to insurance. Insurance companies needed to be taken through the process of understanding what the technologies meant as there was no standard mechanism for them to measure the risk of a building that had a microgrid attached to it (PowerStream 2016). The story with Zibi and Hydro Ottawa is one of attempting to create a commercial microgrid that intended to decarbonize the development project.

Table 2: Author analyzed key business differences in microgrid design

\begin{tabular}{|l|l|l|}
\hline & PowerStream & Ottawa Hydro \\
\hline Design Intention & Validate user case & Facilitate zero carbon development \\
\hline Controller & PowerStream & De-regulated Distributor \\
\hline Customer & PowerStream & Windmill/ Zibi \\
\hline Investment cost & PowerStream & Windmill/ Zibi \\
\hline
\end{tabular}

\subsection{Hydro Ottawa: The sum of its parts}

Windmill was in the process of developing the plans for Zibi, a zero carbon residential development that was expected to be located on the Ottawa/Gatineau border. Hydro Ottawa recognized the potential of what Windmill was trying to accomplish, and considered the development to be an opportunity to learn and innovate while being part of the project. Therefore it would be billed through one meter by Hydro Ottawa. Windmill wanted to design a smart-grid backbone to their development, their intention being that the development's electricity needs could be controlled and adapted to conserve energy use. For example the development would have the ability to sense when units were empty and time specific energy use activities like turning on water heaters, 
dimming lights and turning off air conditioning when units were empty. Much of these smart-grid applications would have placed much of the creativity behind the meter. Windmill would, either themselves or through a third party, sub-meter the units and design controls to create the desired function. Hydro Ottawa, as a regulated utility, cannot operate behind the meter. Thus they decided to consider the alternative of being involved in the project as an unregulated entity - an alter ego. Essentially Ottawa Hydo would set up another business outside of its distribution business that would be involved in the project. This opened the door for a number of options behind the meter for smart-grid applications, these included having controls to automatically change the temperature in a room if it was vacant, controlling when major appliances were brought on line to name a few. Hydro Ottawa has the expertise in dealing with electricity, they wanted to leverage their reputation to lend credibility to the work being done behind the meter.

The Zibi development ran into another challenge related to repurposing the Kruger plant. Windmill wanted to use biomass to generate electricity from the Kruger plant in hopes that they could use the green (or brown) electrons. The intention was that Kruger would sell the electricity to Hydro Ottawa, then Zibi would buy the biomass electricity from Hydro Ottawa. The wrinkle was that Hydro Ottawa would not be the purchaser of electricity, since the regulator prevents this. Thus the Kruger plant would have to sell the electricity to the IESO, and once the electricity passed the meter it would be part of the Ontario system. One could not distinguish the Kruger electrons from any other electrons. Then Zibi could buy the electricity from Hydro Ottawa, passed through the de-regulated entity. An additional complication arose since the Kruger plant would be run as a 
combined heat and power facility — an efficient use of a technology that requires another type of regulation network to be implemented. Figure 16 illustrates the impact of these operational constraints. In the ideal configuration, the Kruger plant would have used biomass to generate electricity and heat that would be supplied to the development. Any excess production would have been sold back to the grid. The additional potential of integrating EVs also exists within the sub-metered installation creating a microgrid that would reduce consumption locally through smart-grid technologies, generate and store electricity through the Kruger plant and EVs, and only draw limited power from the grid as needed while being capable of supplying electricity to the grid. The design of the electricity markets and restrictions imposed by markets have resulted in key changes that would not allow a microgrid architecture. The Kruger plant had to be taken out of the plans for Zibi to operate, it could generate power but would need to interact directly with the IESO rather than the utility, thereby limiting its integration into the local grid. Electricity would flow from the utility to the Zibi development but not from the development to the utility. Furthermore, the sub-metered installation, rather than the operation as a microgrid, is confined to integrate smart-grid technologies alone. 


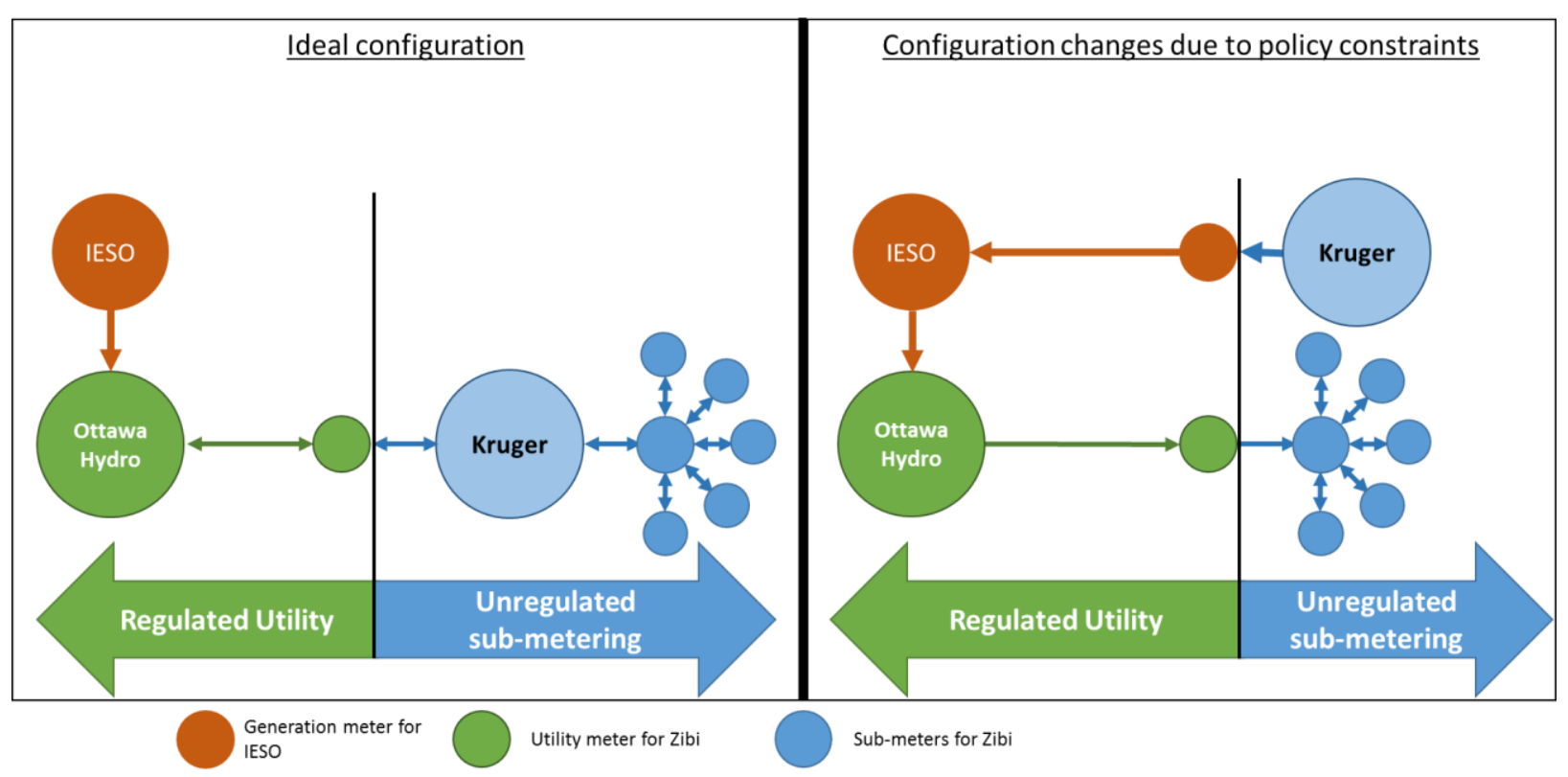

Figure 16: Author's illustration of the impact of policy constraints on Zibi design

If one considers the Zibi development from the perspective of the technology and tools that could have been integrated, then Figure 17 illustrates its potential value along with the constraints. The value in the microgrid could only be realized as all four functions connect. The combined heat and power plant would ensure that minimum energy was wasted, and its proximity to the development would enable faster response time to conditions at the development. Considering the arguments of Mazzucato and Jaccard, the value of the microgrid would be best realized by connecting the four main functions. Mazzucato's ROI would best be realized through this connected interface. The utility that is supplying power to the development, if it could read conditions behind the meter, would be best equipped to respond in order to adjust the smart-grid tools to more consumption inside the development and conserve more electricity. However, administratively valuing the microgrid is difficult since the markets for each of those individual components are separate. Thus Jaccard's condition of administrative feasibility 
is revealed as a challenge. If each of the functions that can be connected have to contend with a separate regulatory process to meet different standards and codes as set out by a rule book that measures each tool individually, then the value of the combination diminishes. A microgrid is not equivalent to the sum of its parts. Administrative feasibility in this context, is not merely about the easiest policy option but rather revealed to be vital in realizing the benefits of this technology in the sector.

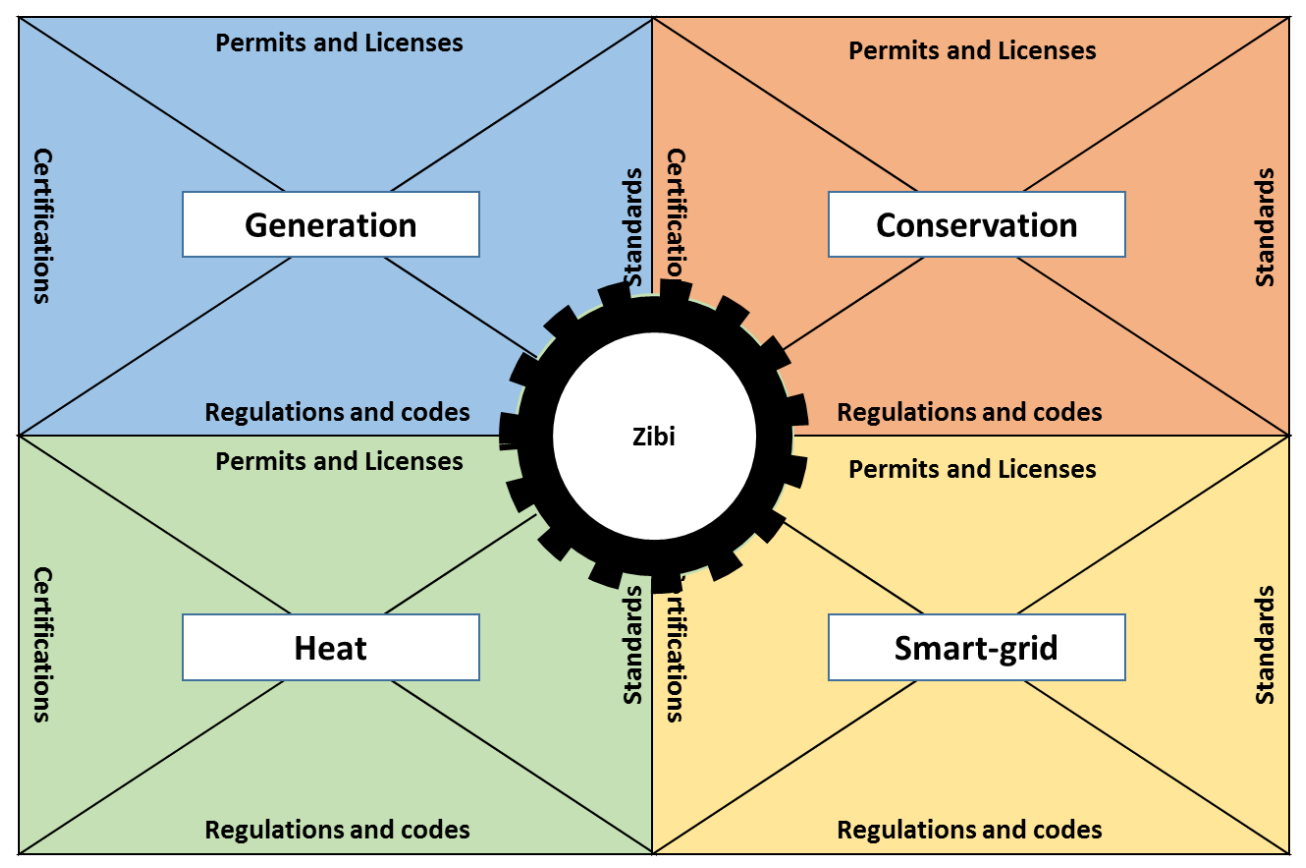

Figure 17: Zibi microgrid technology-policy interface

In contrast to the Zibi experience, the PowerStream microgrid highlights Christensen's key advice of giving the management of disruptive technologies to smaller organizations. In this context, the PowerStream microgrid was embedded in the utility's own distribution grid. This allowed PowerStream to demonstrate the technology while 
removing the administrative burden experienced by Zibi and Hydro Ottawa.

PowerStream's microgrid is analyzed below.

\subsection{PowerStream: the utility eye view}

The PowerStream distribution grid can manage many issues related to the distribution of electricity at the local level. These include fluctuations in power quality and loss of power. Utilities are responsible for maintaining quality control on their networks, thus when an unexpected load such as an EV charging would hit the grid, having batteries ready to discharge would be vital to avoid reliability issues. This concern could be multiplied as Ontario alone has pledged \$140-160 Million in subsidies to increase the number of EVs and over $\$ 80$ Million in infrastructure like charging to support the vehicles (Ontario 2017b). With technologies being developed for fast charging EVs, the ease of driver comfort will be challenging the electricity infrastructure at the distribution system level. Additionally concerns with grid resilience are compounded by extreme weather events and aging infrastructure. The PowerStream microgrid, as illustrated in Figure 18, highlights the value of this technology in helping address these concerns. 

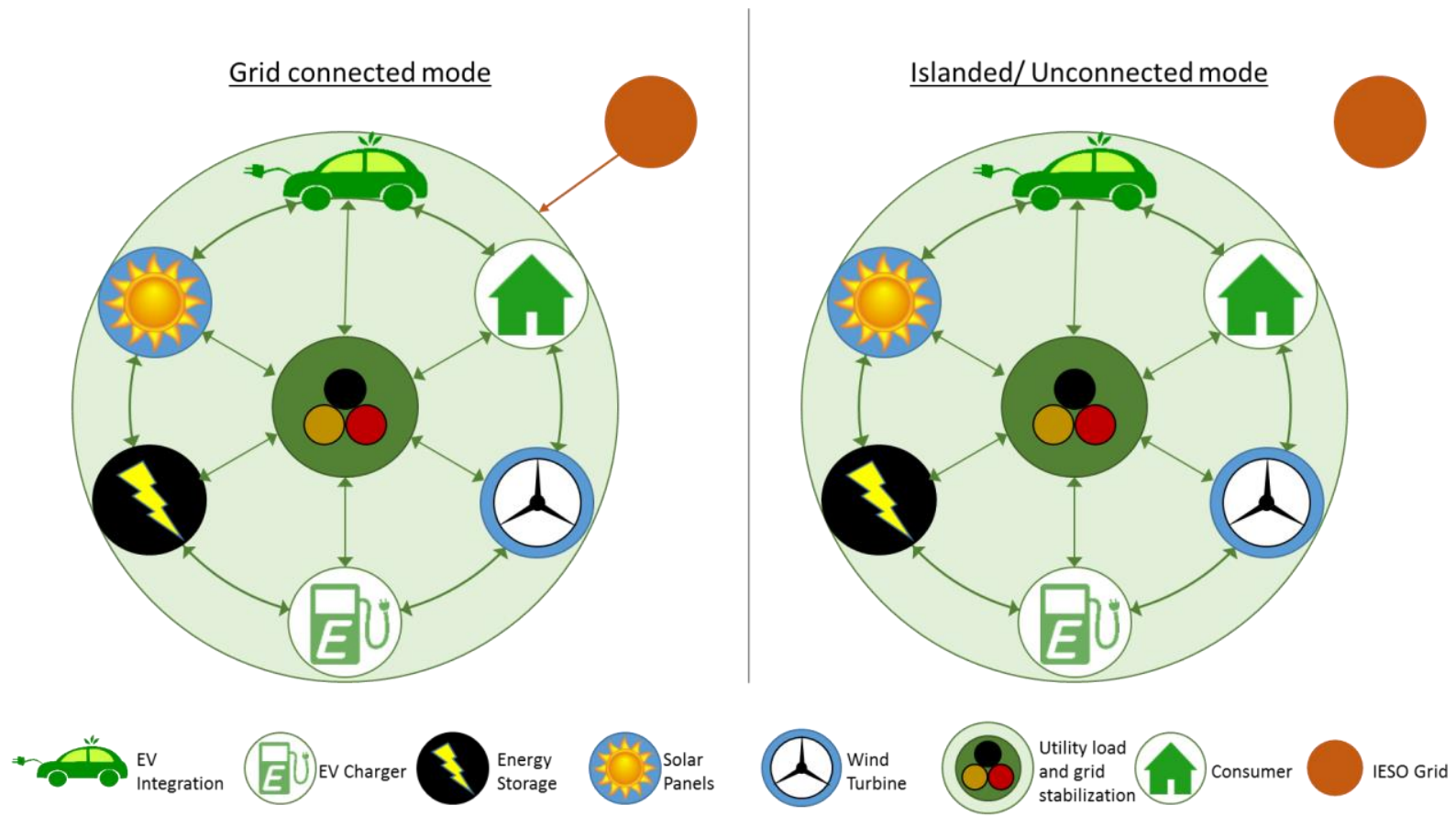

Figure 18: Author's illustration of the PowerStream microgrid

To demonstrate the value of the microgrid illustrated in Figure 18, PowerStream invested in developing the installation at its headquarters in Vaughan. Since the entire system was on PowerStream's own grid, they had the latitude to integrate the microgrid with the most ideal design case configuration. During grid connected operation, the microgrid would draw power from the distribution network as needed but would generate its own power to run the cafeteria load in the building while also integrating EV loads. The microgrid is able to inject power into the distribution grid but not back into the IESO grid. In addition to electricity, the microgrid would locally control grid fluctuations and balance any issues with reactive power. It also had the capability of islanding — essentially disconnecting from the larger grid entirely and being capable of providing local power as needed. As more renewable technologies are integrated into the grid, microgrids like PowerStream's can manage fluctuations in frequency and voltage at the local level with increasing 
efficiencies. These microgrids could then be aggregated to manage these issues for the larger grid. While all utilities are not equal, those serving a large area encompassing over 50,000 people have an increasingly sophisticated operation of managing their local grids. This can be leveraged and built upon to ensure greater resilience for the Ontario grid. With the integration of renewables in the distributors' grid and the integration of EVs or other storage technologies, there exists the potential to build or organize the grid into electricity islands that can sustain some power on their own.

The PowerStream microgrid is able to demonstrate the potential of this technology and the ability of utilities to manage it. This speaks to Christensen's idea of giving control of disruptive technologies to smaller units that can better manage them and can realize benefits from smaller markets. Currently the microgrid demonstrated by PowerStream is a niche application. It serves a small local load that may be of use to a limited number of customers. However, this is not unlike the observations made by Christensen where disruptive technologies often find commercial application in niche markets first. From the perspective of administrative feasibility, PowerStream did not find many challenges in installation or operation. The key here is that this was not an attempt at a commercial microgrid like Zibi but rather a demonstration of the technology on the utilities' own grid. Creating such a microgrid for commercial application would be administratively challenging as there exists significant limitations on what utilities can do behind the meter and what the IESO must do as mandated by the government. This demonstration 
however does highlight that the utility can integrate the technology better than if its integration was left in the larger IESO mandate.

Technology ecosystems like microgrids have the ability to reorganize the grid into localized islands that would operate connected together, but would have the ability to separate from the overall grid while sustaining some function in the event of an emergency or natural climate event. An island could have a self-contained energy storage device to maintain key infrastructure in the event of a blackout. Combined with smart grid technologies, key appliances could be left connected to electricity during such events. Additional power generation could be provided by renewable sources or even local small non-renewable generators, depending on the island. Islands could black start independently and connect back into the grid. The critical piece to recognize is that the technology has significant potential, and this potential has been demonstrated through the PowerStream grid and from the market interest by customers like Zibi. The administrative constraints limiting its effective deployment will not only impact the technologies diffusion but also the governments' ability to realize the benefits from it, such as decarbonizing the economy. To realize these benefits, key changes need to be considered for the Ontario energy sector. The following chapter will analyze these constraints and propose changes which may serve to better realize these benefits. 


\section{Chapter: Discussion; adjusting to industry change}

This study began with the notion of changes in language and technology. It now considers the impact of these shifts on policy frameworks that are built without a mechanism to adjust to these shifts. It will then analyze how failure to adjust to these changes can prevent policy makers from realizing the benefits of technologies that they have invested in and consider key changes that can be made to the electricity sector to help realize these benefits.

\subsection{Evolving policy; rethinking the box}

There is observed to be a discrepancy between how technologies evolve and how policy is made within the context of the frameworks that govern the electricity sector. New technology within this sector has emerged as a response to a need for environmental sustainability. Policy has largely played a game of catch-up to the speed of innovation. One may observe that the issuance of directives are, sometimes, a mechanism for policy makers to adapt to these changes. The impact of the application of this instrument for environmental policy has been a complex patchwork of programs added to the existing architecture. There has been, as Christensen would argue, an attempt by good managers to match the market with a product that cannot be economically integrated or valued due to its disruptive nature. Technologies like microgrids cannot be separated into their respective components and valued in individual markets. They require a different the industry to consider a different market mechanism in which to be valued. Another attempt to adjust to new developments, either technology or policy objectives, in the electricity sector has been the development of the Long Term Energy Plan, a task 
currently underway at the time of writing (August 2017) (Arriaga, Canizares, and Kazerani 2016). This thesis recognizes that in technology focused industries, often policy makers cannot predict the various scenarios of change that may occur. It would be illconceived to imagine that a grid with components dating back 100 years, would have been architected for considerations of climate change or bi-directional electricity flow from EVs. However policy mechanisms can be created to address underlying industry changes by focusing on specifying the intention of the policy rather than the prescription of it. That can be achieved by creating a policy that is guided by decarbonization rather than one focusing on renewable generation with the assumption of emissions reductions. By creating a larger focus on valuing emissions reductions, the Ontario government would stand to create a market for technologies that may not fit its existing market architecture, but may be better suited for the overall policy mandate.

The governance of the electricity sector, through the OEB and relevant acts should be amended to reflect this change in objective, focused policies rather than prescriptive policies. It is critically important that the mechanisms that govern the electricity sector adapt to the reality of new technologies like microgrids have the potential to significantly disrupt the grid, while also presenting a large opportunity to be utilized for emissions reductions that go far beyond current market structures. This paper recognizes that policy makers cannot predict these markets, nor fully appreciate their impact on the current grid. However, many industries, especially technology focused industries, manage significant changes to their underlying technologies on a yearly basis. Take for instance the development and release of a new smartphone. The iPhone itself is an integration of other 
technologies like batteries, cameras and memory storage to name a few. Changes in battery technology have led to significant improvements in iPhone battery life. The release of a new iPhone incorporates technology changes that have occurred since the last phone was released. It does not signify a failure in the previous version of the technology, but rather the continuous improvement of it. Disruptive changes in battery technologies will be incorporated into the newer versions of the smartphones. The technology is managed with the expectation of continued innovation. This paper will borrow this principle and propose that the Ontario electricity sector be governed in a similar way. Conditions in the legislative acts and codes that specify specific technology outcomes or policy objectives should be written with an expiration time that would prompt their automatic review to ensure relevance. Consider the Electricity Act(Ontario 2016). The following section is highlighted as one of the Act's purposes.

(d) to promote the use of cleaner energy sources and technologies, including alternative energy sources and renewable energy sources, in a manner consistent with the policies of the Government of Ontario. (Ontario 2016)

The act defines a renewable energy source as:

"renewable energy source" means an energy source that is renewed by natural processes and includes wind, water, biomass, biogas, biofuel, solar energy, geothermal energy, tidal forces and such other energy sources as may be prescribed by the regulations, but only if the energy source satisfies such criteria as may be 
prescribed by the regulations for that energy source; ("source d'énergie renouvelable"). (Ontario 2016)

This definition then finds its way into the responsibilities of the IESO as follows

(m) to engage in activities to facilitate the diversification of sources of electricity supply by promoting the use of cleaner energy sources and technologies, including alternative energy sources and renewable energy sources.(Ontario 2016)

The IESO delivers on its responsibilities by delivering diversification of supply. The act is devoid of any mention of emissions reductions. Emissions themselves are only mentioned within the context of the consideration made for the Long-Term Energy Plan:

(e) air emissions from the energy sector, taking into account any projections respecting the emission of greenhouse gases developed with the assistance of the IESO; (Ontario 2016)

Consider now how this impacts other technologies that may help achieve emissions reductions from the operational perspective, either in the transmission or distribution grid. The OEB as highlighted in Chapter 3 regulates these sectors and also approves how utilities and transmission operators can earn revenue. The OEB Act legislates the roles and responsibilities of the OEB to include:

5. To promote the use and generation of electricity from renewable energy sources in a manner consistent with the policies of the Government of Ontario, including the timely expansion or reinforcement of transmission systems and distribution systems to accommodate the connection of renewable energy generation facilities. (Ontario 2014)

There is a trickle-down effect from the legislative acts into the distributors' code, where the distributor/utility is largely regulated to specifically allow for renewable generation to 
be connected onto the grid, rather than engaging in any activities that may result in emissions reduction. Emissions reductions are not mentioned in the code at all.

Consider for comparison, that the first occurrence of renewable energy sources was noted to be in the 2004 version of the Electricity Act (Ontario 2004) with the same objective and the same definition as the 2016 Act as highlighted in Table 3 . The definitions between the two acts have remained the same for 12 years. For comparison, the first iPhone was launched in 2007 and was largely a device that built upon the existing iPod and included the first release of a touch screen in a personal phone device (Honan 2017). The smartphone industry is not equivalent to electricity, it is not regulated and the individual functions in a smartphone do not need to be accounted for separately, however it is mentioned here to illustrate the speed of technology innovation in contrast to legislative changes. The author thus questions the wisdom of codifying definitions of emerging technologies in legislation that are used as blueprints to govern industries, when technology innovation has the potential to create entire new segments of markets within the span of 12 years. 
Table 3: Comparison of objective and definitions between the two Electricity Acts

\begin{tabular}{|c|c|c|}
\hline Act & $\begin{array}{l}\text { Electricity Act, } 1998, \text { S.O. 1998, } \\
\text { c. } 15 \text {, Sched. A" } 2004\end{array}$ & $\begin{array}{l}\text { Electricity Act, } 1998, \text { S.O. 1998, } \\
\text { c. } 15 \text {, Sched. A" } 2016\end{array}$ \\
\hline Objective & $\begin{array}{l}\text { to promote energy conservation, } \\
\text { energy efficiency, load } \\
\text { management and the use of } \\
\text { cleaner energy sources, } \\
\text { including alternative and } \\
\text { renewable energy sources, in a } \\
\text { manner consistent with the } \\
\text { policies of the Government of } \\
\text { Ontario. }\end{array}$ & $\begin{array}{l}\text { to promote the use of cleaner } \\
\text { energy sources and technologies, } \\
\text { including alternative energy } \\
\text { sources and renewable energy } \\
\text { sources, in a manner consistent } \\
\text { with the policies of the } \\
\text { Government of Ontario; }\end{array}$ \\
\hline Definition & $\begin{array}{l}\text { "renewable energy source" means } \\
\text { an energy source that is renewed } \\
\text { by natural processes and includes } \\
\text { wind, water, a biomass resource } \\
\text { or product, solar energy, } \\
\text { geothermal energy, tidal forces } \\
\text { and such other energy sources as } \\
\text { may be prescribed by the } \\
\text { regulations, but only if the energy } \\
\text { source satisfies such criteria as } \\
\text { may be prescribed by the } \\
\text { regulations for that energy source; } \\
\text { ("source d'énergie renouvelable") }\end{array}$ & $\begin{array}{l}\text { "renewable energy source" means } \\
\text { an energy source that is renewed } \\
\text { by natural processes and includes } \\
\text { wind, water, biomass, biogas, } \\
\text { biofuel, solar energy, geothermal } \\
\text { energy, tidal forces and such other } \\
\text { energy sources as may be } \\
\text { prescribed by the regulations, but } \\
\text { only if the energy source satisfies } \\
\text { such criteria as may be prescribed } \\
\text { by the regulations for that energy } \\
\text { source; ("source d'énergie } \\
\text { renouvelable") }\end{array}$ \\
\hline
\end{tabular}

Key changes need to be made in how the electricity sector is governed to ensure that the path to decarbonization policies for the Ontario government is mitigated of potential disruptions. This paper recommends the following changes to the policies that govern this sector:

1. Highlight the policy intention of decarbonizing the grid or reducing GHGs rather than the tools that need to be used to achieve that mandate. 
2. Create market mechanisms to value carbon reduction from the grid, rather than specific markets for technologies.

3. Review the definition of emissions reduction and specified technology restrictions within a specified time period to ensure that the value of the mandate remains relevant to the economy.

By stating a policy mandate that speaks to the fundamental goals rather than the tools, a more holistic market is created that can value technologies like microgrids that may not be a natural fit in the current design. Furthermore, by valuing carbon reduction, these technologies would have an opportunity to illustrate how they can reduce carbon emissions by integrating other technologies like EVs or renewable generation. Pollution impacts land, waterways and air. If policy makers consider the strategic direction first, then the incentives can fall in line and have the potential to create markets for more clean technologies adapted for the issue at hand. The incentives and tools should focus on lower emissions and not be prescriptive on how to achieve them. Rather than initiating contracts that specify renewable energy, the contracts should aim to reduce a certain amount of emissions, and this could be achieved in multiple ways. Perhaps renewable generation would be the ideal way to reduce emissions, alternatively, reorganizing the grid with batteries could also be a part of the solution. Batteries could store excess capacity and deploy it to the grid when needed, thereby increasing the efficiency of the grid and limiting the amount of natural gas electricity that needs to be generated, or 
repurposing the nuclear base load to be able to manage peaks by storing it and using it as needed.

By creating an expiration on the time that the definition remains relevant, a mechanism is provided to operationally adjust to technology development in the industry. The expiration of these definitions should coincide with the development of the Long-Term Energy Plan to ensure they will be evaluated in a consistent time frame. Additionally, a review of specific technology restrictions such as a limitation on behind-the-meter applications needs to be carried out. If decarbonization, rather than technology tools, become the government's mandate, then applications such as microgrids may be best suited to address these issues. These applications would operate and connect both in front-of-meter and behind-the-meter technologies. Alternate solutions for the transaction point need to be considered rather than creating an artificial barrier around the meter.

\subsection{Empowering the sector; shooting for the stars}

A noteworthy observation is made through the PowerStream microgrid. The utility with its increasing size and footprint is acting like a local system operator. The success of integration for the PowerStream grid along with the experiences of Hydro Ottawa suggests that utilities are more capable of managing local grids and integrating technologies than they are mandated to do. Utilities are considering new business mechanisms such as unregulated businesses to engage in these activities. The utility death spiral speaks less to the actual loss or irrelevance of the utility, but rather to a broader change in its fundamental business and how it is regulated. Furthermore, these changes 
provide additional weight to Christensen's argument that management of disruptive technologies should be kept with smaller organizations, such as Hydro Ottawa. There would be efficiencies gained and greater ease in solving issues locally if the utility were empowered to enter into agreements with the smaller generators, and given larger latitude in their business operations.

The IESO was originally intended to enter into agreements with generators and manage the transmission grid. This division of work made sense as the IESO operated the transmission grid and was largely entering into bigger contracts for generation that would be connected to the transmission grid. In such a case, the variability or issues that needed to be managed largely impacted the transmission grid. However with the introduction of embedded generation in the distribution grid, smart grid technologies and now energy storage, there is an awkward separation of responsibility and authority. Figure 19 illustrates some key changes in how the grid currently operates. 


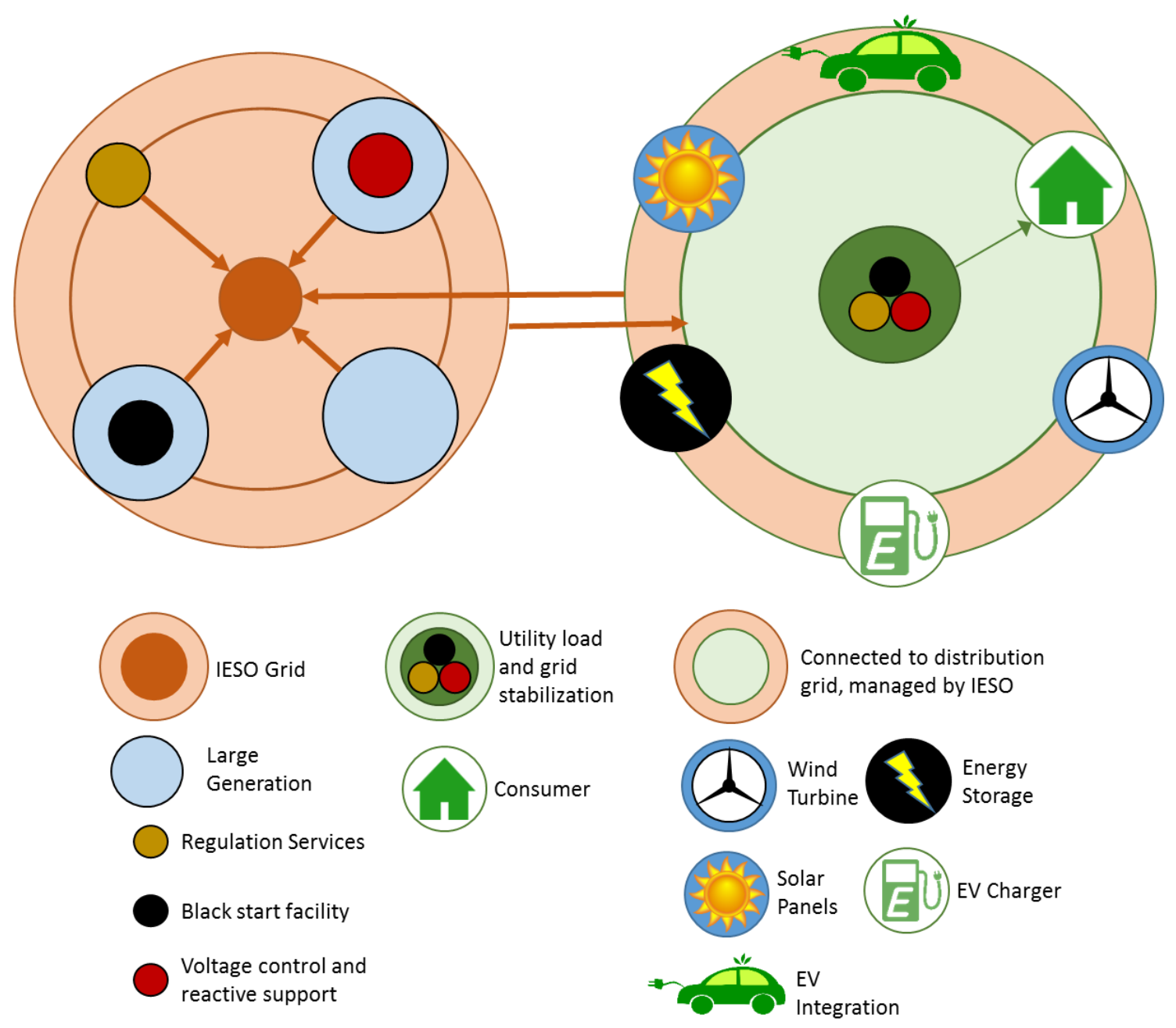

Figure 19: Author's illustration of changes in operation between IESO and utility grid

The IESO remains responsible for all generation and grid stabilization activities, even though the distributors are seeing a growing role in this area but are not being able to economically benefit from it or to diversify their business at all. This is analogous to hardwire telephones going out of business and telephone companies not being allowed to sell mobile phones. The utility death spiral is an inevitable conclusion of this environment. The utility does not need to adapt in isolation, the management of the electricity system needs to reorganize to address these constraints. With a level of 
political acceptance that the economy needs to decarbonize, there is a window of opportunity to consider system redesign. At the time of writing, the Ministry of Energy in Ontario was in the process of developing its 2017 Long Term Energy Plan (Ministry of Energy 2017). As part of these discussions the role of utilities is being evaluated. Additionally, the Ontario government has already put in place a plan to consolidate the fragmented utility landscape into six or seven large utilities (Ontario Ministry of Energy 2017b). This paper proposed to take advantage of these developments by structuring the utilities as dependent system operators. This proposed change is illustrated in Figure 20. The IESO would remain responsible for managing the transmission grid but would delegate the management of distributed generation and other technologies that are embedded in the distribution grid with the utility. This would enable disruptive technologies to be better managed at the local level, where the markets could better value their integration. Furthermore, by valuing reduction of emissions, this could become part of the utilities' mandate, which would enable them to invest in emissions reductions targets while getting a return on that investment. 


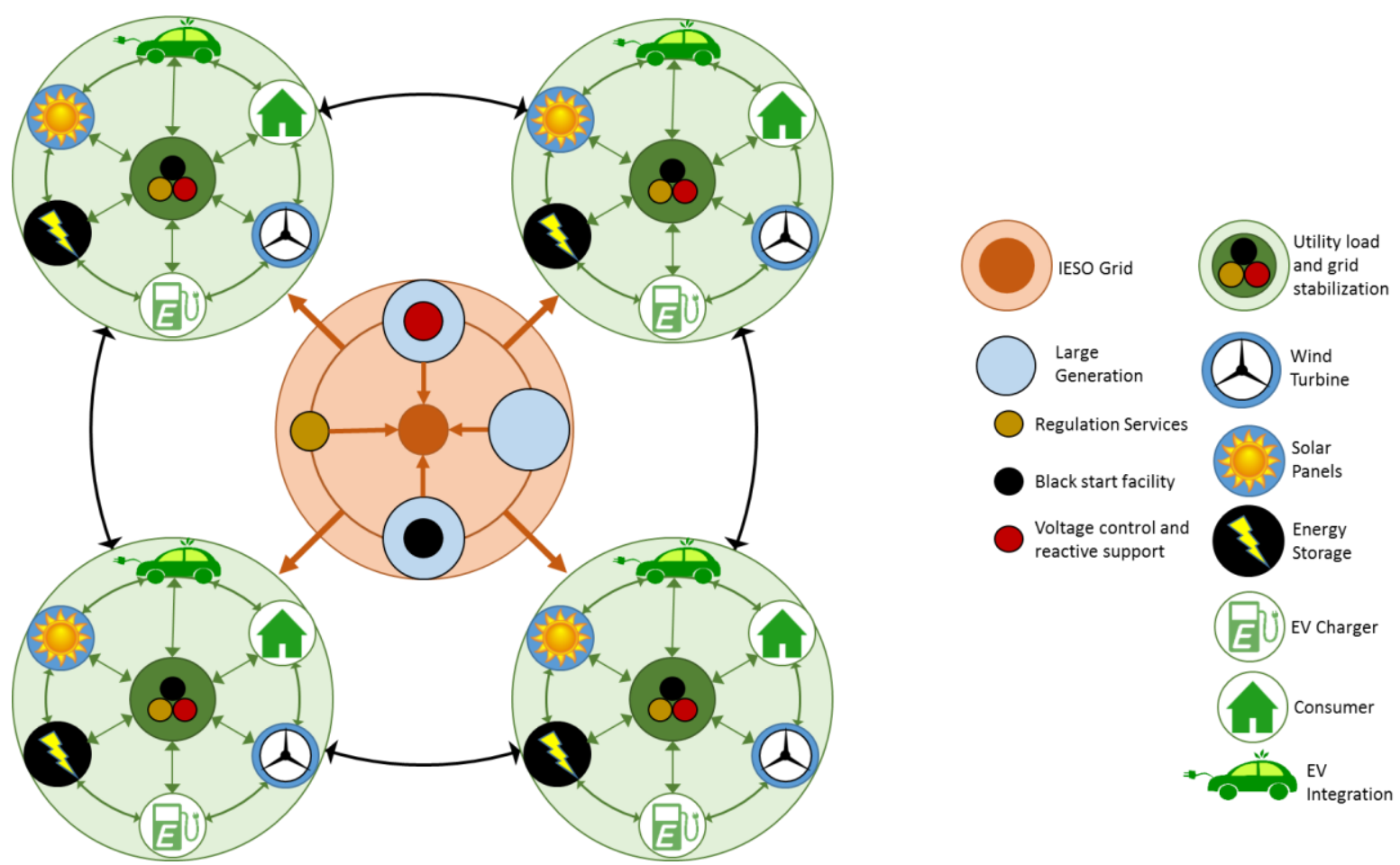

Figure 20: Author's illustration of proposed DSO/IESO grids

Dependent system operators would be clones of the IESO with regards to managing the distribution grid. They would, under the authority of the IESO, enter into contracts with small generators and be empowered to run their respective grids with the same dedication to reliability and safety as the IESO. They would, collaboratively, be involved with system planning. There is a unique level of concern that was noted in the electricity system, one of lack of sight. The IESO needs to operate the grid and manage the various loads with supply. The distributor is largely considered a load and the lack of visibility in the distribution system would be of concern to the IESO. Similarly, lack of sight past the meter was a concern for the distributor. When asked why a campus like Carleton would find resistance from the distributor to install a microgrid, one industry expert noted that 
the distributor does not know what is happening behind the meter, so if the microgrid was say based on solar and the sun stopped shining, the distributor would not be equipped to manage the quick change in demand if the microgrid stopped working. An entirely operational concern (Hydro Ottawa 2017), these changes would need to be reflected in the management of the electricity sector as a whole. The intention of distributing responsibility for the management of disruptive technologies to smaller units is, as Christensen argues, that the management of larger companies is not best equipped with valuing and managing them.

Any changes made to the sector would have to begin with the management of the sector first, through the Ministry of Energy. It is evident through the commitments made by the ministry and the government through the Climate Change Action Plan (Ontario 2017b) that there is a strong willingness to address the concerns of climate change. This willingness has been met by the sector through initiatives that are aimed at addressing how technologies like energy storage can be integrated, as well as what the utility of the future would look like. This paper considers these programs to be indicators that the ministry is looking for considered action to ensure that they can meet the challenges faced by the grid. A thoughtful reorganization of the sector can only be achieved with support from the Ministry of Energy and the OEB. The Ministry of Energy and the OEB would need to institutionalize the ability of utilities to broaden their mandates while modernizing legislation and codes that are prescriptive in nature. Addressing changes in 
the electricity sector requires a considered and operational response rather than an adhoc, directives based approach.

\subsection{Conclusion}

Effective communication requires a level of context, especially when words can change meaning with additional information. Take for instance the word 'lead,' naturally creating the association for many that one is discussing a topic of leadership. 'Lead foot' gives the impression that the conversation is about which foot someone leads their walk with. In the context of speeding however, one would interpret the phrase 'lead foot' as someone who had a 'heavy foot' or kept the gas pedal pressed resulting in speeding, as lead is also a dense metal. The clarity of context is vital in establishing the association.

This thesis began by considering how subtle changes in context can impact how words are understood and used. Within the context of sustainability policy in Ontario the initial definition and understanding of renewable energy revealed a simple association between electricity and the source of its generation. It overlooked the key differences in how that generation was time constrained. Leading to a policy structure that, from the perspective of technology behavior and management, was agnostic to how different generation technologies would be integrated. Within the backdrop of an intention to achieve reduced carbon emissions from the electricity sector, tools like FIT were used to promote renewable technologies. As more technologies like energy storage became commercially viable, their markets were partially dependent on a more sophisticated understanding of 
the limitations and impacts of renewable technologies. One that considered the unique technical and management needs of they could be integrated and operated.

As policy makers recognized the need to incorporate technologies like energy storage on the grid, the mechanisms used to do so were codified in legislation that is difficult to change. Thus, while the industry recognized a value in using technologies like microgrids and energy storage to address key technical issues with renewable generation, they could not find natural markets that would value their functions. Without a recognition that renewable energy is intermittent key applications of energy storage could not be valued in a regulated market. In an effort to integrate technologies like energy storage, policy makers created new programs for energy storage procurement. The prescriptive nature of the policies led to an environment where directives were used to help play catch-up to innovation in the technologies that can facilitate emissions reductions. These prescriptions failed to holistically consider the underlying nature of how different technologies need to be integrated and managed.

Policy tools cannot keep pace with developments in technologies because technologies innovate and mature faster than markets can be created to value them in regulated industries. However, policy makers can adapt markets to value their policy intent thereby create an environment that allows technologies like microgrids or EVs to be valued for their ability to achieve emissions reductions and help integrate other technologies to do the same. This thesis argues that there is a need for policy makers to state the intention of their policies rather than be prescriptive about the means through which they are 
achieved. This is especially vital in industries that are technology driven and evolve faster than policies do.

Within the context of the electricity system, this paper recognizes that the government has made significant investment in the development of new technologies and also in developing support for climate policies. To achieve the environmental benefits possible from these technologies, key reforms are needed in the sector. Leveraging the current window of opportunity, this paper proposes that the ministry recognize and value emissions reduction as their primary policy objective as per the Climate Action Plan. These changes should be signified in the IESO market, as well as in how the OEB regulates the industry. Technology conditions and restrictions like behind-the-meter applications should be reviewed for their intention, and their intended purpose should be regulated rather than the transaction point. All technology condition clauses should have a reevaluation date, on which their relevance in the context of their ability to deliver on the intended purpose should be reevaluated. This review would most naturally fall within the existing process of developing the Long-Term Energy Plan. The Long-Term Energy Plan should be reviewed yearly, or on a period that would eliminate the need for directives to be issued to address these changes. Finally and critically, utilities should be given more control and authority to engage in actions that can facilitate the reduction of emissions. This paper proposed a format that would mimic the existing IESO as it operates in relation to the transmission and large generation segment of the grid. Utilities 
as 'dependent system operators' would engage in developing contracts and integrating technologies on the grid that would help facilitate emission reductions.

This paper agrees most closely with Christensen's argument that it is not bad management that prevents large companies from adopting new disruptive technologies. Personal observations with industry stakeholders confirm that indeed, managers of the system were guided by good management practice even when they may have been constrained by other parties in the sector. This researcher waits in anticipation to see if current reform initiatives will place the ministry to lead reform in the sector or to be like lead in its reform. 


\section{Bibliography}

Advisory Panel for the Review of, Federal Support for Fundamental Science, and Advisory Panel for the Review of. 2017. "Canada's Fundamental Science Review." ISED.

Alectra Inc. 2017. "Enersource, Horizon Utilities, PowerStream Officially Become Alectra Inc.” Marketwire. Accessed June 10. http://www.marketwired.com/pressrelease/enersource-horizon-utilities-powerstream-officially-become-alectra-inc2192398.htm.

Anonymous. 2017. Industry Expert.

Appunn, Kerstine. 2017. "Germany's Greenhouse Gas Emissions and Climate Targets." Clean Energy Wire, February 1.

Arriaga, Mariano, Claudio A. Canizares, and Mehrdad Kazerani. 2016. "Long-Term Renewable Energy Planning Model for Remote Communities.” IEEE Transactions on Sustainable Energy 7 (1): 221-31. doi:10.1109/TSTE.2015.2483489.

Bordeleau, Stéphane. 2011. "Where Canada's Surplus Energy Goes.” CBC, March 30.

Brown, Matthew H., and Richard P. Sedano. 2004. Electricity Transmission: A Primer. Denver, Colo.: National Council on Electric[ity] Policy.

Canada. 2016. "Pan-Canadian Framework on Clean Growth and Climate Change." Guidance. December 12.

https://www.canada.ca/en/services/environment/weather/climatechange/pancanadian-framework.html.

_. 2017a. "Budget 2017.” Accessed June 9. http://www.budget.gc.ca/2017/homeaccueil-en.html.

Canada, National Film Board of. 2017b. Powerful: Energy for Everyone. Accessed June 11. https://www.nfb.ca/film/powerful_energy_for_everyone/.

CBC News. 2017. "Ontario Unveils \$12.8B Darlington Nuclear Refurbishment." Accessed July 31. http://www.cbc.ca/news/canada/toronto/darlington-nuclearrefurbishment-1.3395696.

Chahal, Aman, Zak Jacques, Marc Quintaneiro, and Glen Toner. 2017. "Politics and Policy on the Federal- Provincial Journey to a Low-Carbon Future: A New Era of Canadian Energy/Environment Federalism?" How Ottawa Spends, no. 38 (2018 Forthcoming).

Christensen, Clayton. 2011. The Innovator's Dilemma: When New Technologies Cause Great Firms to Fail. http://www.claytonchristensen.com/books/the-innovatorsdilemma/.

Corcoran, Terence. 2017. “Boondoggle: How Ontario’s Pursuit of Renewable Energy Broke the Province's Electricity System." Financial Post. Accessed June 8. http://business.financialpost.com/fp-comment/boondoggle-how-ontarios-pursuitof-renewable-energy-broke-the-provinces-electricity-system.

DeGusta, Michael. 2017. "Are Smart Phones Spreading Faster than Any Technology in Human History?” MIT Technology Review. Accessed September 16. 
https://www.technologyreview.com/s/427787/are-smart-phones-spreading-fasterthan-any-technology-in-human-history/.

ECO Canada. 2010. "Defining the Green Economy."

Gaddy, Benjamin, Varun Sivaram, and Francis O'Sullivan. 2016. "Venture Capital and Cleantech: The Wrong Model for Clean Energy Innovation.” MIT Energy Initiative.

Gillis, Justin. 2017. "Short Answers to Hard Questions About Climate Change." The New York Times, July 6.

Global News. 2016. “Ontario Electricity Rates: Experts Explain How They Would Make Power Cheaper," November 28. http://globalnews.ca/news/3091320/ontarioelectricity-rates-experts-explain-how-they-would-make-power-cheaper/.

"Green Energy Act." 2009. https://www.ontario.ca/laws/view.

Hardesty, Linda. 2014. "What's a Nanogrid?" Energy Manager Today. March 25. https://www.energymanagertoday.com/whats-a-nanogrid-099702/.

Honan, Mathew. 2017. “Apple Unveils IPhone | Macworld.” Accessed August 6. http://www.macworld.com/article/1054769/smartphones/iphone.html.

Hui, Karen Howlett and Ann. 2010. “Ontario's Aging Grid Puts Province at Risk of More Blackouts," July 6, sec. news.

https://www.theglobeandmail.com/news/national/ontarios-aging-grid-putsprovince-at-risk-of-more-blackouts/article1390171/.

Hydro Ottawa. 2017.

IESO. 2015. "FIT Rules." IESO.

—. 2017a. "Ancillary Services Market." Accessed June 9. http://www.ieso.ca/ancillary-services.

—. 2017b. "Current Supply/ Demand." Accessed June 8. http://www.ieso.ca/. . 2017c. "Ministerial Directives." Accessed June 8. http://www.ieso.ca/corporateieso/ministerial-directives.

- n.d. "Power Data." http://www.ieso.ca/power-data.

Lacey, Stephen. 2014. "This Is What the Utility Death Spiral Looks Like.” March 4. https://www.greentechmedia.com/articles/read/this-is-what-the-utility-deathspiral-looks-like.

Leslie A. Pal. 2014. Beyond Policy Analysis. Public Issue Managementin Turbulent Times. Fifth. Nelson Education.

Mai, Thuy. 2015. "Technology Readiness Level.” NASA. May 6. http://www.nasa.gov/directorates/heo/scan/engineering/technology/txt_accordion 1.html.

Mark Jaccard. 2005. Sustainable Fossil Fuels: The Unusual Suspect in the Quest for Clean and Enduring Energy -.

"Market Rules \& Manuals Library - IESO.” 2017. Accessed June 7. http://www.ieso.ca/Sector\%20Participants/Market\%20Operations/Market\%20Rul es\%20And\%20Manuals\%20Library.

Martin, Richard. 2016. “Germany Runs Up Against the Limits of Renewables.” MIT Technology Review, May 24.

Mazzucato, Mariana. 2014. The Entreprenurial State. Public Affairs.

Ministry of Energy. 2016. "Future Renewable Energy Procurement." Government. 
. 2017. "Planning Ontario's Energy Future.” Accessed January 16.

http://www.energy.gov.on.ca/en/ltep/2017-discussion-guide/.

Navigant Consulting. 2016. "Global Microgrid Capacity Is Expected to Grow from 1.4

GW in 2015 to 7.6 GW in 2024." Navigant Research. March 17.

https://www.navigantresearch.com/newsroom/global-microgrid-capacity-is-

expected-to-grow-from-1-4-gw-in-2015-to-7-6-gw-in-2024.

OEB. 2010. "Electricity Outage and Reliability Study September 2010." Ontatio Energy

Board. https://www.oeb.ca/oeb/_Documents/EB-2010-

0249/OEB_Reliability\%20Residential\%20Survey_2010.pdf.

OECD. 2017. "Clean Technology Definition.” Accessed August 3.

https://stats.oecd.org/glossary/detail.asp? ID=2988.

Ontario. 2004. Electricity Act, 1998, S.O. 1998, c. 15, Sched. A. https://www.ontario.ca/laws/statute/98e15.

. 2014. Ontario Energy Board Act, 1998, S.O. 1998, c. 15, Sched. B. https://www.ontario.ca/laws/view.

. 2016. "Electricity Act, 1998, S.O. 1998, c. 15, Sched. A." https://www.ontario.ca/laws/statute/98e15.

. 2017. "Ministry of Research, Innovation and Science." Government of Ontario. .2017a. "Cap and Trade." Accessed July 28. https://www.ontario.ca/page/capand-trade.

— 2017b. "Climate Change Action Plan." Accessed June 11. https://www.ontario.ca/page/climate-change-action-plan.

.2017c. "Long-Term Energy Plan.” Accessed September 16.

http://www.energy.gov.on.ca/en/ltep/.

Ontario Energy Board. 2011. "EB-2010-0142."

—. 2015a. "Distribution System Code." Ontario Energy Board. . 2015b. "Unit Sub-Metering Code." Ontario Energy Board.

Ontario Ministry of Energy. 2017a. "FIT and MicroFIT Program." Accessed June 7. http://www.energy.gov.on.ca/en/fit-and-microfit-program/. . 2017b. "Renewing Ontario's Electricity Distribution Sector: Putting the Consumer First." Accessed June 5. http://www.energy.gov.on.ca/en/ldc-panel/. .2017c. "The End of Coal." Accessed June 8. http://www.energy.gov.on.ca/en/archive/the-end-of-coal/.

Ontario Power Generation. 2017. "Generating Power." Accessed June 9. http://www.opg.com/generating-power/Pages/generating-power.aspx.

Porter, Kate. 2017. "Zoning Challenge of Zibi Development on Ottawa River Rejected Again." CBC News. Accessed August 5. http://www.cbc.ca/news/canada/ottawa/zibi-development-zoning-challenge1.3602056 .

PowerStream. 2016.

- PowerStream. 2017.

— 2017. "Microgrid Demonstration Project." Accessed January 17. https://www.powerstream.ca/innovation/micro-grid.html.

Press, The Canadian, National Observer in News, Energy, and Politics | November 21st 2016. 2016. "Canada's Catherine McKenna Announces Coal Phase out for 2030." National Observer. November 21. 
http://www.nationalobserver.com/2016/11/21/news/canadas-catherine-mckennaannounces-coal-phase-out-2030.

Pugliese, David, Ottawa Citizen More from David Pugliese, Ottawa Citizen Published on: April 6, 2016 | Last Updated: April 6, and 2016 7:09 Am Edt. 2016. "Last RCAF C-130 E Hercules Flies into History - It Will Become a Display at the Aviation Museum in Ottawa." Ottawa Citizen. April 6. http://ottawacitizen.com/news/national/defence-watch/last-rcaf-c-130-e-herculesflies-into-history-it-will-become-a-display-at-the-aviation-museum-in-ottawa.

Roberts, David. 2017. "Blue America Reaches out to the World, Ignoring Trump." Accessed August 4. https://www.vox.com/energy-andenvironment/2017/6/30/15892040/blue-america-trump.

Royer, Jimmy. 2013. "Status of Remote/Off-Grid Communities in Canada." June 20. http://www.nrcan.gc.ca/energy/publications/sciencestechnology/renewable/smart-grid/11916.

Scrimshaw, Mackenzie. 2017. "Canada's Climate Change Expedition: The Provincial Delegations to COP21." Accessed July 28. http://ipolitics.ca/2015/10/26/canadasclimate-change-expedition-the-provincial-delegations-to-cop21/.

Standing Senate Committee on Energy, the Enviornment and Natural Resources. 2014. "Powering Canada's Territories.Pdf." Government. Ottawa.

Taber, Jane. 2016. "Ontario PC Leader Brown Bringing Progressive Stance to Old Party Values." The Globe and Mail, May 17, sec. news. https://www.theglobeandmail.com/news/national/patrick-brown-bringingprogressive-stance-to-ontario-pcs/article30072406/.

Tao, L., C. Schwaegerl, S. Narayanan, and J. H. Zhang. 2011. "From Laboratory Microgrid to Real Markets \#x2014; Challenges and Opportunities." In 8th International Conference on Power Electronics - ECCE Asia, 264-71. doi:10.1109/ICPE.2011.5944600.

“The Largest Machine Ever Built." n.d. http://www.smithsonianmag.com/videos/category/history/the-largest-machineever-built/.

Toronto Hydro. 2017. "Appliance Usage Chart | Toronto Hydro Electric System.” Accessed June 11. http://www.torontohydro.com/sites/electricsystem/residential/yourbilloverview/Pa ges/ApplianceChart.aspx.

United Nations. 2017a. "Green Economy: Sustainable Development Knowledge Platform." Accessed July 27. https://sustainabledevelopment.un.org/index.php?menu=1446. . 2017b. "List of 175 Signatories to Paris Agreement15 States Deposit Instruments of Ratification." UNFCCC. Accessed February 5. http://newsroom.unfccc.int/paris-agreement/175-states-sign-paris-agreement/.

U.S. Energy Information Administration. 2017. "How Electricity Is Delivered To Consumers - Energy Explained, Your Guide To Understanding Energy - Energy Information Administration." Accessed January 17. http://www.eia.gov/Energyexplained/index.cfm?page=electricity_delivery. 
U.S.-Canada Power System Outage Task Force. 2004. "Final Report on the August 14, 2003 Blackout in the United States and Canada: Causes and Recommendations." U.S. Department of Energy.

Vise, David A., and Mark Malseed. 2005. The Google Story. New York: Delacorte Press. Wald, Matthew L. 2013. "Electric Vehicles Begin to Earn Money from the Grid." The New York Times, April 25, sec. Energy \& Environment. https://www.nytimes.com/2013/04/26/business/energy-environment/electricvehicles-begin-to-earn-money-from-the-grid.html.

Windmill. 2015. "Zibi Master Plan."

—. 2017a. "Greening Our Urban Environments.” Accessed June 10. http://www.windmilldevelopments.com/about-windmill/leadership-team/. . 2017b. "Zibi Developments." Zibi. Accessed June 5. http://www.zibi.ca/.

Winfield, Mark. 2012. Blue-Green Province: The Environment and the Political Economy of Ontario. 